\title{
Circuitos resistivos autossimilares
}

\author{
Claudio Xavier Mendes dos Santos
}



Data de Depósito:

Assinatura:

\title{
Claudio Xavier Mendes dos Santos
}

\section{Circuitos resistivos autossimilares}

\begin{abstract}
Dissertação apresentada ao Instituto de Ciências Matemáticas e de Computação - ICMC-USP, como parte dos requisitos para obtenção do título de Mestre - Programa de Mestrado Profissional em Matemática. VERSÃO REVISADA
\end{abstract}

Área de Concentração: Matemática

Orientador: Prof. Dr. Carlos Molina Mendes 
Ficha catalográfica elaborada pela Biblioteca Prof. Achille Bassi e Seção Técnica de Informática, ICMC/USP, com os dados fornecidos pelo(a) autor(a)

Santos, Claudio Xavier Mendes dos
Circuitos resistivos autossimilares / Claudio
Xavier Mendes dos Santos; orientador Carlos
Molina Mendes. - São Carlos - SP, 2016.
101 p.
Dissertação (Mestrado - Programa de Pós-graduação
em Mestrado Profissional em Matemática em Rede
Nacional) - Instituto de Ciências Matemáticas e de
Computação, Universidade de São Paulo, 2016.
1. circuitos resistivos. 2. funções iteradas.
3. grafos. 4. fractais autossimilares. 5. circuitos
autossimilares. 6. ensino da matemática. I. Mendes,
Carlos Molina, orient. II. Título.




\section{Claudio Xavier Mendes dos Santos}

\section{Autossimilar resistive circuits}

Master dissertation submitted to the Instituto de Ciências Matemáticas e de Computação - ICMC-USP, in partial fulfillment of the requirements for the degree of the Master - Program in Mathematics Professional Master. FINAL VERSION

Concentration Area: Mathematics

Advisor: Prof. Dr. Carlos Molina Mendes

\section{USP - São Carlos}

April 2016 

Agradeço aos meus pais, pelo o que representam para mim, por todo apoio incondicional e todo o carinho que me deram ao longo da minha vida.

À minha amada Alessandra, pela compreensão, afeto e paciência durante esses anos.

Ao Professor Doutor Carlos Molina Mendes, pela sua orientação, disponibilidade, incentivos, críticas e opiniões ao longo do curso.

À CAPES, pelo apoio financeiro. 

"Das leis mais simples nascem infinitas maravilhas que se repetem indefinidamente."

(Benoit Mandelbrot) 



\section{RESUMO}

SANTOS, C. X. M.. Circuitos resistivos autossimilares. 2016. 101 f. Dissertação (Mestrado Programa de Mestrado Profissional em Matemática) - Instituto de Ciências Matemáticas e de Computação (ICMC/USP), São Carlos - SP.

Esse trabalho é um estudo sobre circuitos resistivos que apresentam a característica da autossimilaridade em sua configuração. A construção desses circuitos é feita de uma maneira recursiva, de forma análoga a um fractal autossimilar. Os circuitos são analisados pelas suas resistências equivalentes, sendo obtida uma condição para convergência desse valor. Os conceitos auxiliares necessários ao tema desta dissertação abordam a representação de um circuito resistivo como um grafo, além de conceitos envolvendo fractais autossimilares. São propostas ao final de cada capítulo atividades interdisciplinares acessíveis a alunos de ensino médio, com conteúdos envolvendo resistência equivalente, sequências, conjuntos, e noções de área e perímetro.

Palavras-chave: circuitos resistivos, funções iteradas, grafos, fractais autossimilares, circuitos autossimilares, ensino da matemática. 



\section{ABSTRACT}

SANTOS, C. X. M.. Circuitos resistivos autossimilares. 2016. 101 f. Dissertação (Mestrado Programa de Mestrado Profissional em Matemática) - Instituto de Ciências Matemáticas e de Computação (ICMC/USP), São Carlos - SP.

This work is a study of resistive circuits which present a characteristic of self similarity in their configuration. The construction of these circuits is made in a self recursive way, analogously to a self similar fractal. The circuits are analyzed by their equivalent resistance, and a condition for convergence of this quantity is obtained. Auxiliary concepts that are necessary to this dissertation theme treat the resistive circuit as a graph, and concepts involving self similar fractals. It is proposed at the end of each chapter interdisciplinary activities that are accessible to high school students, with topics involving equivalent resistence, sequences, sets, and notions of area and perimeter.

Key-words: resistive circuits, iterated functions, graphs, self similar fractals, autossimilar circuits, math teaching. 



\section{LISTA DE ILUSTRAÇÕES}

Figura 1 - Um fio com seção $S$ constante. . . . . . . . . . . . . . . 36

Figura 2 - Representação esquemática de um resistor. . . . . . . . . . . . . . . 37

Figura 3 - Exemplos de correntes que "entram" e correntes que "saem" de um nó. . . . 38

Figura 4 - Exemplo de um circuito com duas malhas. . . . . . . . . . . . . . . 39

Figura 5 - Exemplo de aplicação da segunda lei de Kirchhoff. . . . . . . . . . . . . . . 39

Figura 6 - Uma fonte ligada a um resistor. . . . . . . . . . . . . . . . 40

Figura 7 - Associação de $n$ resistores em série ligada a uma fonte. . . . . . . . . . 41

Figura 8 - Associação de $n$ resistores em paralelo ligada a uma fonte. . . . . . . . . . . 42

Figura 9 - Transformação $\Delta$-Y. . . . . . . . . . . . . . . . . . 44

Figura 10 - Esquema representativo entre a teoria e a prática em física (SÉRÉ; COELHO; NUNES, 2003). . . . . . . . . . . . . . . . . . . . . 45

Figura 11 - Uma matriz de contatos. . . . . . . . . . . . . . . . . . . 46

Figura 12 - Um resistor de $100 \Omega \ldots \ldots \ldots$. . . . . . . . . . . . 46

Figura 13 - Representação dos circuitos da atividade didática. . . . . . . . . . . . . . 47

Figura 14 - Possível construção da atividade 1. . . . . . . . . . . . . . . . . 48

Figura 15 - Possível construção da atividade $2 \ldots \ldots$. . . . . . . . . . . . . . . . . . . . . . . . . . 48

Figura 16 - Possível construção da atividade $3 . \ldots$. . . . . . . . . . . . . . 48

Figura 17 - Exemplo de um grafo. . . . . . . . . . . . . . . . . 50

Figura 18 - Exemplos de um grafos isomórficos. . . . . . . . . . . . . . . . 51

Figura 19 - Um subgrafo associado (esquerda) e um grafo (direita). . . . . . . . . . . 51

Figura 20 - Exemplo do caminho de um grafo. . . . . . . . . . . . . . . . . 51

Figura 21 - Representações equivalentes de um grafo planar. . . . . . . . . . . . . . 52

Figura 22 - Um grafo desconexo. . . . . . . . . . . . . . . 53

Figura 23 - Exemplos de árvores. . . . . . . . . . . . . . . . . 53

Figura 24 - Exemplo de uma ponte em um grafo (aresta $u v) \ldots \ldots$. . . . . . . . . 53

Figura 25 - Representação de um circuito da forma convencional (acima) através de um grafo (abaixo). . . . . . . . . . . . . . . . . . . 54

Figura 26 - Representação do problema das pontes de Königsberg (COSTA, 2011). . . . 56

Figura 27 - Folha de respostas com os vértices do grafo. . . . . . . . . . . . . 57

Figura 28 - Grafo esperado para o problema das pontes. . . . . . . . . . . . . . 57

Figura 29 - Exemplo de um fractal na natureza (obtido em (TAYLOR et al., 2005)). . 60

Figura 30 - Distância entre conjuntos (obtido em (KIRILLOV, 2013)). . . . . . . . . 63

Figura 31 - As seis primeiras iterações do triângulo de Sierpinski. . . . . . . . . . . . . 64 
Figura 32 - Triângulo de Pascal construído até a iteração 8 . . . . . . . . . . . 66

Figura 33 - Associação do triângulo de pascal com o triângulo de Sierpinski. . . . . . . 66

Figura 34 - A primeira iteração da curva de Koch. . . . . . . . . . . . . . . . . . 67

Figura 35 - A segunda iteração da curva de Koch. . . . . . . . . . . . . . . . . . 68

Figura 36 - A terceira iteração da curva de Koch. . . . . . . . . . . . . . . . . . 68

Figura 37 - A terceira iteração do floco de neve de Koch. . . . . . . . . . . . . . . . . 68

Figura 38 - As cinco primeiras iterações do conjunto de Cantor. . . . . . . . . . . . 70

Figura 39 - As quatro iterações do Tapete de Sierpinski. . . . . . . . . . . . . . . 74

Figura 40 - Multiplicação de circuito $C_{i}$ por uma constante $\alpha . \ldots . .79$

Figura 41 - Passo inicial da série autossimilar e das árvores autossimilares. . . . . . . . 79

Figura 42 - Construção do circuito série de resistores. . . . . . . . . . . . . . . 79

Figura 43 - As três primeiras iterações da série autossimilar de resistores. . . . . . . . . 80

Figura 44 - Representação da recorrência da árvore binária autossimilar. . . . . . . . . . 81

Figura 45 - Construção do circuito da árvore binária. . . . . . . . . . . . . . . . . 82

Figura 46 - Convergência para o circuito da árvore binária. . . . . . . . . . . . . . 83

Figura 47 - Recorrência da árvore autossimilar com $m$ ramos. . . . . . . . . . . . . . . 84

Figura 48 - Circuito autossimilar da árvore com $m$ ramos. . . . . . . . . . . . . . 84

Figura 49 - Construção da árvore binária com pesos. . . . . . . . . . . . . . . 86

Figura 50 - Árvore binária com pesos representada até a iteração 3. . . . . . . . . . . . 86

Figura 51 - Passo inicial do circuito de Sierpinski. . . . . . . . . . . . . . . . 87

Figura 52 - A recorrência do circuito de Sierpinski. . . . . . . . . . . . . . . . . . . . . . . . . . 88

Figura 53 - A primeira iteração do circuito de Sierpinski. . . . . . . . . . . . . . . . 88

Figura 54 - A segunda iteração do circuito de Sierpinski. . . . . . . . . . . . . . . . . 88

Figura 55 - A resistência entre dois nós para uma configuração $\Delta$. . . . . . . . . . . . 89

Figura 56 - Resistência equivalente entre dois nós para $C_{i}$. . . . . . . . . . . . . 89

Figura 57 - Representação como circuito em $\Delta$ de um circuito $i+1$ em função dos pesos do circuito $i \ldots \ldots \ldots$. . . . . . . . . . . . . . . . 90

Figura 58 - Representações dos circuitos das iterações da atividade proposta. . . . . . . 92 
INTRODUÇÃO . . . . . . . . . . . . . . . . . . 17

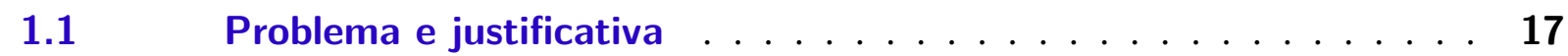

$1.2 \quad$ Estado da arte . . . . . . . . . . . . . . . 20

1.3 Desenvolvimento do trabalho ............... 22

2 PROPOSTA CURRICULAR DO ENSINO MÉDIO PARA FÍSICA E MATEMÁtICA . . . . . . . . . . . . . . . 25

$2.1 \quad$ As competências em matemática . . . . . . . . . . . 25

$2.2 \quad$ A interdisciplinaridade . . . . . . . . . . . . 28

2.3 A Lei de Diretrizes e Bases e os Parâmetros Curriculares Nacionais 30

$2.4 \quad 0$ ensino da matemática e da física $\ldots \ldots \ldots \ldots$

3 ELEMENTOS DE UM CIRCUITO RESISTIVO . . . . . . . . . . . 35

3.1 Corrente, diferença de potencial e resistência . . . . . . . . 35

$3.2 \quad$ Circuitos resistivos e leis de Kirchhoff . . . . . . . . . . . . . . 37

3.3 Teorema de Thevenin e a resistência equivalente . . . . . . . . . 40

$3.4 \quad$ Atividade didática . . . . . . . . . . . . . . 44

$3.4 .1 \quad$ Justificativa . . . . . . . . . . . . . . . . . . 44

3.4.2 Proposta de atividade . . . . . . . . . . . . . . 45

3.4.3 Resultados esperados . . . . . . . . . . . . . . 47

4 GRAFOS E OS CIRCUITOS RESISTIVOS . . . . . . . . . . . 49

$4.1 \quad$ Definição de grafo . . . . . . . . . . . . . . . . . 49

4.2 Definições complementares . . . . . . . . . . . 50

4.3 Circuitos resistivos como grafos $\ldots \ldots \ldots \ldots$

$4.4 \quad$ Atividade didática . . . . . . . . . . . . 55

$4.4 .1 \quad$ Justificativa . . . . . . . . . . . . . . . . 55

4.4.2 Proposta de atividade .................... 55

4.4.3 Resultados esperados . . . . . . . . . . . . . 56

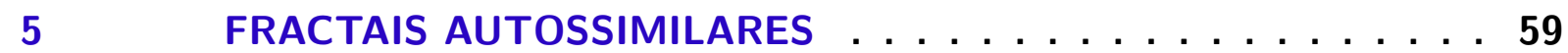

$5.1 \quad$ Definição informal de fractal . . . . . . . . . . . . 59

$5.2 \quad$ Noções sobre espaços métricos . . . . . . . . . . . 61

$5.3 \quad$ Triângulo de Sierpinski . . . . . . . . . . . . . 63 


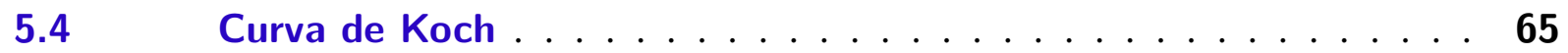

$5.5 \quad$ Conjunto de Cantor . . . . . . . . . . . . . . . . 69

$5.6 \quad$ Atividade didática $\ldots \ldots \ldots \ldots \ldots \ldots \ldots \ldots$

5.6.1 Justificativa . . . . . . . . . . . . . . . . . 73

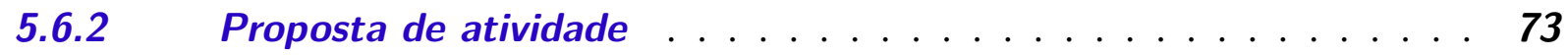

5.6.3 Resultados esperados . . . . . . . . . . . . . . . 75

$6 \quad$ CIRCUITOS AUTOSSIMILARES $\ldots \ldots \ldots \ldots$

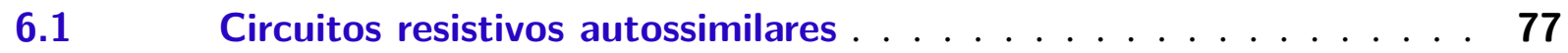

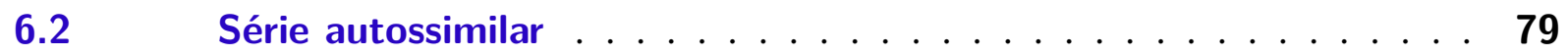

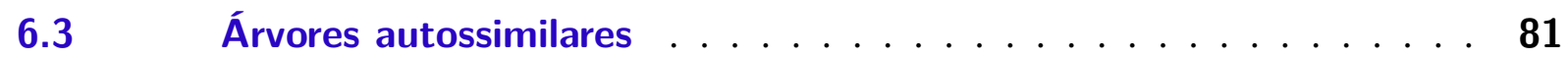

6.3.1 Árvore binária autossimilar . . . . . . . . . . . . . . 81

6.3.2 Árvore autossimilar com $m$ ramos . . . . . . . . . . . 83

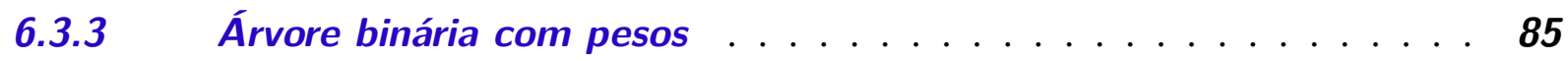

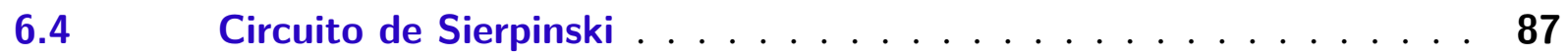

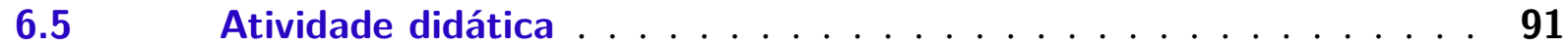

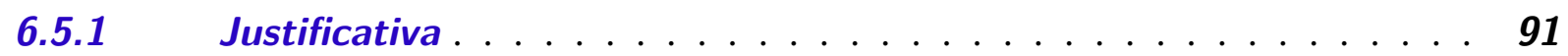

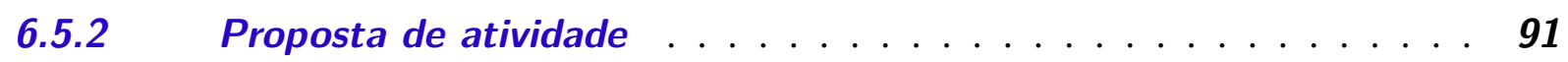

6.5.3 Resultados esperados . . . . . . . . . . . . . . . 93

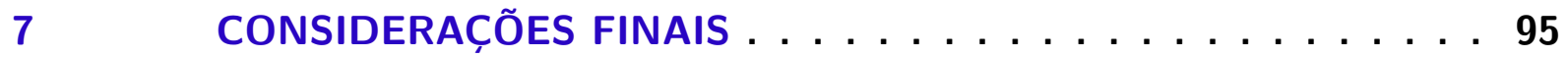

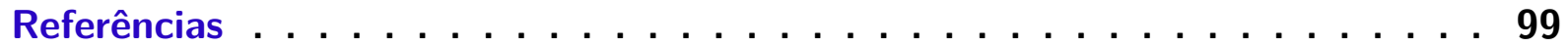




\section{1}

\section{INTRODUÇÃO}

\subsection{Problema e justificativa}

O ensino da matemática tradicionalmente ocorre de forma fragmentada. Os conceitos são apresentados muitas vezes de forma desconexa, com exercícios mecânicos sem ligação com outros conceitos correlatos. Nesse modelo, os conteúdos são apresentados de forma linear, onde não se apresentam elos com outros conteúdos relacionados dentro ou fora da disciplina (MACHADO, 1995).

Atualmente propõe-se processos de ensino não-lineares, nos quais um mesmo assunto é trabalhado em diferentes momentos, com diferentes níveis de complexidade. Tal modelo possibilita uma formação de conceitos a se construir ao longo de sua escolaridade. Com isso, novos conceitos dentro de certo conteúdo são inseridos com o passar do tempo, e para a aprendizagem do aluno ocorre um processo de reorganização e até mesmo mudanças de ponto de vista acerca do conteúdo (CARVALHO, 2014).

Uma das formas de promover a atração dos alunos pela matemática é através das abordagens interdisciplinares. Para tal, os conhecimentos de duas ou mais disciplinas são abordados em torno de um mesmo problema. Essa constitui uma estratégia para interrelacionar os conteúdos de naturezas diversas. Desse ponto de vista, atualmente a interdisciplinaridade constitui uma importante ferramenta para a comunicação entre as disciplinas, sendo estabelecido um objeto comum entre todas elas (MACHADO, 1995).

Caracterizada como uma das possibilidades de abordagem dos conteúdos em matemática, a realização da interdisciplinaridade e da resolução de problemas é uma estratégia que busca ampliar a visão do aluno acerca dos conteúdos da disciplina, fazendo que sejam criados elos com a vida real e com os outros conteúdos da própria disciplina. É interessante que o aluno de ensino médio seja capaz de usar diferentes habilidades para fazer representações, utilizar estratégias, e resolver problemas que aparecem na sala de aula e no dia a dia (SEE-SP, 2011b). 
Um importante mecanismo para a aprendizagem em matemática ocorre através da identificação de padrões. Problemas desse tipo possibilitam o desenvolvimento do raciocínio assim como relaciona conteúdos de matemática diversos. Um importante elo ocorre ao se estabelecer generalizações algébricas, que resultam nos estudos das funções. Para que esse processo realizado, é exigido ao aluno fazer conjecturas, generalizações e estabelecer relações (OLIVEIRA, 2008), todas consideradas habilidades fundamentais em matemática.

Um conteúdo que oportuniza amplamente essa identificação é através do estudo dos fractais. Uma geometria fractal é construída a partir de uma regra que se aplica aos crescentes níveis de sua construção. Um fractal pode ser construído por essas regras, relativamente simples, que a medida que ocorrem as iterações, resultam em formas complexas. O estudo dos fractais está relacionado a compreensão de diversos fenômenos naturais, sendo seu estudo uma ferramenta importante para um ensino interdisciplinar (PEITGEN; JÜRGENS; SAUPE, 2012).

A identificação dos padrões em uma geometria fractal possibilita o estudo de temas matemáticos variados. Além das progressões geométrica e aritmética, são estudados outros como área, perímetro, sequências definidas recursivamente, etc. A abordagem dos fractais favorece uma visão diferenciada de diversas formas presentes na natureza, e possibilita um tratamento matemático quando é identificado um padrão (BARBOSA, 2002).

O estudo dos fractais possibilita a exploração de conteúdos fundamentais como os limites das progressões aritmética e geométrica. Essa identificação ocorre através da observação da regularidade das quantidades observadas e da formulação das equações, como para o termo geral e de soma dos elementos a cada iteração. Para os fractais essas quantidades são relacionadas aos diversos componentes existentes nele, como área, perímetro ou qualquer outra característica quantificável.

Grafos, que são costumeiramente estudados no ensino superior, quando trazidos para o ensino médio, possibilitam que o estudante seja capaz de sistematizar situações, fazer representações mais simples de um problema mais complexo. O estudo desse conteúdo aparece com importância para a resolução de problemas, onde é facilitada a representação de situações complexas para outras simplificadas (MALTA, 2008).

Os grafos tem a característica de representar objetos que são apenas relevantes os elementos que os constituem e a relação existentes entre esses objetos. Em particular, pode-se citar os circuitos resistivos ideais, nos quais são definimos pelos resistores que os constituem e a forma que esses resistores são ligados entre si.

Dentro dos conceitos de física, os fenômenos relacionados a eletricidade nos circuitos elétricos é importante no cotidiano, uma vez que os componentes elétricos existentes no dia a dia das pessoas fazem uso de resistores em suas composições. De forma geral, a compreensão dos circuitos resistivos surge como pré-requisito para a compreensão de circuitos com um grau de complexidade maior. Entretanto, é habitual que tais conteúdos sejam aprendidos no ensino 
médio de forma mecânica, com perguntas direcionadas sobre aspectos quantitativos. É comum os problemas aparecerem para serem resolvidos a partir das leis de Kirchhoff, lei de Ohm, etc. Uma estrutura de aprendizagem conceitual muitas vezes é omitida e os alunos respondem a questões qualitativas erroneamente (COHEN; EYLON; GANIEL, 1983).

Um circuito resistivo ideal tem a característica de depender apenas da forma em que são ligados os terminais de seus resistores. Para representações com essa característica, os grafos são representações desses circuitos, com as linhas representando os resistores (WEST et al., 2001). Essas representações são justificáveis quando os circuitos apresentam um grau de complexidade crescente, como é feito nesse estudo.

No presente trabalho propõe-se a construção de circuitos resistivos que apresentem a autossimilaridade em sua configuração, uma característica que estão também presentes nos fractais autossimilares. Tais circuitos podem ser representados como grafos, uma vez que pode ser estabelecida a correspondência de resistores como arestas, nós como vértices e resistências como pesos.

Usando as propriedades de associações de resistores, será analisada a resistência equivalente dos circuitos autossimilares como um problema de ponto fixo. Para tal, é proposta uma definição geral para caracterização desses circuitos. Feito isso, são analisados diversos casos de interesse, representados por diversas configurações dos circuitos resistivos autossimilares.

Os circuitos nesse estudo são considerados ideais, ou seja, as resistências dos fios são consideradas nulas assim como não ocorre variação na resistência dos resistores. Os conceitos de corrente, resistência e diferença de potencial são considerados fundamentais para a caracterização de um circuito resistivo. Os resistores podem ser associados em diferentes configurações, sendo que para cada uma delas está associado um valor de resistência equivalente, cuja existência é garantida a partir do teorema de Thevenin. As diferentes associações são obtidas a partir das associações básicas: série, paralelo e $\Delta$-Y.

Como principais pontos desse trabalho destacam-se a revisão dos temas tratados, com uma especial ênfase nas interconexões entre física, matemática e ensino. Com o intuito de se aproximar do ensino médio e buscar atividades possíveis de serem trabalhadas nesse nível de ensino, ao final dos capítulos 3, 4, 5 e 6 são propostas atividades didáticas. Os temas propostos são abordados com uma proposta interdisciplinar que relaciona os conteúdos da disciplina com os conteúdos abordados em cada capítulo.

Na próxima seção é feito uma pesquisa envolvendo os temas abordados nessa dissertação, comentando-se uma amostra da literatura que apresenta intersecção com esse trabalho. 


\subsection{Estado da arte}

Nessa seção são descritos trabalhos que apresentam proximidades com os tópidos abordados nesse estudo. Os temas principais consistem em fractais autossimilares, grafos e/ou circuitos resistivos. Como critério para definir essa proximidade levou-se em considerações as aplicações para circuitos resistivos autossimilares, e exemplos de abordagem desses tópicos no ensino médio.

Em relação às características da importância das práticas interdisciplinares, o artigo Interdisciplinaridade em ensino de ciências e de matemática no ensino médio (LAVAQUI; BATISTA, 2007) mostra que a presença de novos fatores, como a existência de amplas possibilidades decorrentes da presença dos recursos científicos e tecnológicos, são potencializadas a partir de práticas interdisciplinares no ensino de ciências e de matemática. São mostradas as formas de interdisciplinaridade existentes e suas principais definições relacionadas, como a multidisciplinaridade, interdisciplinaridade e transdisciplinaridade. Em relação a essa integração, foi visualizado as características da articulação em uma abordagem relacional, o respeito as especificidades, a complementaridade e a integração.

$\mathrm{O}$ artigo Geometria fractal: propriedades e características de fractais ideais (ASSIS et $a l ., 2008)$ apresenta de forma breve e elementar algumas definições e aplicações relacionadas à geometria dos fractais ideais. São apresentadas algumas aplicações dos temas na medicina; análise de imagens; engenharia; e relativo à otimização da captação de frequências. Alguns fractais autossimilares são caracterizados pelas suas medidas de comprimento, área e volume, cujas quantificações conduzem a resultados contraditórios, justificados pela dimensão fractal.

A possibilidade de trabalho no ensino médio com o tema fractais é mostrado do artigo Fractais no ensino médio, de Élvia Sallum (SALLUM, 2005). Nesse artigo o estudo dos fractais no ensino médio se justifica como uma oportunidade de se trabalhar com processos iterativos, escrever fórmulas gerais, criar algoritmos e trabalhar com área e perímetro. São apresentados exemplos de fractais cujas representações podem ser feitas a partir de recortes de papéis ou softwares. Nesse trabalho são abordados aspectos como perímetro e área de cada fractal com suas progressões associadas, com uma sistematização da equação que os descrevem e o valor a convergência quando o número de iterações tende ao infinito.

A dissertação Estudo e aplicações da geometria fractal (RABAY, 2013) apresenta uma revisão da pesquisa sobre os fractais, incluindo a história, aplicações e conceitos matemáticos envolvidos. A análise dos fractais inclui conceitos de ensino superior, como Teoria dos Números e Álgebra Linear. Ainda como conteúdos relacionados ao ensino médio, a partir das generalizações obtidas no estudo dos fractais são trabalhados as progressões aritmética e geométrica, geometria, logaritmo e noções de limite.

Ainda dentro da abordagem de fractais na sala de aula no ensino médio, o livro Fractals for the classroom (PEITGEN; JÜRGENS; SAUPE, 2012) faz uma rica abordagem sobre o tema, 
propondo atividades diversas, com exemplos variadas de fractais, assim propõe a construção de fractais usando softwares, a exemplo do fractal bastante conhecido chamado Conjunto de Julia. Esse livro mostra exemplos que relacionam esse conteúdo matemático com fenômenos físicos, biológicos e sociais, como a turbulência de líquidos, a formas de rios e de relâmpago e a variação de preços na economia. São mostrados exemplos de fractais com propriedades geométricas inesperadas e são apresentados conceitos fundamentais assim como técnicas de resolução de problemas.

Em relação à teoria dos grafos no ensino médio, a dissertação Grafos no ensino médio: uma inserção possível (MALTA, 2008) justifica a aplicação do tema através da resolução de problemas. Para tal, são apresentados exemplos clássicos de aplicação dessa teoria, como o problema das pontes de Königsberg e o problema do caixeiro viajante. As atividades didáticas foram aplicadas em uma escola de ensino médio, sendo que a atividade realizada foi de encontro a uma metodologia de resolução de problemas e interdisciplinar, através de uma matemática dinâmica, com constante aplicações na vida real.

Na dissertação Teoria dos grafos e suas aplicações (SOUZA, 2013) são apresentados conceitos básicos dos grafos, como a definições de trilhas e caminhos, que são bases para problemas clássicos, como o da ponte de Königsberg e do Caixeiro Viajante. É mostrada a associação existente entre grafos planares com os poliedros regulares, com a fórmula de Euler para grafos. Outra aplicação importante mostrada é na coloração de grafos e suas aplicações, como a representação de mapas.

A aproximação dos estudos dos grafos com os fractais em circuitos resistivos é mostrada no artigo Electrical resistance of n-gasket fractal networks (BOYLE et al., 2007), no qual são analisados e definidos circuitos autossimilares em termos de suas resistências equivalente, em são atribuídas distribuições de probabilidade nos valores de resistência. Nesse artigo são estudados circuitos resistivos autossimilares baseados em uma classe de fractais denominados $N$-Gaskets. São provadas a existência e a unicidade da resistência equivalente e são obtidas as fórmulas associadas a distribuições de probabilidades. A construção é analisada quando o número de iterações tende ao infinito.

Os circuitos resistivos autossimilares são também estudados no artigo "Thermodynamical formalism" for an infinite hierarchy of fractal resistor networks (ALSTROM; STASSINOPOULOS; STANLEY, 1988), no qual é atribuída uma diferença de potencial variável ao circuito autossimilar construída em uma estrutura com múltiplos fractais (multifractais). Para essa análise, é estudada a distribuição de tensão ao longo do circuito resistivos através de uma representação matricial. $\mathrm{O}$ artigo mostra que a distribuição de voltagem ao longo do circuito resistivo possui uma função que depende da dimensão fractal da estrutura e do número de resistores.

A partir do que nesse trabalho é chamado árvore binária, o artigo Resistance and fluctuation of a fractal network of random resistors: a non-linear law of large numbers (ESSOH; BELLISSARD, 1989) propõe que os resistores que formam essa árvore tenham resistência 
aleatória. Nesse estudo são estudadas as condições para que a resistência desse circuito seja convergente. Para tal, é estudada rigorosamente a resistência e a sua variação em uma estrutura fractal em um número infinito de resistores. O artigo prova que imposta uma condição de distribuição normal relativizada, a resistência equivalente converge para a distribuição normal padrão, em uma propriedade denominada lei não-linear dos grandes números.

O livro A tale two fractals (KIRILLOV, 2013) traz um amplo estudo dos fractais, considerando elementos de análise e de espaços métricos. É definido um fractal autossimilar rigorosamente, assim como são discutidas propriedades decorrentes, como as definições de dimensão e distância de Haussdorf. Para os principais fractais autossimilares, são definidas funções de interações que os definem, sendo analisados seus principais aspectos. Para fractal triângulo de Sierpinski ocorre um estudo detalhado, com a análise segundo o Operador de Laplace e das Funções harmônicas. Enfim, as definições acerca dos fractais de uma forma geral, são apresentadas com uma maior precisão e de uma forma simplificada.

O artigo Pascal-Sierpinski gasket fractal networks: some resistance properties (BEDROSIAN; SUN, 1989) mostra como um circuito resistivo pode ser construído com a configuração de um triângulo de Sierpinski. Usando as propriedades de transformação $\Delta$-Y, obtém-se a resistência para diferentes níveis de circuito. O artigo mostra outras aplicações para esses circuitos resistivos, como em processos de difusão e passeios aleatórios em estruturas de rede.

\subsection{Desenvolvimento do trabalho}

Considerando os temas circuitos resistivos, grafos e fractais, nesse trabalho é proposta a construção de circuitos de resistores, com base em uma característica típica de fractais: a autossimilaridade. Os circuitos resistivos ideais podem ser representados como grafos, o que facilita a notação para circuitos com complexidade crescente. Dessa forma, os objetos desse estudo são denominados circuitos autossimilares, nos quais através das propriedades de associação de resistores, são estudados os valores de resistência equivalente e as condições de existência desses valores.

Dos circuitos resistivos são estudadas as principais associações de resistores e suas resistências equivalentes. Da teoria dos grafos mostra-se que um circuito resistivo tem a representação facilitada quando representado como um grafo. E dos fractais mostra-se o conjunto de funções iteradas que definem um fractal autossimilar, sendo que os circuitos autossimilares são definidos a partir desse conceito.

A estrutura da dissertação é comentada a seguir. No capítulo 2 é mostrado de forma sucinta como o conteúdos de matemática e de física são estruturados no estado de São Paulo. Além disso é apresentada a justificativa de como uma proposta interdisciplinar através de resolução de problemas pode auxiliar no processo de ensino e aprendizagem em matemática. No currículo do estado paulista, o ensino de física tem início no último ano do ensino fundamental, quando 
alguns conceitos fundamentais são aprendidos, como carga elétrica. $\mathrm{O}$ ensino de eletricidade ocorre na última série do ensino médio, quando se ensina os circuitos elétricos, que corresponde a um dos temas centrais desse estudo.

No capítulo 3 são estudados os conceitos físicos envolvidos no estudos dos circuitos elétricos. Dentro desse estudo são estudadas as associações elementares de circuitos em série, em paralelo, e na configuração $\Delta$-Y, sendo quantificadas as resistências equivalentes entre esses resistores. Os circuitos estudados são considerados ideais, assim, não existe resistência elétrica nas conexões entre os resistores e a resistência de cada resistor não sofre variações devido a influências externas.

No capítulo 4 é apresentada a definição de um grafo, assim como os tipos de grafos e suas aplicações. Em especial são abordados os grafos denominados árvores e os grafos com peso, com o intuito de se mostrar como os circuitos resistivos podem ser representado como um grafo. Em alguns circuitos autossimilares desse estudo existe características dos grafos categorizados como árvore, uma vez que não apresentam ciclos. Ainda nesse estudo, são atribuídos fatores aos diferentes níveis dos circuitos, o que em um grafo corresponde a atribuir um peso a uma aresta.

Os circuitos autossimilares apresentam a característica da autossimilaridade conforme mostrado no capítulo 5, onde são apresentados fractais essa característica. Quando algumas características dos fractais são quantificadas, para uma melhor compreensão, são exigidas noções de espaços métricos, que são apresentadas nesse capítulo. Como exemplos de fractais autossimilares, são apresentados o triângulo de Sierpinski, a curva de Koch e o conjunto de Cantor, sendo que para todos eles existe um sistema de funções de recorrência que os definem a cada nível.

No capítulo 6 é apresentada uma definição geral para os circuitos autossimilares estudados, assim como as condições de convergência da resistência equivalente. Feito isso, em seguida são apresentados circuitos autossimilares: série de resistores, árvore autossimilar, árvore binária, árvore com $m$ ramos, árvore binária com pesos e o circuito de Sierpinki.

Finalmente, no capítulo 7 são apresentados os comentários finais e conclusões sobre os conteúdos abordados nesse trabalho e sobre as atividades didáticas. 



\section{PROPOSTA CURRICULAR DO ENSINO MÉDIO PARA FÍSICA E MATEMÁTICA}

Nesse capítulo são discutidos aspectos básicos sobre o processo de ensino e aprendizagem nas disciplinas de matemática e física. $\mathrm{O}$ desenvolvimento de competências é apontado objetivo central da disciplina, acompanhado de seus mecanismos, como a proposta de um ensino interdisciplinar. As habilidades aparecem associadas às competência como "saber-fazer", sendo que a um conjunto de habilidades está associada uma competência.

São discutidos os documentos que norteiam o processo educativo no Brasil, dos quais os principais são a Lei de Diretrizes e Bases e os Parâmetros Curriculares Nacionais. É descrito brevemente a proposta curricular do estado de São Paulo, sobretudo sobre a organização do ensino de física e matemática em eixos e competências.

\subsection{As competências em matemática}

Sobre as competências, Perrenoud afirma que consistem na capacidade do sujeito de ativação de conhecimentos, habilidades e estratégias em uma variedade de contextos ou situaçõesproblema. Dessa forma, as pessoas têm a capacidade de mobilizar uma série de recursos mentais com a finalidade de resolver com eficácia e pertinência uma série de situações do cotidiano. $\mathrm{O}$ pedagogo ainda afirma que competência tem relação com a capacidade de improvisar, como sendo um produto resultante de um processo de aprendizagem, portanto, não de uma forma espontânea (PERRENOUD; RAMOS, 2000).

Com o intuito de fornecer uma base teórica e conceitual para a definição e seleção de competências chave, a Organização para cooperação e desenvolvimento econômico (OCDE) publicou o documento The Definition and Selection of Key Competencies. Este discorre sobre a necessidade das pessoas serem capazes de utilizar diversas ferramentas para interagir com o ambiente de forma eficiente, tal como a informática e a linguagem. Aponta que em um mundo 
cada vez mais globalizado, as pessoas devem ampliar suas capacidades de se envolver umas com as outras, assim como serem capazes de interagir com grupos heterogêneos (OCDE, 2005), (BUSQUINI, 2013).

Tendo como base o conjunto de competências a se desenvolver em matemática apontadas pela OCDE, mostrou-se que deve-se ter como intuito desenvolver "a capacidade de identificar e compreender o papel que a matemática desempenha no mundo, fazer julgamentos fundamentados e também, de usar e se envolver com a matemática de maneira a atingir as necessidades de sua vida com um cidadão construtivo, preocupado e reflexivo (OCDE, 2005)”.

Alternativamente, ter competência em matemática é ter conhecimento para utilizá-la com propriedade e em amplos contextos onde a matemática tem um papel relevante. Para tal, o aluno deve identificar e compreender a importância da matemática no mundo, fazendo uso das ferramentas com base nas necessidades de sua vida como um cidadão construtivo, comprometido e reflexivo (OCDE, 2005).

As competências em matemática consistem em uma combinação de habilidades que, relacionadas ao meio social, associada a valores de comportamento, mobilizam uma ação. $\mathrm{O}$ sujeito deve ser capaz de relaciona-as com uma profissão, um papel social ou um projeto social concreto (BUSQUINI, 2013).

Em relação as competências, a organização pode ser organizada da seguinte forma: pensamento matemático; formular e resolver problemas; modelagem matemática; e argumentação matemática (NISS, 2003), (BUSQUINI, 2013). Tais competências são resumidas a seguir.

Pensamento matemático. Essa competência é resumida pela capacidade do sujeito saber fazer perguntas típicas de matemática, reconhecer e distinguir os diferentes resultados em matemática, como teoremas, hipóteses, definições. Outros aspectos importantes são:

- saber impor limitações para um problema;

- reconhecer instruções diretas;

- utilizar raciocínios diretos e interpretar literalmente;

- tomar decisões sequenciais;

- interpretar sobre diferentes fontes de informação;

- usar um raciocínio flexível e bem desenvolvido;

- uso de pensamento e raciocínio matemático avançados.

Modelagem matemática. O estudante deve saber analisar e compreender as propriedades dos modelos existentes, avaliando seu alcance e sua validade. A partir de uma realidade existente, criar um modelo, estruturando o domínio do problema a ser modelado, criando uma regra de para a solução do problema, e identificando seu alcance. Outros aspectos importantes são: 
- reconhecer, aplicar e interpretar modelos básicos pré-definidos;

- utilizar diferentes modelos de representação;

- conceitualizar o uso de modelos matemáticos complexos e suas relações, reflexão e explicação dos resultados.

Formular e resolver problemas. Essa competência se resume a saber caracterizar os problemas de matemática em geral, puros ou aplicados. Dessa forma, deve ter a capacidade de criar relações usando o conhecimento matemático com a matemática, ou com outras áreas. Outros itens importantes são:

- saber verificar as soluções propostas para o problema;

- lidar com problemas diretos e explícitos;

- usar inferência direta;

- usar estratégias simplificadas de resolução de problemas;

- trabalhar com pressupostos e restrições;

- selecionar, comparar e avaliar diferentes estratégias de resolução;

- investigar e modelar situações complexas.

Argumentação matemática. Outra finalidade da matemática, como linguagem, corresponde a competência do aluno saber elaborar e estruturar argumentos formais e informais que sustentem uma afirmação em matemática. Outros aspectos são resumidos a seguir:

- análise de informação e interpretações literais;

- produção de comunicação que sustente suas afirmações;

- construção e comunicação de explicações e argumentos;

- formulação de comunicações precisas.

Em relação aos domínios das ferramentas e linguagens, incluem se: representação; uso de símbolos e formalismos; registros matemáticos; e ferramentais matemáticas (BUSQUINI, 2013) (NISS, 2003). Esses pontos são detalhados a seguir:

Representação. Essa competência envolve decodificar, interpretar e distinguir as representações de objetos matemáticos, situações e fenômenos. É necessário saber escolher entre os pontos fortes e fracos entre cada um deles, escolhendo segundo a conveniência. 
- lidar com informação direta e informal;

- extrair informação de representação isoladas;

- interpretar e usar diferentes formas de representação;

- selecionar e integrar diferentes formas de representação e relacioná-las com o mundo real;

- usar representações estratégicas e interligações entre diferentes representações;

- relacionar informações e representações de forma flexível.

Uso dos símbolos e dos formalismos. Para essa competência é necessário reconhecer os símbolos e linguagem matemática e relacionar na linguagem natural. Essa conexão envolve a compreensão da natureza e sua relação com os sistemas matemáticos formais. O estudante deve manipular adequadamente as afirmações que contém símbolos e fórmulas. Os conceitos específicos são listados a seguir:

- aplicar procedimentos de rotina;

- usar algoritmos, formulas, procedimentos e convenções básicas;

- trabalhar com representações simbólicas;

- usar símbolos e representações formais;

- dominar operações matemáticas simbólicas e formais e suas interligações.

Na próxima seção é mostrado a interdisciplinaridade como uma ferramenta para o desenvolvimento das competências no processo de ensino e aprendizagem.

\subsection{A interdisciplinaridade}

As disciplinas no currículo da educação básica são estruturadas de modo relativamente independentes, com poucas interações. Essa fragmentação do conhecimento em diversas áreas tem como consequência a especialização dos saberes em um única disciplina, resultam sobretudo em um currículo que desorienta o aluno em seu processo de aprendizagem (MACHADO, 1995).

A organização tradicional dos conteúdos ocorre de forma linear, onde é estabelecida a fixação de pré-requisitos e com uma seriação rígida. A organização linear ocorre em todas as disciplinas, sendo mais visível em matemática. Dessa forma, estabelece-se que os conteúdos devem ser percorridos sequencialmente, com um ordenamento criado do assunto mais simples para o mais complexo (MACHADO, 1995).

Considerando uma visão de ensino atual, verifica-se a existência de uma dificuldade de enquadramento de fenômenos que ocorrem fora da escola dentro de apenas uma disciplina. 
Nesse sentido, uma forma de substituir a organização linear dos conteúdos, nas relações internas e externas da disciplina, é através da organização do conhecimento em rede. Em tal concepção, o significado de um conhecimento é construído a partir das múltiplas relações existentes com outros conhecimentos adquiridos dentro e fora da escola (MACHADO, 1995).

Dessa forma, é desejável que os conteúdos em matemática não sejam organizados sequências rígidas. Assim, em vez de se buscar esgotar todas as nuances que um conteúdo contém em um intervalo fixo de tempo, é necessário que um conteúdo seja abordado em momentos diferentes, com a inserção de novos elementos, permitindo ao aluno reelaborar o conteúdo aprendido, ampliando seu significado (CARVALHO, 2014).

Em relação a interação entre as disciplinas, a escola é naturalmente multidisciplinar, pois existentes diversas disciplinas que são autônomas e possuem seus objetos particulares. Deseja-se uma comunicação efetiva entre as disciplinas, na qual se considere objetos comuns entre elas. Tal processo é chamado interdisciplinaridade (MACHADO, 1995).

A interdisciplinaridade surge como uma possibilidade de quebrar essa rigidez e isolamento na qual os conteúdos escolares são organizados. Dessa forma, existe uma real cooperação e diálogo entre as diversas disciplinas, com os conceitos organizados em tornos de estruturas conceituais e metodológicas compartilhadas entre várias disciplinas. A disciplina de Matemática, assim como a de Língua Portuguesa, podem ser entendidas desenvolvedoras de linguagens que são condições para todos os ramos de conhecimento, enquanto mecanismos fundamentais para comunicação e de representação da realidade.

Dentro dos conceitos de física, do ponto de vista da interdisciplinaridade, podem ser propostos pela proposição de um corpo teórico único, onde as aproximações entre as áreas são evidentes e os conteúdos ganham uma maior significação por serem abordados a partir de uma temática comum de caráter social, científico e tecnológico. Nas sugestões didáticas contidas nos PCNEM buscam evidenciar os conceitos de física de forma integrada e não fragmentada, como por exemplo, o conceito de energia com variadas aplicações em diferentes contextos. A ampliação das disciplinas que contribuem para a construção de um conceito favorecem mostrar como tal se aplica em outros contextos e outras linguagens, preservando sua coerência e universalidade (ZIMMERMANN; CARLOS, 2005) (BRASIL, 2010).

Na próxima seção são descritos documentos básicos que norteiam o educação básica brasileira. 


\subsection{A Lei de Diretrizes e Bases e os Parâmetros Curricu- lares Nacionais}

As orientações do currículo no Brasil são norteadas pela Lei n ${ }^{0}$ 9394/96, a Lei de diretrizes e bases da educação nacional (LDBEN). Esse documento define aspectos para a busca do aprimoramento do ser humano através de sua formação ética; desenvolvimento de autonomia intelectual e de pensamento crítico; de sua preparação para o mundo de trabalho e o desenvolvimento de competências para a continuidade dos estudos (BRASIL, 1996).

A publicação da LDBEN obrigou uma adequação dos sistemas de educação em todo o país, sendo que nos anos seguinte a Secretaria da educação básica, vinculada ao Ministério da Educação, elaborou as publicações dos Parâmetros curriculares nacionais, que normatizam os níveis e modalidades de ensino em acordo com a LDBEN (BUSQUINI, 2013).

Dessas publicações, em especial, foi publicação no ano de 2000 os Parâmetros curriculares para o ensino médio, que consiste em um documento organizado nas áreas: linguagens, códigos e suas tecnologias; Ciências da natureza, matemática e suas tecnologias; e Ciências humanas e suas tecnologias. Essa organização provocou um amplo debate sobre a interdisciplinaridade durante a construção das matrizes do Exame nacional do ensino médio (ENEM). Em particular, dos documentos que caracterizam a área da matemática, foram organizados os conhecimentos, conteúdos e orientações didáticas, assim como a vinculação com os temas transversais (BUSQUINI, 2013).

A partir do observado nos parâmetros curriculares nacionais (PCN), a matemática do ensino médio deve valorizar o raciocínio dedutivo, auxiliando o aluno a formar a capacidade de resolver problemas, favorecendo o hábito de investigação com confiança de resolver problemas novos em variados contextos (CARVALHO, 2014). Dessa forma, as atividades em matemática devem priorizar a construção conhecimento pelo aluno para que ele transforme e conheça a sua realidade.

Uma aprendizagem em matemática efetivamente ocorre quando o sujeito consegue estabelecer relações desse conhecimento com os objetos do cotidiano e com os outros conhecimentos que ele adquire. Sendo assim, é desejável que a construção do conhecimento ocorra de forma espiralizada, ou seja, evitando uma apresentação rígida e linear dos conteúdos (BRASIL, 2010).

Ainda dentro dos parâmetro curriculares nacionais, em relação ao desenvolvimento das competências e habilidades, destacam-se (BRASIL, 2010):

- ler e interpretar textos de matemática;

- ler, interpretar e utilizar representações matemáticas (tabelas, gráficos, expressões etc);

- transcrever mensagens matemáticas da linguagem corrente para linguagem simbólica (equações, gráficos, diagramas, fórmulas, tabelas etc.) e vice-versa; 
- procurar, selecionar e interpretar informações relativas ao problema;

- formular hipóteses e prever resultados;

- selecionar estratégias de resolução de problemas;

- interpretar e criticar resultados numa situação concreta;

- distinguir e utilizar raciocínios dedutivos e indutivos;

- fazer e validar conjecturas, experimentando, recorrendo a modelos, esboços, fatos conhecidos, relações e propriedades;

- aplicar conhecimentos e métodos matemáticos em situações reais, em especial em outras áreas do conhecimento.

A partir dessas exigências, conclui-se sobre a necessidade da elaboração de um conjunto de estratégias para o aluno, de tal forma que se estabeleça relação entre os conteúdos dentro e fora da matemática. É interessante o uso de situações-problema, em que a partir de situações reais, o aluno estabeleça padrões matemáticos e conjecture modelos para sua resolução (NILSSON, 2003).

Além dos as aspectos práticos, deve-se enquanto ciência, o aluno deve perceber o caráter estrutural da matemática. Assim, deve compreender os axiomas e seus teoremas, construídos a partir de uma sequência lógica e conceitual.

Paralelamente à matemática, estrutura-se no ensino médio os conteúdos de física, no qual espera-se que seu ensino contribua para a formação de uma cultura científica, com a percepção e compreensão dos fatos que ocorrem na natureza em transformação. Para o ensino da física deve se promover um conhecimento contextualizado, a partir de indagações que promovam as curiosidades dos alunos. A inserção de novos saberes em física leva a novas compreensões do mundo e a novos problemas. Assim como no ensino da matemática, a física têm características que propiciam construções ricas em abstrações e generalizações (BRASIL, 2010).

O ensino da matemática e da física deve contemplar o "domínio das formas contemporâneas de linguagem" ou "dos princípios científicos-tecnológicos que presidem a produção moderna". Tal abordagem evidencia a necessidade de um diálogo entre os conteúdos abordados nas disciplinas e novas tecnologias da informação, as diversas aplicações, a pesquisa, etc (SEE-SP, 2011b).

Buscando atender à Lei de diretrizes e bases da educação (LDB), em termos dos grandes campos de competência tal como "os princípios científicos-tecnológicos que presidem a produção moderna", o documento da Proposta Curricular para o estado de São Paulo separa a composição dos saberes em competências gerais e habilidades específicas. 
Em especial, para a competência geral, investigar e intervir em situações reais, deve se ter a habilidade de formular questões, realizar observações, selecionar variáveis e estabelecer relações, diagnosticar e enfrentar problemas. Como habilidade específica; interpretar, propor e fazer experimentos; e fazer e verificar hipóteses.

Outra competência geral citada no documento corresponde estabelecer conexões e dar contexto. Associada as habilidades de relacionar informações e processos com seus contextos e diversas áreas do conhecimento.

\subsection{O ensino da matemática e da física}

O documento Proposta curricular para o ensino da matemática da Secretaria de Educação do Estado de São Paulo (SEE-SP) considera a disciplina de matemática como um meio para o desenvolvimento de competências como a compreensão de fenômenos, argumentação consistente e de problematização dos conteúdos estudados em diferentes contextos (SEE-SP, 2011b).

O currículo de matemática da SEE-SP considera as disciplinas como bases fundamentais para a ação educacional, com foco para o desenvolvimento das competências dos alunos. Nesse documento são apresentados três eixos compreensão e expressão; argumentação e decisão; e contextualização e abstração.

- O eixo expressão e compreensão é relativo a capacidade do aluno se expressar através das diversas linguagens, que envolve a compreensão do outro.

- O eixo argumentação e decisão inclui a capacidade da articulação de informações e relações, assim como a capacidade de decisão e elaboração da síntese resultados.

- E o eixo contextualização e abstração envolve a capacidade de aplicação e percepção dos conteúdos estudados na realidade, em especial no mundo de trabalho.

O enraizamento da informação passa pela capacidade de abstração, de imaginação e a consideração de novas possibilidades para o conceito aprendido. Essas competências estão contidas as situações de aprendizagem que estão contidas nos quatro cadernos do professor e do aluno de cada série do ensino médio.

O estado de São Paulo divide o ensino da matemática em quatro grandes blocos temáticos: números, geometria, medidas e tratamento da informação. Esses blocos devem ser contemplados respectivamente através de situações que ampliem a noção de campo numérico, como contagens e medições (números); o ensino das formas geométricas planas e espaciais ao longo de todas as séries, como por exemplo, através das observações da natureza (geometria). As grandezas e medidas como um eixo favorável para a interdisciplinaridade. Por fim, tratamento da informação 
surge como a capacidade de tomar decisões através da compreensão de uma coleção de dados (SEE-SP, 2011b).

Os conteúdos abordados em matemática aplicam-se principalmente para a primeira série do ensino médio onde são estudadas as sequências, seus padrões e regularidades, e deduzidas suas equações. É interessante levar o aluno a observar esses padrões em diferentes contextos, e fazer com que seja capaz de modelar a partir da observação.

Em termos de conteúdos básicos, que apresentam conexões com esses estudo, temse conjuntos numéricos; regularidades numéricas e sequências; e progressões aritméticas e geométricas. Sendo a proposta curricular, para esses conteúdos são desenvolvidas as habilidades (SEE-SP, 2011b):

- saber reconhecer padrões e regularidades em sequências numéricas ou de imagens, expressando-as matematicamente quando possível;

- conhecer as características principais das progressões aritméticas-expressão do termo geral, soma dos $n$ primeiros termos, entre outras, sabendo aplicá-las em diferentes contextos;

- conhecer as características principais das progressões geométricas-expressão do termo geral, soma dos $n$ primeiros termos, entre outras, sabendo aplicá-las em diferentes contextos;

- compreender o significado da soma dos termos de uma progressão geométrica infinita (razão de valor absoluto menor do que 1) e saber calcular tal soma em alguns contextos físicos ou geométricos.

O ensino da física, paralelamente ao ensino da matemática, é visto como um instrumento fundamental para compreensão e ação na realidade. Nesse sentido, é necessário que práticas que visam apenas a memorização de fórmulas sejam substituídas pela criação de significados traduzem fisicamente o que ocorre no mundo real (COHEN; EYLON; GANIEL, 1983).

O ensino da física deve ter como objetivo se constituir como um elemento básico para a compreensão e ação no mundo comtemporâneo. Deve se considerar os conhecimentos físicos como constituintes para a formação da cidadania, além de satisfazer culturalmente o cidadão atual. Para isso, deve se romper com o paradigma tradicionalmente, que organiza os conteúdos em temas centrais em áreas específicas da física, como a Mecânica, Termologia, Óptica e Eletromagnetismo. Deve-se ainda evidenciar as ligações entre essas áreas (SEE-SP, 2011a).

As competências e habilidades em física são desenvolvidas a partir de problemas concretos, descritos por leis, conceitos e princípios. Para tal, são feitas observações na natureza e observadas relações entre as grandezas, que a partir da experimentação são comprovadas ou rejeitadas. Essas relações correspondem a modelos matemáticos que buscam reproduzir situações da realidade (SEE-SP, 2011a). 
O ensino de física é significativo quando abrange as competências elencadas por Niss, e através da interdisciplinaridade, estabelece relação com os conhecimentos das outras áreas e com o mundo real. Para tal, é apontado três novas eixos de ampliam o aprendizagem da física segundo essa nova concepção (SEE-SP, 2011a):

- abordagem de sua construção histórica, e não apenas de sua exploração meramente através de fórmulas, de forma a ampliar o valor e o sentido dos conteúdos;

- estabelecimento de conexões da física com as necessidades e desafios da sociedade moderna, ampliando o interesse e a motivação do aprendiz;

- na visão dos fenômenos físicos como desafios, pois estimulam a imaginação, gerando prazer de aprender e gosto pela ciência.

Segundo a proposta curricular para o estado de São Paulo para o ensino de física, como conteúdos que apresentam elos com esse estudo, destacam-se equipamentos elétricos. Dentro desse conteúdos, estão inclusos os tópicos circuitos elétricos; aparelhos e dispositivos domésticos e suas especificações elétricas, como potência e tensão de operação; e modelo clássico de propagação de corrente em sistemas resistivos. Para esses conteúdos são desenvolvidas as seguintes habilidades (SEE-SP, 2011a):

- identificar a presença de eletricidade no dia a dia, tanto em equipamentos elétricos como em outras atividades;

- identificar e caracterizar os principais elementos de um circuito elétrico simples;

- relacionar as grandezas mensuráveis dos circuitos elétricos com o modelo microscópico da eletricidade no interior da matéria.

Por fim, conclui-se nesse capítulo que os ensinos da matemática e da física devem buscar atender as competências para a formação do sujeito, considerando as múltiplas possibilidades de ligações com o conhecimento proveniente das outras disciplinas e do mundo real. Para isso, deve-se considerar a realidade do aluno com um fator de despertar o interesse pelos conteúdos, e como favorecimento de uma aprendizagem efetiva. De uma gama de possibilidades, esse estudo tem como intuito de reunir, de uma forma interdisciplinar, conteúdos que aparecem nessas duas disciplinas, ampliando os conceitos previstos no currículo.

Na próxima seção é feita um estudo sobre conceitos de física fundamentais nesse estudo. São abordados os circuitos resistivos ideais assim como as propriedades fundamentais de seus conceitos relacionados. 


\section{3}

\section{ELEMENTOS DE UM CIRCUITO RESISTIVO}

Os objetos desse estudo são circuitos resistivos. Para caracterizá-los, são apresentados conceitos fundamentais que consistem em diferença de potencial, corrente e resistência elétrica. Para as associações de resistores desse estudo existe uma medida denominada resistência equivalente, cujo valor é obtido por equações de associações de resistores, descritas ao final do capítulo.

\subsection{Corrente, diferença de potencial e resistência}

Esse trabalho se estabelece em circuitos resistivos sendo que para tal existem três medidas fundamentais: corrente elétrica, resistência elétrica e diferença de potencial. Tais medidas baseiam-se no fluxo ordenado de cargas elétricas e na forças relacionadas (HALLIDAY R. RESNICK, 2009).

A mínima carga elétrica corresponde a de um elétron, cuja unidade de medida no sistema Internacional de Peso e Medidas (SI) é o coulomb, é aproximada em 1,6022 x 10 ${ }^{-19}$ coulombs (CLOSE, 1975). Nesse sentido, a carga elétrica de um corpo corresponde a um múltiplo inteiro da carga do elétron.

Os elétrons possuem naturalmente um movimento desordenado. Um movimento ordenado de elétrons pode ocorrer, por exemplo, quando ocorre um excesso ou falta de elétrons; ou através de um campo elétrico criado por uma bateria.

A corrente elétrica $i(t)$ através de uma secção de um fio condutor é definida como

$$
i(t)=\frac{d q(t)}{d t}
$$

onde a função $q(t)$ expressa a quantidade de carga que atravessa o condutor em um determinado espaço de tempo (NUSSENZVEIG, 1999). A medida da intensidade de corrente elétrica foi 
definida no sistema internacional de unidades e medidas, como ampere (A), sendo definida a partir da equação (3.2):

$$
1 A=\frac{1 \text { Coulomb }}{1 s}
$$

Para um fio com secção constante $S$, para um comprimento $l$ de fio, entre os pontos $A$ e $B$ indicados na figura 1 , pode-se escrever que a resistência elétrica do material é dada por:

$$
R=\sigma \frac{l}{S}
$$

onde $\sigma$ é a resistividade do material. Assim, a resistência de uma porção de fio é diretamente proporcional ao seu comprimento $l$ e inversamente proporcional à área da secção transversal do fio (S) (NUSSENZVEIG, 1999). A unidade de medida no sistema internacional dado por $\Omega$ (ohm). Essa unidade é tal que:

$$
1 \Omega=\frac{1 V}{1 A}
$$

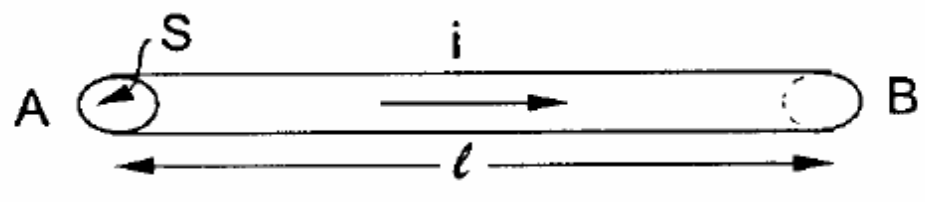

Figura 1 - Um fio com seção $S$ constante.

Para um fio percorrido por uma corrente constante, ou seja, por uma corrente contínua, define-se diferença de potencial entre os pontos $A$ e $B$ a partir lei do Ohm:

$$
v=R i \text {. }
$$

A unidade no sistema internacional (SI) é o volt $(V)$, relacionada pela equação

$$
1 V=1 \Omega \times 1 A
$$

Em resumo, ao se medir a diferença de potencial e a corrente nos terminais de um resistor, utilizando uma fonte de tensão, que fornece uma diferença de potencial de valor variável, observa-se que a razão entre a tensão e a corrente é constante. Essa propriedade é conhecida como Lei de $\mathrm{Ohm}$, que corresponde a seguinte afirmação: a corrente que atravessa um resistor é sempre diretamente proporcional à diferença de potencial aplicada ao resistor (NILSSON, 2003).

A resistência nesse estudo é restrita a um componente denominado resistor. Este é um elemento básico em um circuito. Sua função em um circuito é converter a energia elétrica em térmica. Uma das representações pictóricas comuns para um resistor, utilizada nesse estudo, é feita na Figura 2.

Na próxima seção são descritas as leis que caracterizam corrente, diferença de potencial e resistência elétrica em termos de conservação de energia e de carga elétrica. 


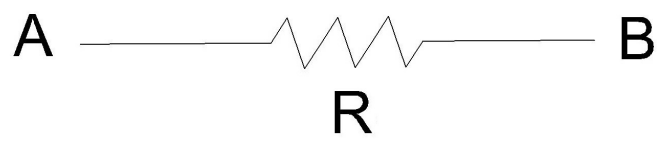

Figura 2 - Representação esquemática de um resistor.

\subsection{Circuitos resistivos e leis de Kirchhoff}

Esse estudo é baseado em componentes ideais. Tais elementos possuem características que considera apenas uma quantidade limitada de variáveis. Em outras palavras, para um componente ideal consideram-se apenas variáveis consideradas relevantes para o estudo (NILSSON, 2003). Delimitado um sistema, as variáveis selecionadas implicam em variações significativas quando alteradas.

Um componente ideal permite, de uma forma simplificada, a modelagem matemática para um caso real. Caso o modelo matemático criado não se aproxime do caso real, conclui-se que o descarte de variáveis foi inadequado (NILSSON, 2003).

Para um circuito elétrico, define-se que componentes ideais possuem dois terminais que podem ser ligados a outros componentes. Estes são caracterizados em termos de corrente e/ou diferença de potencial e não podem ser subdivididos em outros componentes (NILSSON, 2003).

Um conjunto de ligações de componentes elétricos é denominado circuito elétrico. Para esse estudo será analisado um circuito elétrico composto por resistores, denominado circuito resistivo. De forma geral, um circuito elétrico linear é composto por resistores, capacitores $e$ indutores conectados geometricamente e alimentados por uma fonte de tensão e corrente (SCOTT, 1960).

O dispositivo responsável por fornecer uma diferença de potencial ao circuito é denominado fonte de tensão, sendo que a energia elétrica fornecida por esse componente foi através da transformação de outras formas de energia em energia elétrica (NILSSON, 2003). Uma fonte de tensão ideal não apresenta nenhuma resistência interna à corrente (HALLIDAY R. RESNICK, 2009).

A conexão entre os componentes eletrônicos satisfazem leis básicas formuladas pelo físico alemão Gustav Kirchhoff. As leis de Kirchhoff são consequências das leis de conservação de energia e da conservação de carga, que afirmam que energia e carga não podem ser destruídas (HALLIDAY R. RESNICK, 2009).

Denomina-se nó ao ponto no qual dois ou mais elementos são conectados. Como ilustração, a Figura 3 representa um ponto A ligado por quatro componentes. Segundo Kirchhoff, a soma das intensidades de corrente que entram é igual a soma das correntes que saem. Considerando, em relação ao nó, corrente que entra com sinal positivo e corrente que sai com sinal 
negativo, pode se escrever

$$
i_{1}+i_{2}=i_{3}+i_{4}
$$

ou de outra forma

$$
i_{1}+i_{2}-i_{3}-i_{4}=0
$$

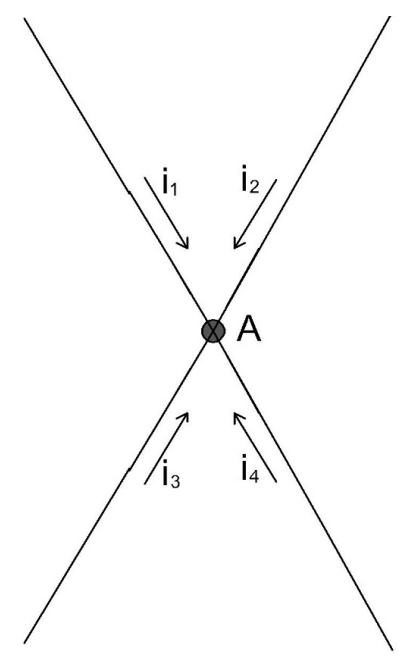

Figura 3 - Exemplos de correntes que "entram" e correntes que "saem” de um nó.

Generalizando a situação proposta no exemplo, a Primeira Lei de Kirchhoff, conhecida como Lei dos Nós, afirma que o total de carga que chega à uma junção é igual ao total de carga que deixa a junção. Convencionado-se que a corrente que chega com sinal positivo e a carga que sai como sinal negativo, tem-se que a soma de todas as correntes é igual a zero, onde o índice $j$ é referente à corrente que chega ao nó (CLOSE, 1975). Dessa forma,

$$
\sum i_{j}=0
$$

Denomina-se malha qualquer percurso que partindo de um nó, permita voltar para o mesmo nó sem passar mais de uma vez pelo mesmo nó (NILSSON, 2003). Analisando em termos de diferença de potencial, o movimento de uma unidade de carga através da malha ABCD, da Figura 4, necessita de uma quantidade correspondente a:

$$
v_{A B}+v_{B C}+v_{C D}+v_{D A}=0,
$$

cuja igualdade se deve à conhecida lei da conservação da energia (CLOSE, 1975). Considerando por unidade de carga, essa relação pode ser generalizada para:

$$
\Sigma v_{i}=0
$$


onde o índice $i$ refere-se ao intervalo considerado entre dois pontos do circuito.

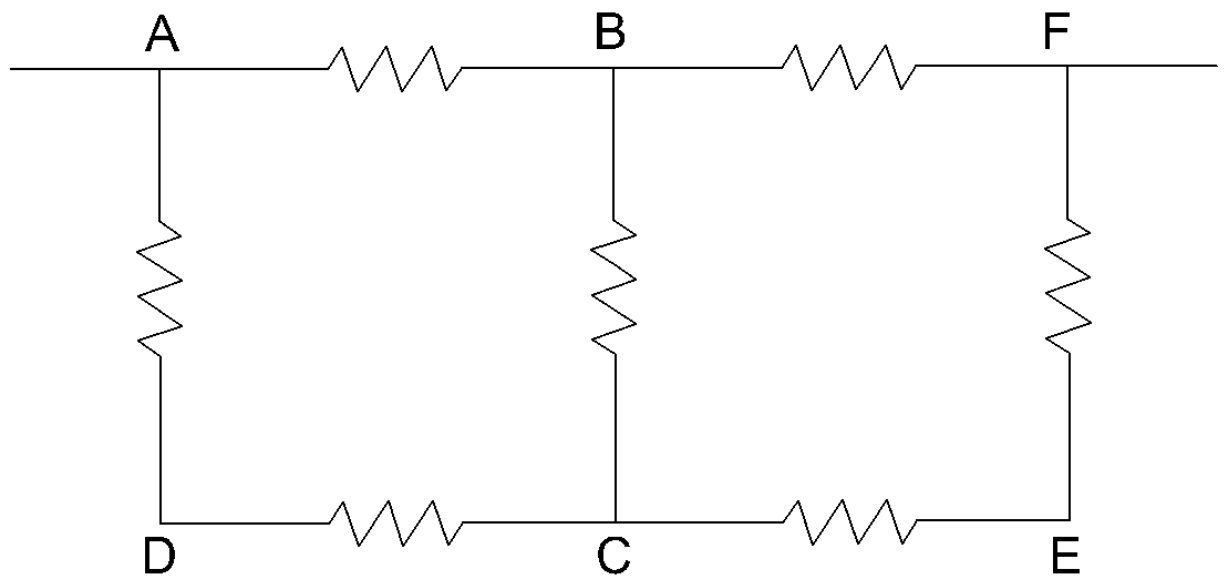

Figura 4 - Exemplo de um circuito com duas malhas.

Dessa forma, enuncia-se a segunda lei de Kirchhoff, também conhecida como Lei das Malhas: a soma algébrica das variações de potencial ao percorrer uma malha fechada é igual a zero. Como ilustração, considere a Figura 5. Partindo de A para a B pela parte superior, ou inferior, obtém-se uma redução de potencial igual a $v_{1}+v_{2}=v_{3}+v_{4}$, pois em B o potencial é o mesmo independente do caminho. Pode se fazer uma analogia com o caminhar por uma montanha e voltar para o mesmo lugar de partida: não há variação de altura em relação ao mar após se completar o trajeto (HALLIDAY R. RESNICK, 2009).
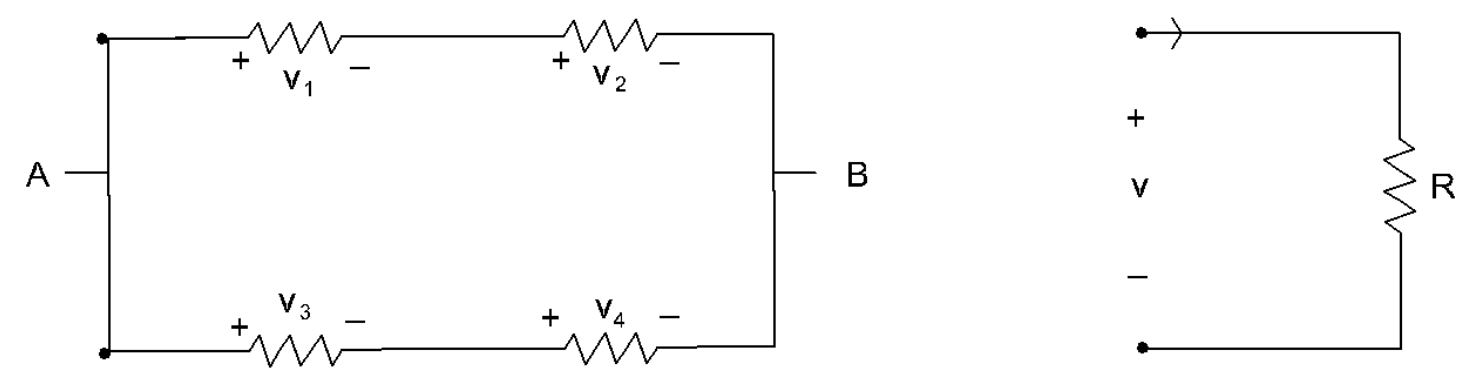

Figura 5 - Exemplo de aplicação da segunda lei de Kirchhoff.

Estabelecido os conceitos básicos, na próxima seção são estudados as associações de resistores em um circuito elétrico. 


\subsection{Teorema de Thevenin e a resistência equivalente}

A existência da resistência equivalente é garantida pelo Teorema de Thevenin, enunciado a seguir:

Teorema de Thevenin: Qualquer circuito resistivo pode ser representado, de forma equivalente, por uma fonte de tensão em série com um resistor (CLOSE, 1975). O valor de resistência do resistor é chamada de resistência equivalente.

Considerando o teorema de Thevenin, a partir das leis de Kirchhoff, é possível obter tais simplificações para um circuito resistivo. A figura 6 representa uma fonte de tensão ideal, ou seja, com resistência interna considerada desprezível, ligada a um resistor com resistência $R$. A fonte apresenta uma diferença de potencial elétrico entre os terminais estabelecendo que os portadores de carga positivos se movam do terminal de alto potencial elétrico para o de baixo potencial elétrico.

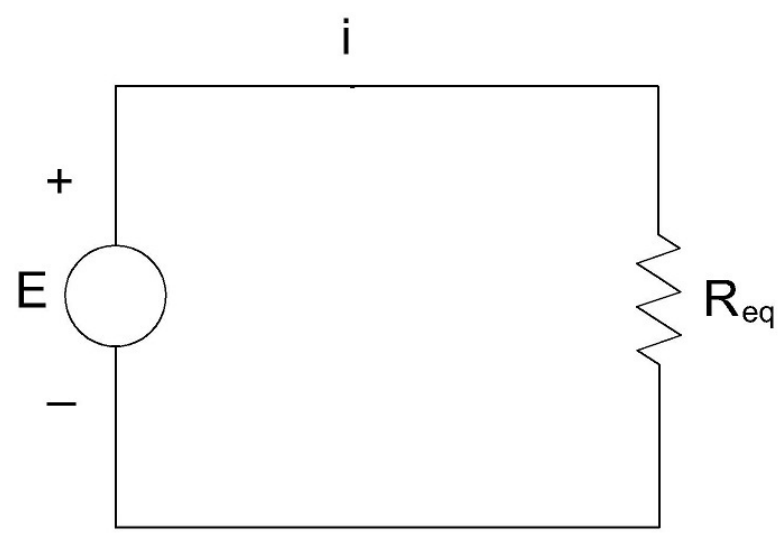

Figura 6 - Uma fonte ligada a um resistor.

Ao analisar um circuito, a partir dos pares de terminais, quando não podem ser distinguidos por medidas de corrente e de diferença de potencial efetuada entre seus terminais diz-se que esses são equivalentes (CLOSE, 1975).

Nessa seção são apresentadas as associações de resistores em série, em paralelo e as circuitos equivalentes obtidos através da Transformação $\Delta-Y$. Qualquer circuito resistivo pode ser reduzido para um resistor equivalente, quando se considera um par de terminais (SCOTT, 1960).

Analisando-se o potencial elétrico no circuito da figura 6, observa-se que o potencial é aumentado em $v$ na fonte de tensão. $\mathrm{O}$ fio da fonte até o resistor apresenta resistência desprezível, portanto com queda de potencial desprezível. No resistor, a queda de potencial elétrico é dado pela Lei de Ohm. Do resistor até a fonte é completado o processo com um potencial igual a $V_{i}$. Através da $1^{\text {a }}$ Lei de Kirchhoff obtém-se a equação (3.12) e em seguida, a equação (3.13)

$$
V_{i}+v-R i=V_{i},
$$


ou seja:

$$
i=\frac{v}{R}
$$

Quando apenas dois resistores estão ligados a um nó, diz-se que esses resistores estão ligados em série. Quando todos os nós de um circuito apresentam essa característica, tem-se um circuito com resistores em série. Tal circuito é percorrido pela mesma corrente elétrica (NILSSON, 2003). Assim, ao se medir a corrente em um terminal de um resistor sabe-se consequentemente a corrente nos outros resistores e em todo o circuito.

Analisa-se agora um circuito com $n$ resistores, cada qual com resistência $R$, dispostos em série como na figura 7. De forma similar a análise anterior, entretanto com $n$ quedas de potencial dadas por:

$$
U_{k}=R_{k} i
$$

tem-se pela lei de Kirchhoff que

$$
v-\sum R_{k} i=0
$$

O que pode ser escrito como

$$
i=\frac{v}{\sum R_{k}}
$$

Assim, resistência total dos resistores pode ser igualada a resistência de um único resistor equivalente $R_{e q}$ como é feita na equação (3.17),

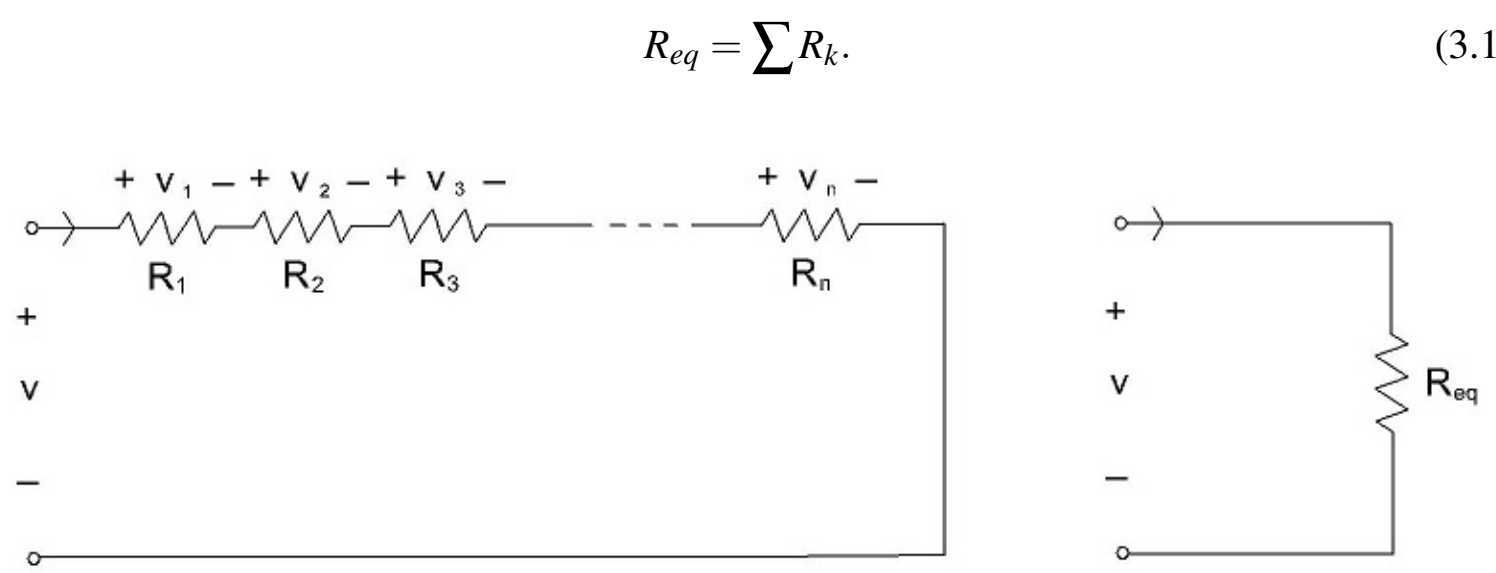

Figura 7 - Associação de $n$ resistores em série ligada a uma fonte.

Quando dois ou mais resistores estão ligados aos mesmos pares de nó, diz-se que esses resistores estão dispostos em paralelo. Um circuito que apresenta somente resistores com essa característica é denominado circuito em paralelo. Esses circuitos estão sujeitos à mesma diferença de potencial (NILSSON, 2003). 
Assim, analisemos outra disposição de $\mathrm{n}$ resistores conhecida como associação em paralelo na figura 8. Como o terminal de cada resistor está submetido a mesma diferença de potencial, pode-se escrever a equação (3.18) para cada resistor $k$,

$$
i_{k}=\frac{v}{R_{k}}
$$

Substituindo o valor de intensidade de corrente, correspondente a cada malha, na equação (3.18), obtém-se a equação (3.19),

$$
i=\frac{v}{R_{1}}+\frac{v}{R_{2}}+\frac{v}{R_{3}}+\ldots+\frac{v}{R_{n-1}}+\frac{v}{R_{n}}=v\left(\frac{1}{R_{1}}+\frac{1}{R_{2}}+\frac{1}{R_{3}}+\ldots+\frac{1}{R_{n-1}}+\frac{1}{R_{n}}\right) .
$$

Comparando a equação (3.19) com a equação (3.13), pode se determinar uma resistência equivalente $R_{e q}$ através da equação (3.20):

$$
\frac{1}{R_{e q}}=\frac{1}{R_{1}}+\frac{1}{R_{2}}+\frac{1}{R_{3}}+\ldots+\frac{1}{R_{n-1}}+\frac{1}{R_{n}} .
$$
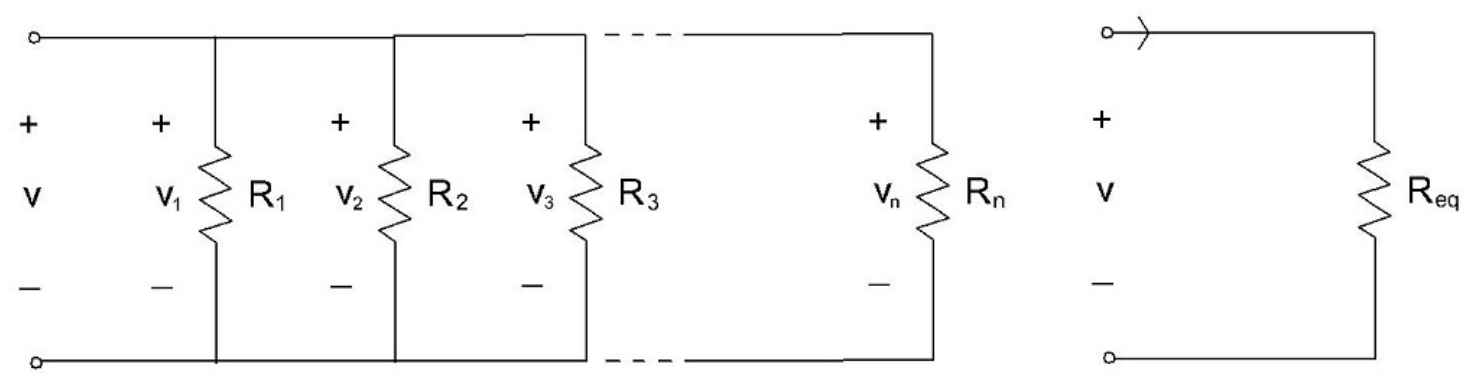

Figura 8 - Associação de $n$ resistores em paralelo ligada a uma fonte.

Para trechos de circuitos com três terminais, pode não ser possível calcular a resistência equivalente apenas com as equações de resistência em série e em paralelo. Nesse caso, é encontrado um circuito equivalente (SCOTT, 1960) através de uma transformação $\Delta-Y$, onde a resistência equivalente entre três pontos de um circuito permanece inalterada. Tais associações são assim nomeadas porque as configurações lembram um $\Delta$ e um Y, conforme se observa na figura 9.

O procedimento, denominado transformação $\Delta-Y$, é ilustrado na figura 9 sendo realizado considerando-se a igualdade das resistências equivalentes entre os pontos $A$ e $B, B$ e $C$ e $A$ e $C$ das representações $\Delta$ e $Y$. Em outras palavras, a resistência equivalente entre cada par de terminal deve ser a mesma em ambas as configurações.

Considerando conhecido os valores da configuração em $\Delta$, para os três pares de terminais da configuração em $\Delta$, a resistência equivalente é encontrada através da associação em série e em paralelo. No caso do par de terminal AB, o terminal C é considerado em aberto. Dessa forma, os resistores $R_{2}$ e $R_{3}$ estão em série e o resistor $R_{1}$ é paralelo a esses dois. Para a associação 
em Y, a resistência equivalente é encontrada através da associação em série dos resistores $R_{1}^{\prime}$ e $R_{3}^{\prime}$, ressaltando que para o trecho correspondente ao resistor $R_{2}^{\prime}$ é descartado. Para os trechos AC e BC adota-se o mesmo procedimento. Assim, obtém-se as equações (3.21), (3.22) e (3.23) (SCOTT, 1960):

$$
\begin{aligned}
& R_{A B}=R_{1}^{\prime}+R_{3}^{\prime}=\frac{R_{1}\left(R_{2}+R_{3}\right)}{R_{1}+R_{2}+R_{3}}, \\
& R_{B C}=R_{2}^{\prime}+R_{3}^{\prime}=\frac{R_{3}\left(R_{1}+R_{2}\right)}{R_{1}+R_{2}+R_{3}}, \\
& R_{A C}=R_{1}^{\prime}+R_{2}^{\prime}=\frac{R_{2}\left(R_{1}+R_{3}\right)}{R_{1}+R_{2}+R_{3}} .
\end{aligned}
$$

Somando a equação (3.21) com a equação (3.23) e subtraindo o resultado pela equação (3.22) obtém-se:

$$
R_{1}^{\prime}+R_{2}^{\prime}+R_{1}^{\prime}+R_{3}^{\prime}-R_{2}^{\prime}-R_{3}^{\prime}=\frac{R_{1} R_{2}+R_{2} R_{3}+R_{1} R_{2}+R_{1} R_{3}-R_{2} R_{3}-R_{1} R_{3}}{R_{1}+R_{2}+R_{3}}
$$

Com a simplificação obtém-se:

$$
R_{1}^{\prime}=\frac{R_{1} R_{2}}{R_{1}+R_{2}+R_{3}}
$$

Usando o mesmo procedimento, ao se resolver o sistema formado pelas equações (3.21), (3.22) e (3.23) para $R_{1}^{\prime}, R_{2}^{\prime}$ e $R_{3}^{\prime}$, obtém-se as equações 3.26, 3.27 e 3.28, que permitem obter cada valor de resistência na associação em $\mathrm{Y}$, a partir dos valores de resistência em $\Delta$ :

$$
\begin{aligned}
& R_{1}^{\prime}=\frac{R_{1} R_{2}}{R_{1}+R_{2}+R_{3}}, \\
& R_{2}^{\prime}=\frac{R_{2} R_{3}}{R_{1}+R_{2}+R_{3}}, \\
& R_{3}^{\prime}=\frac{R_{1} R_{3}}{R_{1}+R_{2}+R_{3}} .
\end{aligned}
$$

Em particular, para $R_{1}=R_{2}=R_{3}=R$, tem-se a equação,

$$
R_{1}^{\prime}=R_{2}^{\prime}=R_{3}^{\prime}=\frac{R}{3}
$$



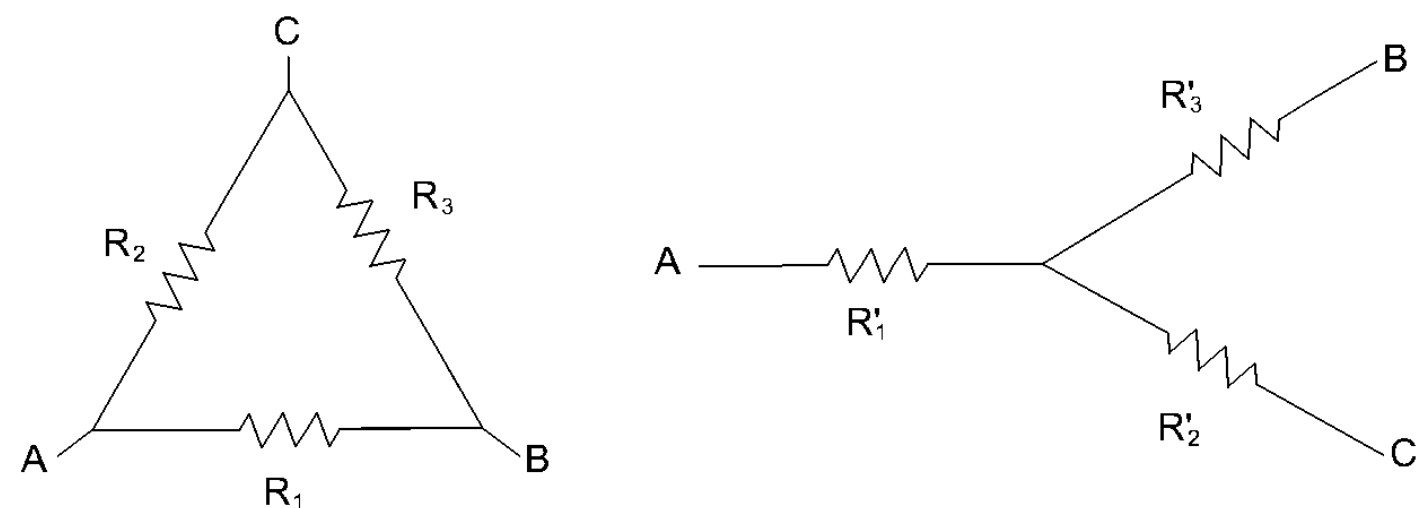

Figura 9 - Transformação $\Delta$-Y.

De forma similar, conhecida as resistências da configuração em Y, pode-se obter as respectivas resistências da configuração em $\Delta$ usando as equações:

$$
\begin{aligned}
& R_{1}=\frac{R_{1}^{\prime} R_{2}^{\prime}+R_{1}^{\prime} R_{3}^{\prime}+R_{2}^{\prime} R_{3}^{\prime}}{R_{2}^{\prime}}, \\
& R_{2}=\frac{R_{1}^{\prime} R_{2}^{\prime}+R_{1}^{\prime} R_{3}^{\prime}+R_{2}^{\prime} R_{3}^{\prime}}{R_{3}^{\prime}}, \\
& R_{1}=\frac{R_{1}^{\prime} R_{2}^{\prime}+R_{1}^{\prime} R_{3}^{\prime}+R_{2}^{\prime} R_{3}^{\prime}}{R_{1}^{\prime}} .
\end{aligned}
$$

Em particular para $R_{1}^{\prime}=R_{2}^{\prime}=R_{3}^{\prime}=R$, tem-se

$$
R_{1}=R_{2}=R_{3}=3 R
$$

A representação de um circuito resistivo pode alcançar níveis maiores de complexidade. Considerando a característica do circuito manter as medidas de diferença de potencial e corrente, independente da geometria em que é feito o circuito, pode se considerar um circuito resistivo com um grafo, cuja teoria é resumida no próximo capítulo.

\subsection{Atividade didática}

\subsubsection{Justificativa}

Para o Ensino Médio, o tema "equipamentos elétricos", em particular, "circuitos elétricos", está previsto para a $3^{\mathrm{a}}$ série quando se considera o proposta curricular para o ensino de física do estado de São Paulo. O estudo se justifica pelo fato que os fenômenos elétricos e magnéticos estão presente no cotidiano de todos, com muitos equipamentos que dependem de corrente elétrica e que contém resistores em sua composições (SEE-SP, 2011a). 
Para que o ensino da matemática transcorra de forma mais efetiva, é importante que ocorra interligações com outras disciplinas, para que seja verificada a aplicabilidade de leis e conceitos físicos, de tal forma que torne a disciplina interessante (FERNANDES, 2003). Nesse ponto de vista, são indicadas abordagens valorizem aspectos interdisciplinares de forma a ultrapassar um estudo apenas conceitual e isolado de outros temas.

Nessa atividade é proposta uma atividade prática para a verificação da validade da lei de Ohm e dos resultados envolvendo associação de resistores. A articulação dos conceitos, leis e teorias são potencializados através da experimentação. $\mathrm{O}$ aluno deve aprender esquemas, relações matemáticas e utilizar as demais linguagens simbólicas. De forma complementar, o aluno deve fazer experimentações para perceber que para desvendar um fenômeno é necessária uma teoria (SÉRÉ; COELHO; NUNES, 2003). As relações existentes entre o ensino da matemática e da física, do ponto de vista interdisciplinar, são mostradas no esquema da figura 10.

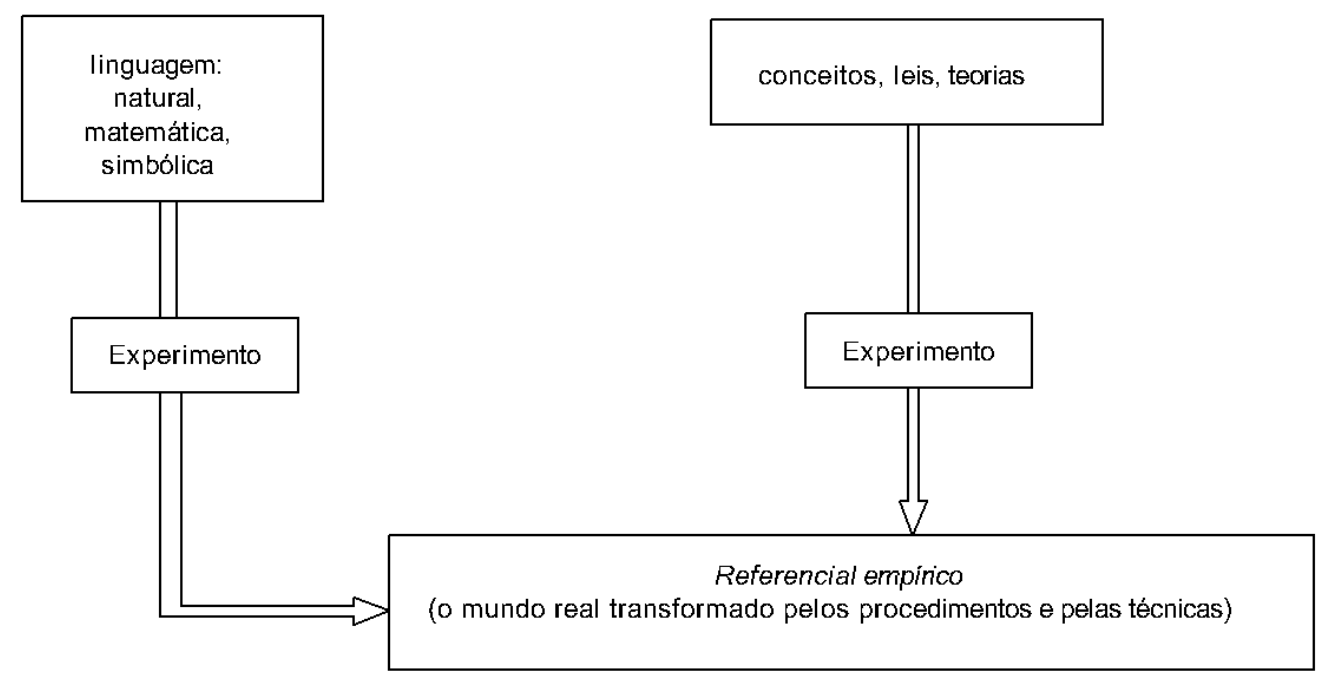

Figura 10 - Esquema representativo entre a teoria e a prática em física (SÉRÉ; COELHO; NUNES, 2003).

\subsubsection{Proposta de atividade}

Um circuito elétrico pode ter uma infinidade de configurações, entre as associações em série e em paralelo. Variações na configuração do circuito e/ou nos valores das resistências podem provocar variações nas medidas de corrente e de diferença de potencial em todo o circuito.

Um maneira prática de se construir circuitos elétricos é através da matriz de contatos ou proto board. A partir dela é possível fazer medições e testar as variações nos circuitos elétricos, sendo um equipamento fundamental para os alunos de cursos relacionados à eletrônica, por exemplo. Esse instrumento é ilustrado na figura 11.

A matriz de contatos é uma placa com diversos furos dispostos em fileiras. De acordo 


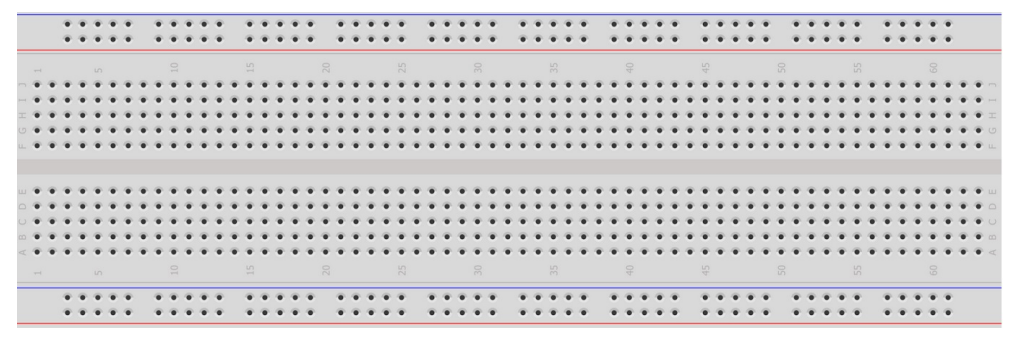

Figura 11 - Uma matriz de contatos.

com a fileira de pontos são criadas as conexões entre os componentes. A partir dessas fileiras é possível reproduzir circuitos elétricos.

O resistor é outro elemento básico do circuito proposto nessa atividade didática. $\mathrm{Na}$ figura 12, na qual é representado um resistor com resistência $100 \Omega$.

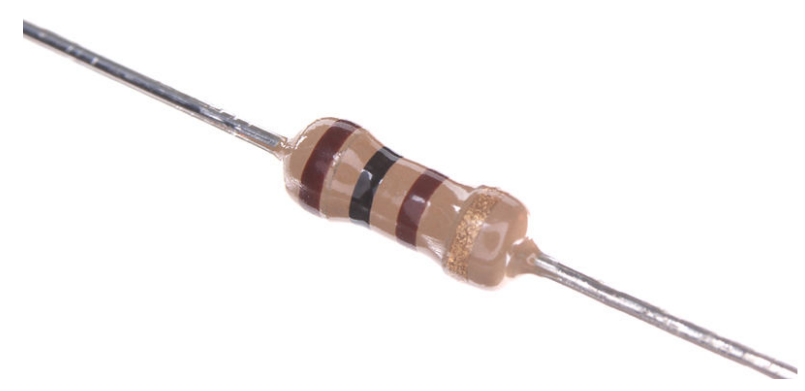

Figura 12 - Um resistor de $100 \Omega$.

Para a atividade a seguir, os conceitos teóricos são verificados a partir de um conjunto de atividades de reprodução de uma circuito resistivo em uma matriz de contatos.

- espaço utilizado: laboratório de física;

- grupos com 3 alunos;

- tempo previsto para realização da atividade: 2 horas.

Os materiais utilizados são:

- uma matriz de contatos;

- 8 pilhas comuns de $1,5 \mathrm{~V}$;

- suporte para pilhas em série;

- 3 resistores com resistência de $100 \Omega$;

- multímetro. 
Dentro desse contexto, propõe-se para estudantes de terceiro ano do ensino médio, durante a aprendizagem de circuitos de resistores:

1. Usando uma matriz de contatos, reproduzir os circuitos $a, b$ e $c$ da figura 13 , onde os resistores tem resistência $100 \Omega$ e a fonte fornece uma diferença de potencial de $12 \mathrm{~V}$.

2. Usando um multímetro, medir a diferença de potencial e a corrente elétrica para cada resistor do circuito. Comparar os resultados com a teoria.

A construção de diferença de potencial de $12 \mathrm{~V}$ pode ser feita através da disposição de 8 baterias comuns em série, usando um suporte adequado.

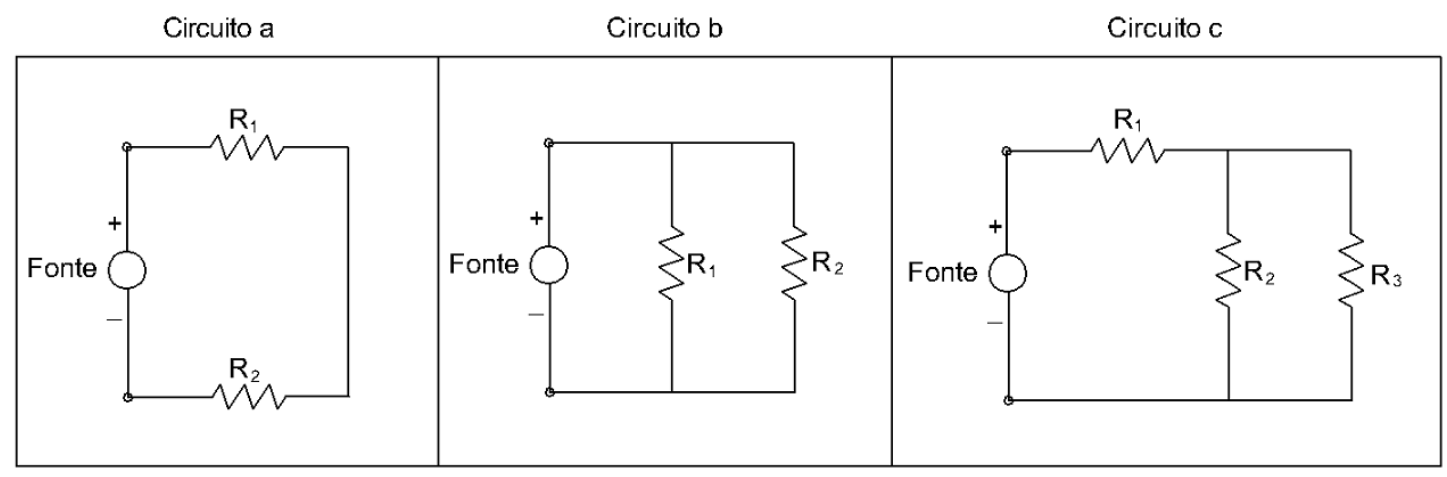

Figura 13 - Representação dos circuitos da atividade didática.

\subsubsection{Resultados esperados}

No ensino médio, existe alguma carência na realização de atividades práticas, sendo que essa atividade propicia que a teoria possa ser verificada com a prática. Em particular, para essa atividade é verificada experimentalmente a Lei de Ohm, com a medição da corrente e a diferença de potencial para cada resistor, assim como as relações decorrentes de suas associações.

Para a atividade 1, o aluno deve verificar a corrente através de cada resistor e verificar que não se altera. Uma vez que os resistores estão dispostos em série, deve ser medido um valor de corrente de $0,06 \mathrm{~A}$ e uma diferença de potencial de $6 \mathrm{~V}$ em cada resistor. A construção dessa atividade na matriz de contatos é mostrada na figura 14.

Para a atividade 2, por sua vez, a diferença de potencial entre cada resistor é constante. Deve ser observado a validade das associações de resistores e consequentes mudanças nas medidas de corrente e de diferença de potencial. Como os resistores estão em paralelo, a diferença de potencial observado neles é a mesma que o circuito oferece, assim deve ser medida diferença de potencial de $12 \mathrm{~V}$. E pela lei dos nós, deve ser medida uma corrente de $0,12 \mathrm{~A}$, já que os resistores são iguais e passam por eles correntes iguais. A construção dessa atividade na matriz de contatos é mostrada na figura 15. 


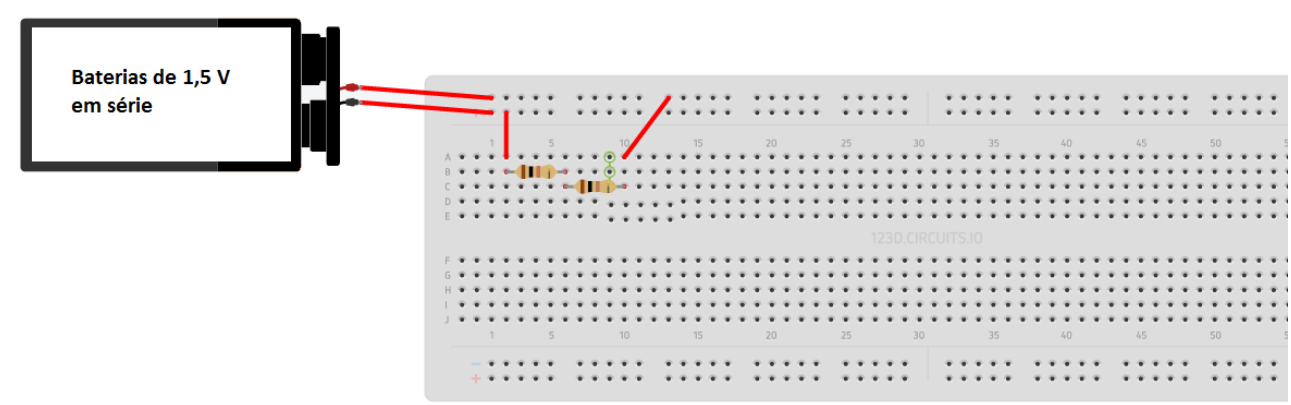

Figura 14 - Possível construção da atividade 1.

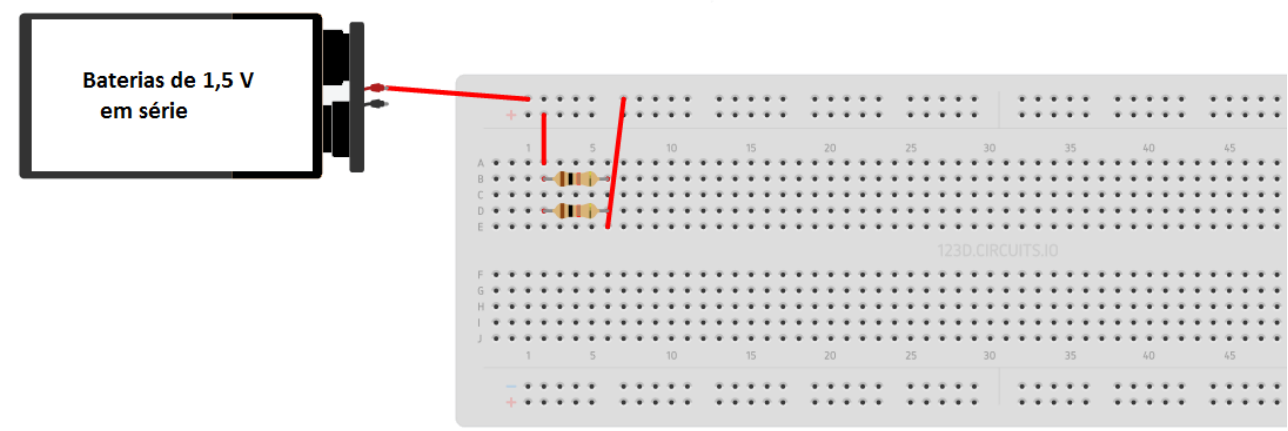

Figura 15 - Possível construção da atividade 2.

Para a atividade 3 inicialmente deve ser observada a resistência equivalente usando as equações da seção 3.3. Feito isso, deve ser calculada uma resistência equivalente de $50 \Omega$ para os resistores em paralelo $R_{2}$ e $R_{3}$, resultando em uma resistência equivalente de $150 \Omega$, ao se considerar o resistor $R_{1}$. Assim, deve ser medida uma corrente de $0,08 \mathrm{~A}$ no resistor $R_{1}$ com diferença de potencial de $8 V$. Para os resistores $R_{2}$ e $R_{3}$, deve ser medida a diferença de potencial de $4 V$ entre seus terminais, com uma corrente de $0,04 \mathrm{~A}$ em cada um deles. A construção dessa atividade na matriz de contatos é mostrada na figura 16.

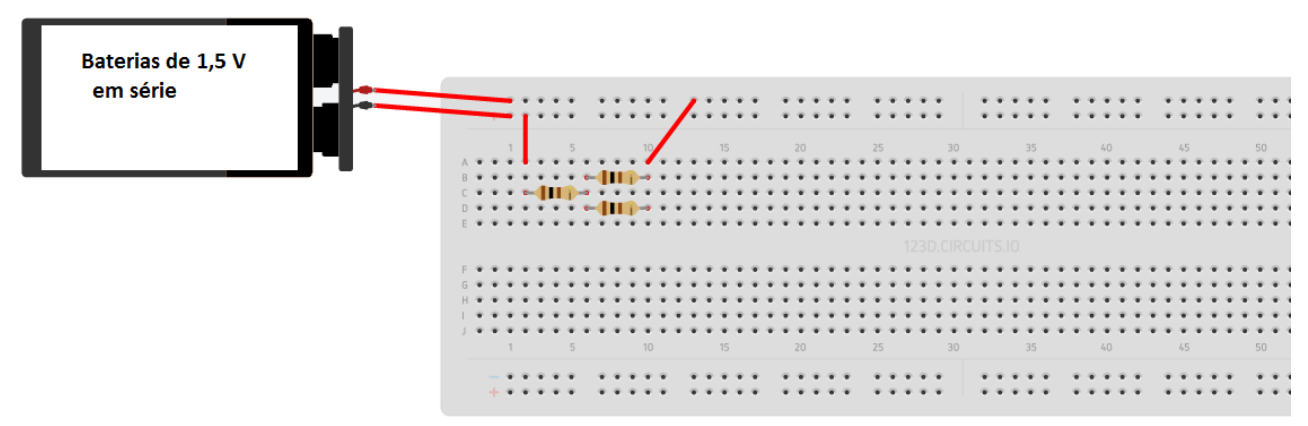

Figura 16 - Possível construção da atividade 3. 


\section{GRAFOS E OS CIRCUITOS RESISTIVOS}

A teoria dos grafos consiste em uma importante ferramenta para solucionar problemas. Existem aplicações importantes em áreas diversas como química, genética, linguística e arquitetura. Os grafos são ferramentas importantes para resolução e representação de problemas de combinatória assim como de otimização (BEINEKE, 2005). Em particular, grafos representam circuitos resistivos, como mostrado nesse capítulo.

Nesse capítulo é definido grafo e conceitos relacionados importantes, que caracterizam essa estrutura e se aplicam para o desenvolvimento apresentado nessa dissertação.

\subsection{Definição de grafo}

De forma geral, os elementos de um conjunto podem ser representados através de um grafo quando apenas são relevantes os elementos e as relações entre eles, em particular, para um circuito resistivo ideal, no qual só interessam as medidas de resistências e as ligações entre os resistores.

Um grafo simples $G$ é formado por um um conjunto $V(G)$ finito de elementos denominados vértices (ou nós) e um conjunto finito $A(G)$ de pares ordenados de elementos diferentes de $V(G)$ denominados arestas (BEINEKE, 2005). É comum representar arestas por letras minúsculas e vértices por letras maiúsculas, ou simplesmente denotar os vértices como $v_{i}$ e arestas como $a_{i}$, conforme a conveniência.

Sendo o conjunto $V$ de vértices com $n$ elementos, forma-se o conjunto $V_{(2)}$ com o número de pares não ordenados de $V$ com uma quantidade,

$$
\left(\begin{array}{l}
n \\
2
\end{array}\right)=\frac{n(n-1)}{2}
$$

Os subconjuntos desses pares são denominados arestas do grafo. 
Usualmente é comum representar um grafo a partir de uma figura formada por um conjunto de vértices representados por pontos, que podem ser unidos por arestas, representadas por linhas ou arcos. Nesse sentido, ilustra-se que a posição ou formato, ou mesmo a forma, dos vértices e as arestas são irrelevantes, sendo importante a relação entre os vértices. A Figura 17 representa um grafo com 5 vértices e 6 arestas. Esse grafo é formado pelo conjunto de vértices

$$
v=\left\{v_{1}, v_{2}, v_{3}, v_{4}, v_{5}\right\}
$$

conectados pelo conjunto de arestas

$$
A=\left\{\left(v_{1}, v_{2}\right),\left(v_{1}, v_{3}\right),\left(v_{1}, v_{4}\right),\left(v_{2}, v_{3}\right),\left(v_{3}, v_{4}\right),\left(v_{2}, v_{5}\right)\right\}=\left\{a_{1}, a_{6}, a_{4}, a_{2}, a_{3}, a_{5}\right\} .
$$

Quando dois vértices de um grafo são ligados por uma aresta, estes dois vértices são chamados adjacentes entre si.

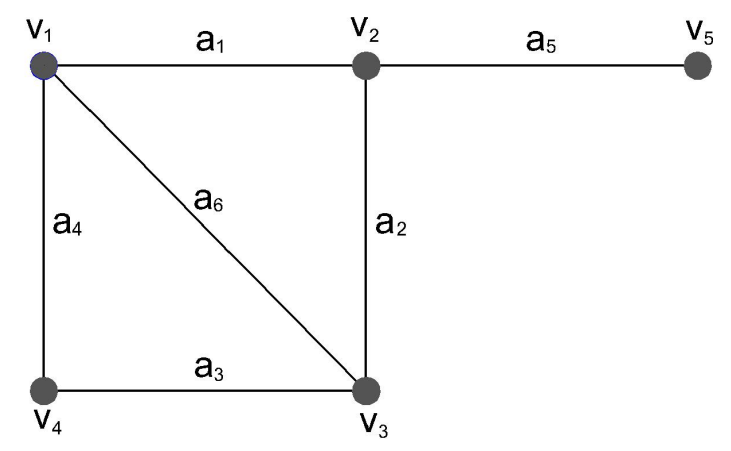

Figura 17 - Exemplo de um grafo.

\subsection{Definições complementares}

Dois grafos $G_{1}$ e $G_{2}$ são isomórficos quando existe uma correspondência biunívoca $f$ entre os vértices de $G_{1}$ e $G_{2}$ tal que o número de arestas que deixam cada vértice é igual ao número de arestas que deixam o vértice correspondente. A Figura 18 é um exemplo de dois grafos isomórficos. Para dois grafos isormórficos, dois vértices $v$ e $w$ de $G_{1}$ são adjacentes se e somente se $f(v)$ e $f(w)$ também são adjacentes em $G_{2}$. Uma característica dos grafos isomórficos: é possível alterar o nome da arestas e dos vértices de modo que estes grafos se tornem iguais.

Um subgrafo $H$ de um grafo $G$ é um grafo tal que o conjunto de vértices e de arestas do grafo $H$ estão contidos respectivamente no conjunto de vértices e arestas do grafo $G$. Assim, $V(H) \subseteq V(G)$ e $A(H) \subseteq A(G)$. Nesse caso afirma-se que $G$ contém $H(H \subseteq G)$. A Figura 19 representa um grafo $H$ contido em um grafo $G$.

Um caminho é um grafo $C$ tal que seus vértices podem ser colocados na forma:

$$
\left(\left\{v_{1}, v_{2}, v_{3}, \ldots, v_{n}\right\},\left\{v_{i} v_{i+1}, 1 \leq i<n\right\}\right),
$$



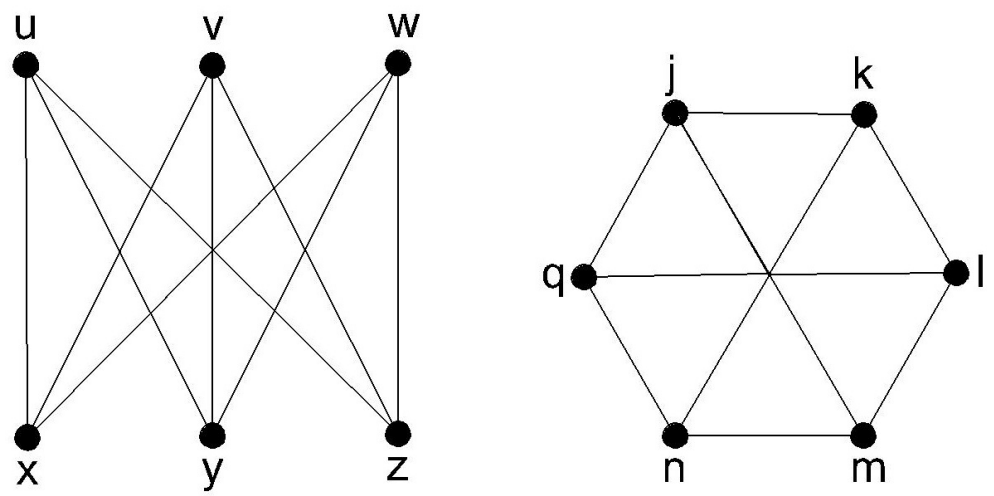

Figura 18 - Exemplos de um grafos isomórficos.
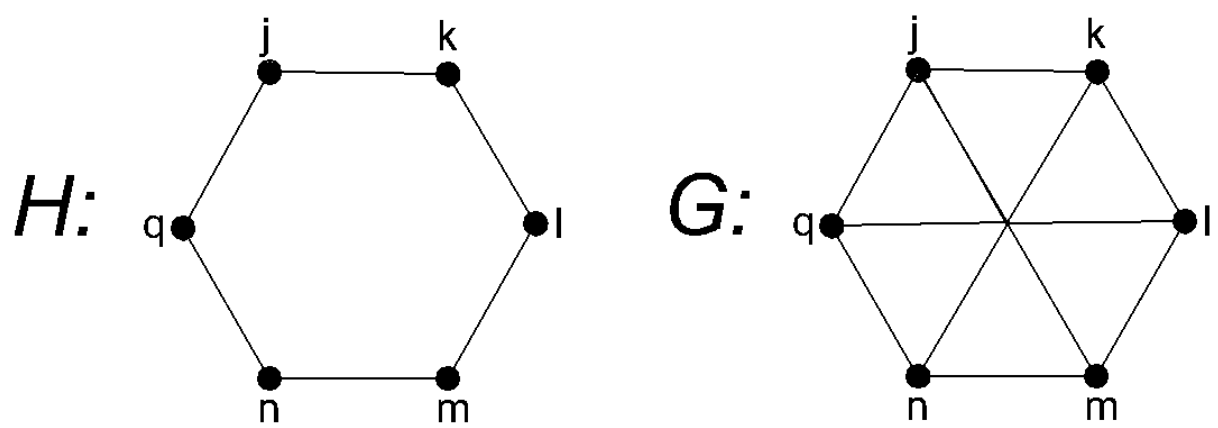

Figura 19 - Um subgrafo associado (esquerda) e um grafo (direita).

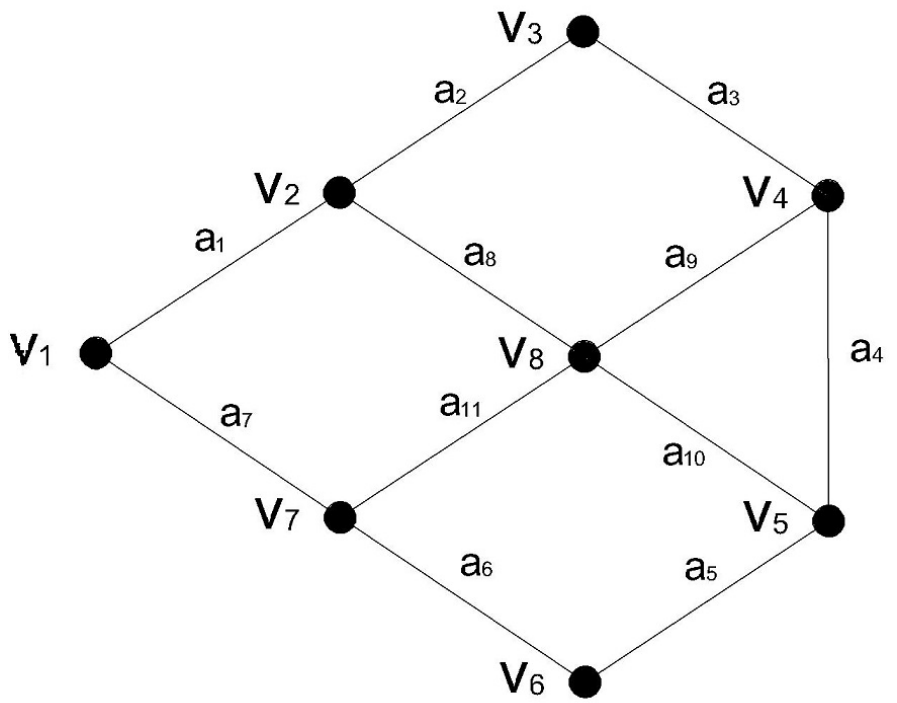

Figura 20 - Exemplo do caminho de um grafo. 
no qual $v_{1}$ e $v_{n}$ são os extremos do caminho. Este pode ser denotado simplesmente por $v_{1} v_{2} v_{3} \ldots v_{n}$. Na Figura 20, as sequências $v_{1} v_{2} v_{1} v_{2}, v_{3} v_{4}$ e $v_{7} v_{6} v_{5} v_{8}$ são exemplos de caminhos.

Quando, para um caminho, tem-se $v_{k}=v_{0}$, o grafo $O$ representa um ciclo. Seus vértices são da forma

$$
\left(\left\{v_{1}, v_{2}, v_{3}, \ldots, v_{n}\right\},\left\{v_{i} v_{i+1}, 1 \leq i<n\right\} \cup\left\{v_{n} v_{1}\right\}\right),
$$

$\operatorname{com} n \geq 3$. Na figura 20, o caminho $v_{7} v_{6} v_{5} v_{8} v_{7}$ é um exemplo de um ciclo. Um caso particular de caminho ocorre quando nenhum vértice é repetido. Nesse caso o subgrafo é denominado trilha. Na figura 20, o caminho $v_{1} v_{2} v_{3} v_{4}$ é uma trilha. Para um caminho, se $v_{k}=v_{0}$, tem-se um ciclo. Por exemplo, na figura 20, o caminho $v_{1} v_{2} v_{8} v_{7} v_{1}$ representa um ciclo (BEINEKE, 2005).

O número de arestas de um caminho é denominado comprimento do caminho. Na Figura 20, as sequências $v_{1} v_{2} v_{1} v_{2} v_{3} v_{4}$ e $v_{7} v_{6} v_{5} v_{8}$ tem comprimentos 5 e 3 , respectivamente. Um grafo é Euleriano se ele tem um caminho fechado contendo todas as suas arestas. Denomina-se Circuito Euleriano um caminho que contém todos os vértices e independe do ponto de partida.

Um grafo é conexo quando existe caminho para quaisquer pares $v, w$ de vértices. Caso contrário, o grafo é desconexo. O grafo da Figura 17 representa um grafo conexo e o grafo da Figura 22 representa um grafo desconexo. Para um vértice $v$ de um grafo $G$, o maior subgrafo conexo de $G$ que contém $v$ é denominado componente de $G$.

Um grafo é denominado como grafo planar caso exista uma representação cujas arestas não se cruzam (WEST et al., 2001). Os poliedros regulares apresentam uma relação com os grafos planares. Definindo um grafo $G$ a partir dos vértices de um poliedro, tem-se que uma face $f$ corresponde a uma componente desse grafo. Por exemplo, são conhecidas as planificações dos cubos. Na figura 21 são mostradas duas representações $G$ e $H$ equivalentes de grafos, no grafo $H$ as arestas não se cruzam, portanto, os grafos são planares.
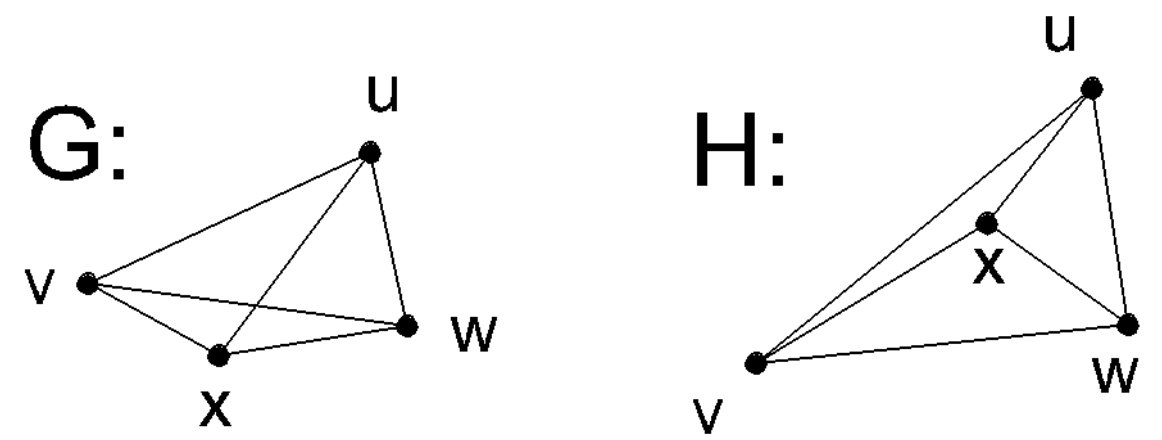

Figura 21 - Representações equivalentes de um grafo planar.

Um grafo com peso $G$ é um grafo cujas as arestas são associadas ao conjunto dos números reais (WEST et al., 2001). Um grafo com peso é útil para a arestas que representam valores, denominados pesos, diferentes. Em outras palavras, se uma aresta $a \in G$, define uma função $p$ que associa um valor numérico a essa aresta denominada peso de $a$, ou $p(a)$. Um grafo com 
pesos é comumente usado quando são atribuidos valores diferentes entre seus vértices. No caso de um circuito elétrico, pode-se citar como exemplo os valores associados aos resistores.

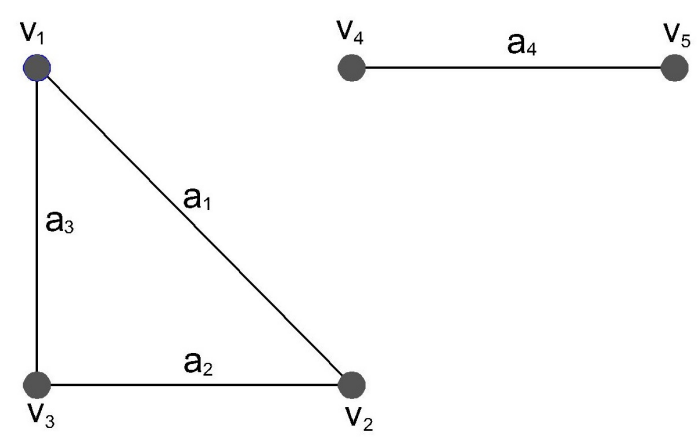

Figura 22 - Um grafo desconexo.

Uma floresta consiste em um grafo que não contém ciclos. Um caso particular é denominado árvore, como um grafo conexo que não contém ciclos. Uma folha é um vértice de grau 1, ou seja, uma vértice que incide apenas uma aresta. Na figura 23 são representadas as árvores $H, I$ e $J$, sendo que a união desses conjuntos representa uma floresta (WEST et al., 2001).

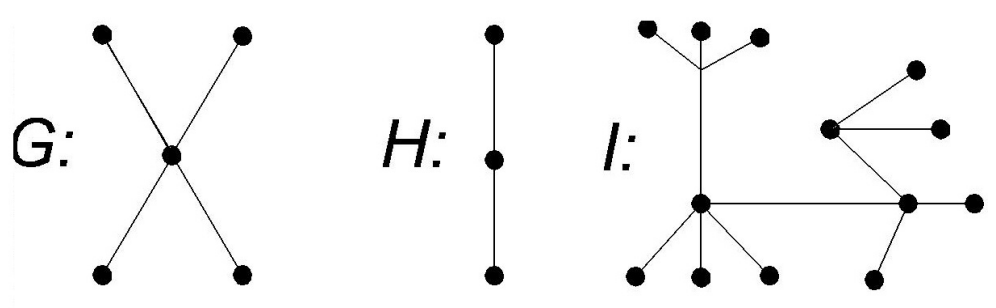

Figura 23 - Exemplos de árvores.

Uma aresta $u v$ é uma ponte quando um par de vértices é conectado por apenas 1 aresta. Uma ponte, ao ser retirada de um grafo, aumenta o número de componentes desse grafo (WEST et al., 2001).

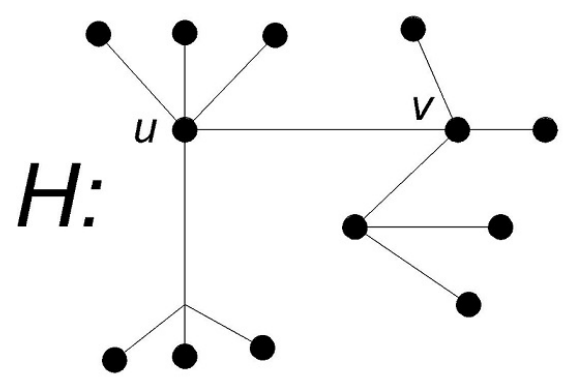

Figura 24 - Exemplo de uma ponte em um grafo (aresta $u v$ ).

Na próxima seção é feita a conexão entre grafos e circuitos resistivos. 


\subsection{Circuitos resistivos como grafos}

Uma aplicação da teoria dos grafos, a ser considerada nesse estudo, ocorre com utilização desses objetos para a descrição de circuitos resistivos ideais. Da mesma forma que grafos, circuitos elétricos são compostos por nós e interligações entre esses nós (SCOTT, 1960).

Para um circuito ideal, a disposição dos componentes de um circuito não altera os valores de corrente, diferença de potencial e resistência. Essa é característica indica que um circuito pode ser representado por um grafo. A teoria dos grafos aplicadas para circuitos, ou Topologia dos Circuitos, estuda a forma na qual os componentes estão ligados no circuito, considerando apenas quais são as conexões que são estabelecidas entre eles, independente da natureza desses componentes (CLOSE, 1975).

Para um circuito resistivo, a construção do grafo ocorre através da substituição do resistor pela aresta de um grafo. A figura 25 mostra exemplos da representações de circuitos através de grafos para representações de um único resistor, de resistores em série e de resistores em paralelo. Como grafos correspondem a circuitos ideais, os valores de resistência elétrica independem do comprimento do fio condutor do circuito, o que implica que a resistência dos fios pode ser considerada nula.

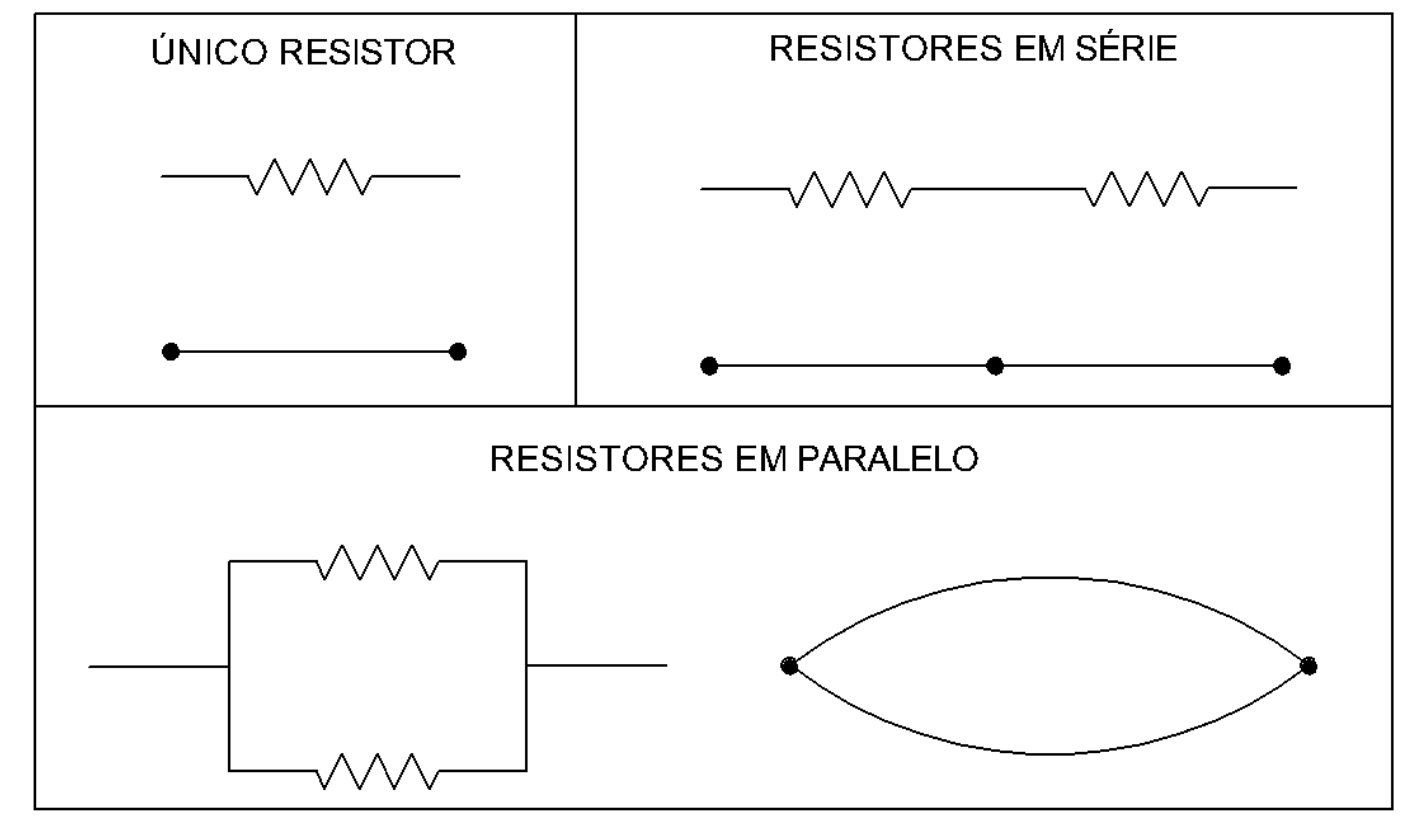

Figura 25 - Representação de um circuito da forma convencional (acima) através de um grafo (abaixo).

Um circuito resistivo é representado como um grafo $G$ conexo, com pesos e não-orientado. Nessa construção, é associado aos nós do circuito a um conjunto de vértices $V(G)$, os resistores correspondem ao conjunto de arestas do grafo $A(G)$ e a resistência de cada resistor é o peso atribuído a cada aresta.

Na próxima seção é proposta uma atividade didática para o ensino médio, abordando os conceitos vistos nesse capítulo. 


\subsection{Atividade didática}

\subsubsection{Justificativa}

Essa atividade é elaborada considerando a proposta curricular para o ensino de matemática do estado de São Paulo, quando é estudada análise combinatória no $3^{\circ}$ bimestre. Nesse conteúdo são investigadas as possibilidades de permutação, combinação e arranjo de objetos (SEE-SP, 2011b).

O uso da teoria dos grafos no ensino médio aparece como uma forma de aproximar o conteúdo universitário do ensino médio. Tal tema surge como uma ferramenta importante para a resolução de problemas, uma habilidade fundamental para o aluno aprender a gostar de matemática. Tal aproximação é justificável pelos parâmetros curriculares nacionais (PCN), dada a necessidade da inclusão de temas que respondam a necessidade da vida contemporânea (MALTA, 2008).

A partir do conteúdo da análise combinatória, e com os conteúdos de grafos, que podem ser úteis para sistematização de um problema, a seguir é proposto um problema histórico, que é comumente utilizado para a apresentação da teoria dos grafos. Vila e Callejo apontam a importância do uso de problemas iniciais que foram sementes para o desenvolvimento de determinados assuntos, como motição inicial para um despertar de aprendizagem dos alunos (CORTS; CALLEJO, 2006).

\subsubsection{Proposta de atividade}

Propõe-se uma atividade com grafos. Para tal tem-se as seguintes características e recursos:

- atividade para a $2^{\mathrm{a}}$ série do ensino médio;

- espaço: sala de aula com data show;

- tempo de aplicação: 2 horas;

- material: mapa de Königsberg na figura 26 e a folha de respostas na figura 27.

O estudo da Teoria dos Grafos tem início em um problema que data há 300 anos atrás. O Problema das Pontes de Königsberg (MALTA, 2008). Tal cidade da Prússia possuia duas ilhas cortadas pelo rio Pregel com pontes que atravessavam o rio como representado na figura 26.

Os moradores dessa cidade se perguntavam se era possível fazer um caminho em que se atravessasse cada uma das pontes uma única vez e retornasse ao ponto de partida. A partir da teoria dos grafos, através de uma atividade em grupo, pede-se para se realizar os seguintes procedimentos. 


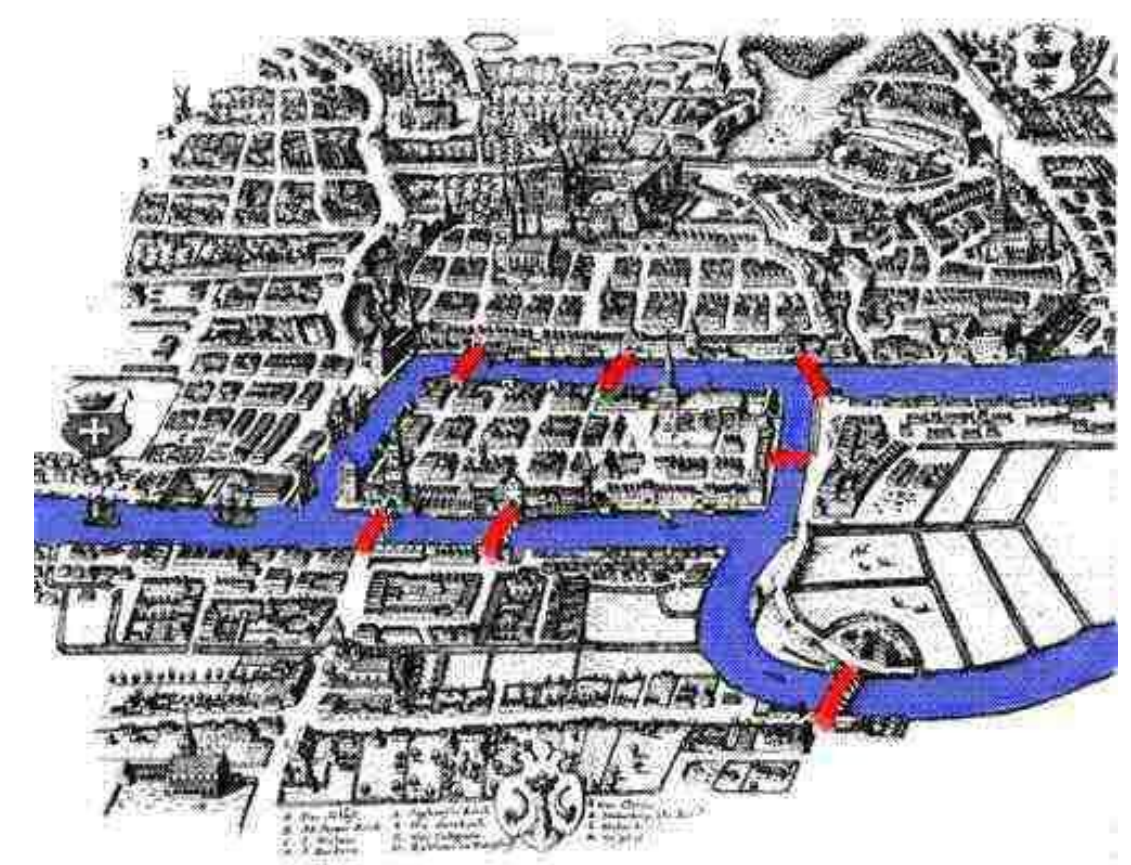

Figura 26 - Representação do problema das pontes de Königsberg (COSTA, 2011).

1. O problema das pontes de Königsberg pode ser representado de uma forma mais simples. Para tal, deve-se representar a ilha assim como as margens com pontos (M,A,B,C), que também são chamados de vértices. Represente a pontes, que fazem a ligação entre a ilha e as margens com linhas, que também são chamadas de arestas. Para tal, utilizar a figura 27.

2. Verificar se o problema tem solução. Como dica, observe que, por exemplo que para um local (vértice) ligado por duas 2 pontes (arestas), é possível apenas chegar e sair. E um local ligado por 3 pontes, é possível chegar e sair, porém observe no caso de volta para esse local não existe possibilidade de saída.

3. Como uma variação para o problema, agora vamos supor que a ponte que dá acesso a ilha para margem $M$ esteja interrompida. Nesse caso, é possível fazer o caminho proposto?

\subsubsection{Resultados esperados}

É esperado que o aluno associe o problema das pontes, representado na figura 26, com um grafo. Para isso, deve usar os vértices representados na figura 27, e traçar as arestas corretamente. A atividade pode ser extrapolada, a critério do professor ou através da curiosidade dos alunos, colocando restrições de pontes e reformulado o problema. Um resposta possível é representada na figura 28.

Em relação à solução ao problema inicial, os grupos de alunos devem chegar a conclusão que o problema não tem solução, uma vez que seria necessário que todos os vértices tivessem 

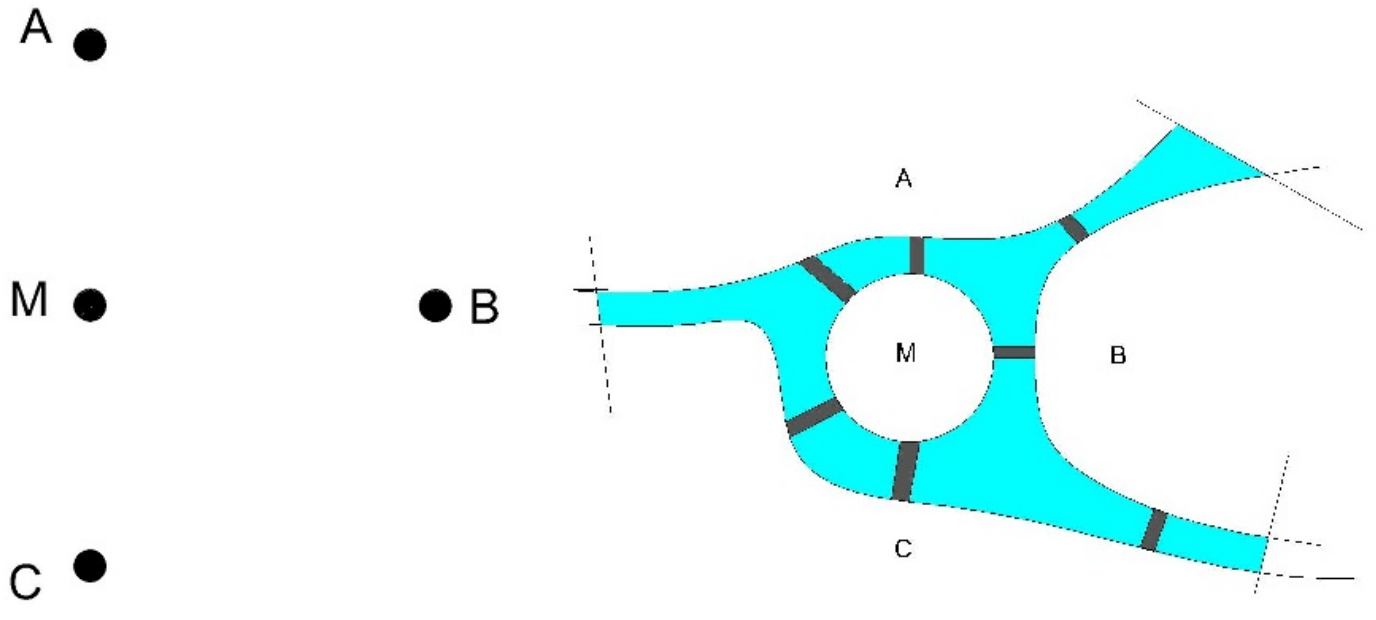

Figura 27 - Folha de respostas com os vértices do grafo.

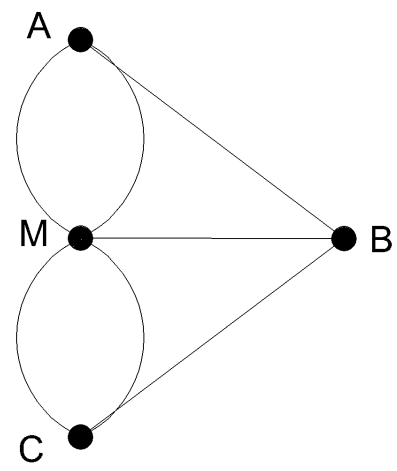

Figura 28 - Grafo esperado para o problema das pontes.

grau par. Essa solução é possível na adaptação do problema, quando é retirada uma aresta do grafo resultando em um vértice com um número par de arestas incidentes. 



\section{FRACTAIS AUTOSSIMILARES}

Nesse capítulo é apresentada uma definição usual para a estrutura informalmente denominada "fractal". Em seguida, são construídos e discutidas as características de quatro fractais típicos: Triângulo de Sierpinski, Poeira de Cantor e Curva de Kock.

Através desses exemplos são observados aspectos que implicam em uma certa particularidade aos fractais, comparados as outras definições ou temas matemáticos. Tais fractais possibilitam a exploração do conteúdo matemático como noções de limites fundamentais. Para uma exploração mais formal, é necessária uma abordagem usando conceitos de espaços métricos para a caracterização desses fractais.

\subsection{Definição informal de fractal}

"Fractalidade" é uma característica amplamente encontrada na natureza (MANDELBROT, 1983). Inicialmente, a palavra fractal começa a ser usado quando o matemático Benoit Mandelbrot procura uma palavra para descrever as formas da natureza (PEITGEN; JÜRGENS; SAUPE, 2012). Mandelbrot afirma que "nuvens não são esferas, montanhas não são cones, nem relâmpagos viajar em uma linha reta" (PEITGEN; JÜRGENS; SAUPE, 2012). A figura 29 ilustra um exemplo de geometria fractal na natureza. Quando se observa essa árvore em diferentes escalas, embora não ocorra uma repetição exata, existe um padrão que se repete o que cria uma dificuldade de distinção entre suas partes.

De forma geral, na natureza é possível observar diversas formas que apresentam característica fractal. Por exemplo, uma couve-flor apresenta forma invariável ao ser observar os floretes e a couve-flor inteira. Um relâmpado é semelhante a suas partes quando analisadas individualmente. As ramificações dos galhos de uma árvore e o sistema arterial de um rim são outros exemplos de fractais na natureza (MANDELBROT, 1983).

Apesar das propriedades fractais já intrigarem a matemáticos no passado, a geometria 


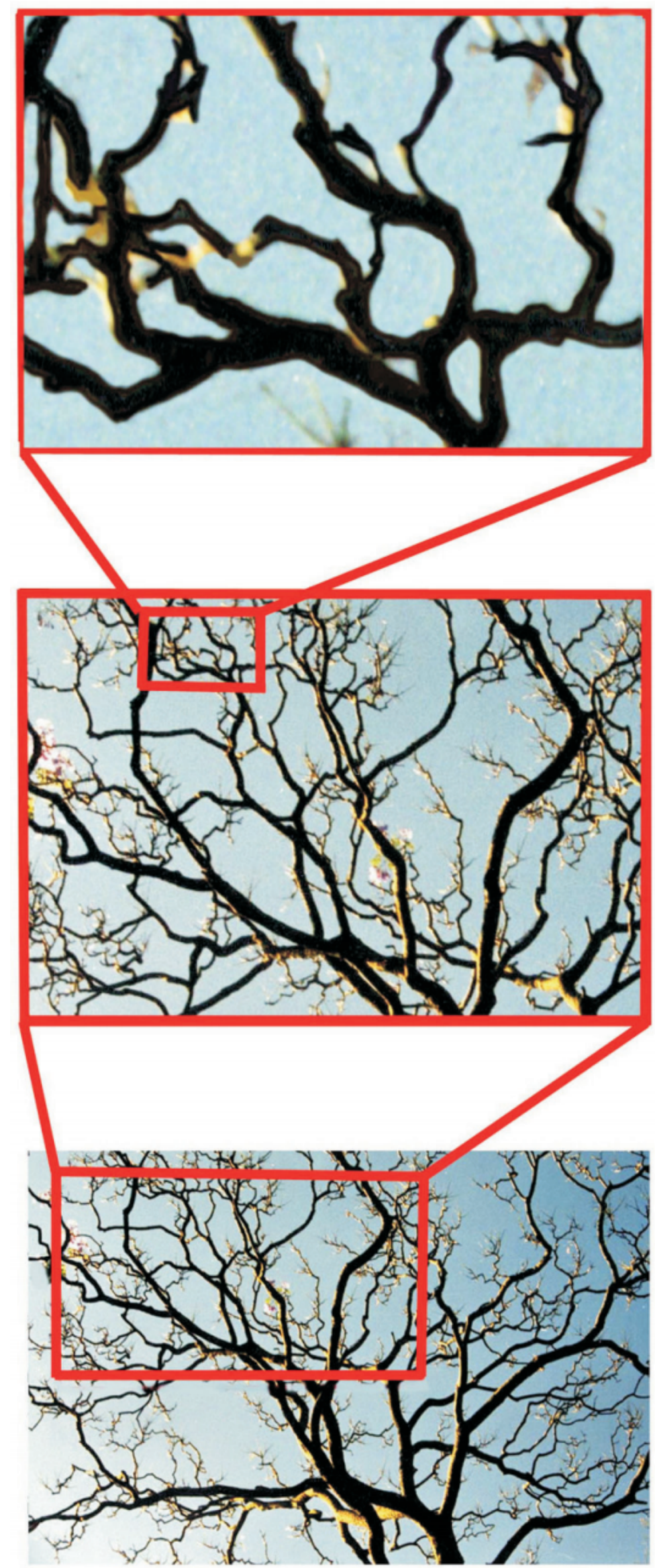

Figura 29 - Exemplo de um fractal na natureza (obtido em (TAYLOR et al., 2005)). 
fractal é estudada amplamente a partir dos livros de Benoit Madelbrot: Fractals e The Fractal Geometry of Nature (MANDELBROT, 1983). Em relação aos estudos escolares de nível médio, Peitgen e Jürgens (PEITGEN; JÜRGENS; SAUPE, 2012) fazem uma análise minunciosa de importantes fractais, definem dimensão fractal e mostram importantes aplicações sobre a geometria fractal.

De forma simplificada, um fractal pode ser entendido como um objeto que mantém suas características, independente da escala na qual se observa. Sendo assim, uma circunferência não pode ser considerada um fractal pois a medida que se aumenta a escala de observação, a curvatura aparentemente diminui.

Mandelbrot utiliza como definição parab fractal como o conjunto no qual a dimensão de Haussdorff difere da dimensão topológica (EDGAR, 2007). Nesse sentido, um fractal não possui dimensão necessariamente igual a um valor inteiro, diferentemente do que se observa nas dimensões da reta, do plano e do espaço, respectivamente 1, 2 e 3. Como define Mandelbrot, o valor da dimensão corresponde ao grau de ocupação da estrutura do espaço que o contém.

Além da dimensão não-inteira, os fractais são caracterizados pela autossemelhança e pela complexidade infinita. A primeira característica se deve ao fato que um fractal, a partir de sua lei de formação, pode ser construído indefinidamente.

Nesse trabalho são considerados fractais autossimilares, para os quais são necessários alguns conceitos de Espaços Métricos. Para os fractais definidos aqui, estabelece-se uma relação de equivalência com o conjunto dos números reais. Ao se abordar questões sobre a convergência de parâmetros é importante que tais noções estejam definidas.

\subsection{Noções sobre espaços métricos}

Um espaço métrico é um par $(M, d)$, onde $M$ é um conjunto e $d: M \times M \rightarrow \mathbb{R}$ é uma função que associa um número real positivo ou nulo a dois pontos $x$ e $y$ de $M$, denominada distância entre $x$ e $y$, de tal forma que são satisfeitas as condições dadas pelas equações 5.1, $5.2 \mathrm{e}$ 5.3. Ou seja, para quaisquer $x, y, z \in M$ (LIMA, 1993),

$$
d(x, x)=0, \quad \text { se } \quad x \neq y \quad \text { então } \quad d(x, y)>0,
$$

que estabelece que a distância é positiva para pontos diferentes e só é nula para pontos iguais. A condição,

$$
d(x, y)=d(y, x)
$$

estabelece que $d$ é uma função simétrica. A condição,

$$
d(x, z) \leq d(x, y)+d(y, z)
$$

é conhecida como desigualdade triangular. 
Uma sequência $x_{n} \in M$ é convergente, ou limitada, se existe $a \in M$ tal que $d\left(x_{n}, a\right) \rightarrow 0$ quando $n \rightarrow \infty$. Uma sequência $x_{n}$ é chamada de Cauchy se possui a propriedade (LIMA, 1993):

$$
\lim _{m, n \rightarrow \infty} d\left(x_{m}, x_{n}\right)=0 .
$$

Ou seja, se existe um $N$ com $m, n>N$ tal que $\left|x_{m}-x_{n}\right|<\varepsilon$, esta sequência de Cauchy. Decorre da definição que toda sequência convergente é de Cauchy (LIMA, 1993).

Um espaço métrico é chamado compacto se toda sequência $x_{n}$ de pontos de $M$ tem uma subsequência convergente (LIMA, 1993); e um espaço métrico é completo se toda sequência de Cauchy contido nele tem um limite.

Uma função $f: M \rightarrow N$ é chamada aplicação lipschitziana (KIRILLOV, 2013) quando existe uma constante real tal que

$$
d(f(x), f(y)) \leq \lambda d(x, y) .
$$

Além disso, $f$ é denominada contração essa constante $\lambda$ satisfaz $0 \leq \lambda<1$.

Um teorema importante, consequente relacionado com essa definição, é o Teorema de ponto fixo de Banach, afirma que para um espaço métrico completo $M$ com uma contração $f: M \rightarrow M$, existe um único ponto $x$ que satisfaz $f(x)=x$ (LIMA, 1993).

Para a definição de distância entre dois conjuntos, consideramos $K(M)$ como uma coleção de todos os conjuntos compactos não-vazios de $M$. Define-se como a distância entre um ponto $x \in X$ e um conjunto compacto $Y$, como a menor das distâncias entre $x$ e $y \in Y$ (LIMA, 1993):

$$
d(x, Y)=\min _{y \in Y} d(x, y)
$$

A distância de Haussforf (EDGAR, 2007) entre dois conjuntos $X$ e $Y$ é definida por:

$$
d(X, Y)=\max _{x \in X} \min _{y \in Y} d(x, y)+\max _{y \in Y} \min _{x \in X} d(x, y) .
$$

A figura 30 ilustra tal definição, a distância entre $A$ e $B$, corresponde o máximo entre a menor distância entre um ponto $A \in X$ e um ponto $B \in Y$ assim como entre os pontos $C$ e $D$.

Um espaço métrico $M$ é compacto quando todos os subconjuntos $K(M)$ é compacto como um todo (KIRILLOV, 2013). Consideremos a família de funções de contrações $f_{1}, f_{2}, \cdots, f_{k}$ em $M$ é dada. Definimos a transformação $F: K(M) \rightarrow K(M)$ por:

$$
F(X)=f_{1}(X) \cup f_{2}(X) \cup \cdots \cup f_{k}(X)
$$

A função $F$ é uma contração. Assim, existe um único conjunto não-vazio $X$ que satisfaz $F(X)=X$ (KIRILLOV, 2013). Esse conjunto $X$ denominado fractal autossimilar homogêneo. O sistema de funções $f_{1}, f_{2}, f_{3}, \cdots, f_{k}$ é chamado sistema de funções iteradas, o que define um fractal (KIRILLOV, 2013). 


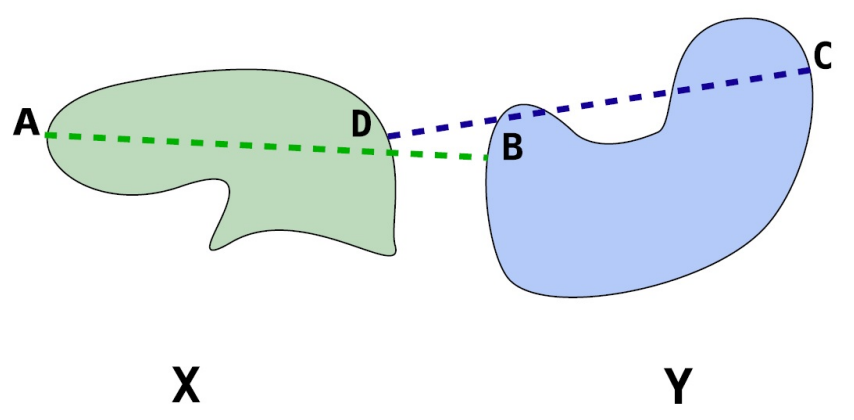

Figura 30 - Distância entre conjuntos (obtido em (KIRILLOV, 2013)).

Assim, os fractais estudados nesse texto partem de uma função iterada, ou seja, uma função que a partir de um nível $i$ produz o nível $i+1$. Geometricamente, a partir de uma fractal no nível $i$ é obtido um fractal no nível $i+1$ para cada qual está associada uma função iterada $i$.

Os fractais conjunto de Cantor, triângulo de Sierpinski e curva de Koch apresentam particularidades interessantes sendo que tais figuras e suas respectivas propriedades são descritas a seguir.

\subsection{Triângulo de Sierpinski}

O triângulo de Sierpinski foi inicialmente definido pelo matemático polonês Waclav Sierpinski (1882-1969). Tal matemático é apontado como um dos grandes matemáticos de seu país, e além disso, uma das crateras da Lua foi batizada em sua homenagem (PEITGEN; JÜRGENS; SAUPE, 2012).

Para a construção do fractal adota-se a seguinte iteração: dado um triângulo equilátero, consideram-se os triângulos formados pelos pontos médios dos lados do triâgulo inicial e retira-se o central. Sobre cada triângulo formado adota-se o passo mencionado (PEITGEN; JÜRGENS; SAUPE, 2012). Geometricamente, na figura 30 segue as primeiras iterações da construção do fractal.

Os vértices do triângulo de Sierpinski podem ser reproduzidos no plano complexo, através do sistema de funções iteradas (KIRILLOV, 2013),

$$
\begin{gathered}
f_{1}(z)=\frac{z}{2}, \\
f_{2}(z)=\frac{z+w}{2}, \\
f_{3}(z)=\frac{z+1}{2},
\end{gathered}
$$

sendo $w=e^{\frac{\pi i}{3}}$. Essas equações definem os vértices do triângulo sólido (de cor preta) para cada nível $k>0$, sendo que $S_{0}^{\prime \prime}=\{0, w, 1\}$. Cada nível $i$ é dado pelo conjunto $S_{n}^{\prime \prime}=F\left(S_{n-1}\right)$, com 

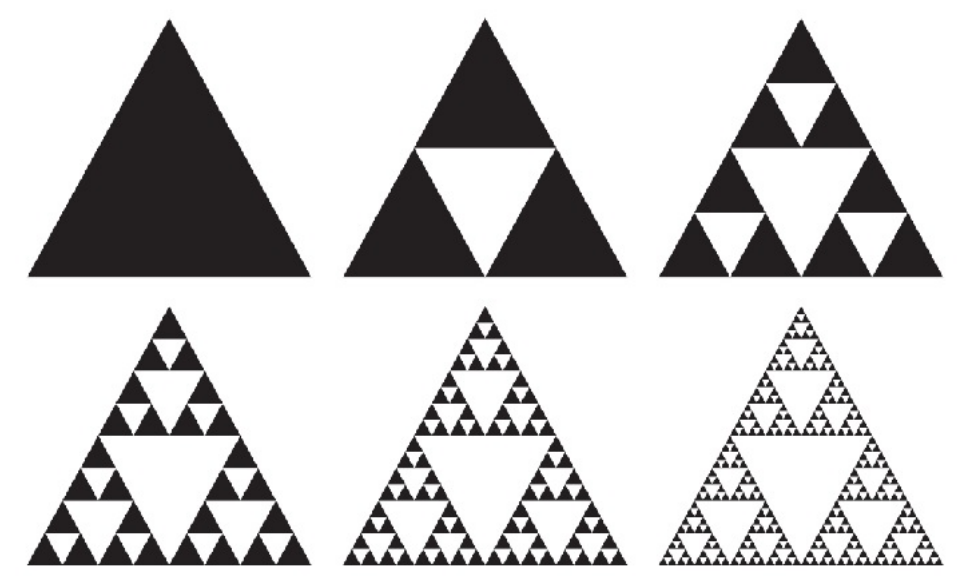

Figura 31 - As seis primeiras iterações do triângulo de Sierpinski.

$F=\left\{f_{1}, f_{2}, f_{3}\right\}$. Assim, verifica-se a construção para o próximo nível,

$$
S_{1}^{\prime \prime}=F\left(S_{0}\right)=\left\{\left\{0, \frac{w}{2}, \frac{1}{2}\right\},\left\{\frac{w}{2}, w, \frac{w+1}{2}\right\},\left\{\frac{1}{2}, \frac{1+w}{2}, 1\right\}\right\},
$$

e assim por diante. O triângulo de Sierpinski no nível $i$ é dado pela intersecção $S_{n}=\bigcap S_{i}^{\prime \prime}$, com $0<i<n$.

Analisando os triângulos de cor preta do triângulo de Sierpinski, a cada figura verifica-se que a quantidade de triângulos $Q$ aumenta segundo uma progressão geométrica com termo inicial igual a 1 e razão igual a 3 , assim:

$$
\begin{aligned}
Q_{0} & =3^{0}, \\
Q_{1} & =3^{1}, \\
Q_{1} & =3^{2}, \\
\vdots & \\
Q_{n} & =3^{n} .
\end{aligned}
$$

A área de cada triângulo $A$ reduz segundo uma progressão geométrica com termo inicial igual a $\sqrt{3} L^{2} / 4$ e razão $1 / 4$. Assim:

$$
\begin{aligned}
A_{0} & =\frac{\sqrt{3} L^{2}}{4}, \\
A_{1} & =\frac{\sqrt{3} L^{2}}{4^{2}}, \\
A_{2} & =\frac{\sqrt{3} L^{2}}{4^{3}}, \\
\vdots & \\
A_{n} & =\frac{\sqrt{3} L^{2}}{4^{n+1}} .
\end{aligned}
$$

Ao se analisar a área total dos triângulo em cor preta $T$, essa é dado pelo produto da quantidade de triângulos de cor preta a cada iteração pela área individual de cada triângulo $A$. Assim:

$$
T_{n}=Q_{n} A_{n}=3^{n} \frac{\sqrt{3} L^{2}}{4^{n+1}}
$$


Tal progressão geométrica tem razão 3/4, assim essa área total tende a zero a medida que se aumenta o número de iterações.

Em termos de perímetro $P$, essa medida de cada triângulo reduz pela metade a cada iteração. Em outras palavras, pode se associar essa sequência primeiro termo igual a $3 L$ e razão $1 / 2$. Considerando o perímetro total de cada iteração, tem-se a sequência:

$$
\begin{gathered}
P_{0}=3 L, \\
P_{1}=3 \frac{3 L}{2^{1}}, \\
P_{2}=3^{2} \frac{3 L}{2^{2}}, \\
\vdots \\
P_{n}=3^{n} \frac{3 L}{2^{n}} .
\end{gathered}
$$

Por fim, verifica-se a curiosa propriedade do triângulo de Sierpinski. A área tende a zero ao passo que o perímetro tende ao infinito, ao se analisar as equações $A_{n}$ e $T_{n}$ quando $n$ tende ao infinito.

Uma construção geométrica, em função dos números que compõem as linhas do triângulo de Pascal, apresenta semelhanças com o triângulo de Sierpinski (EDGAR, 2007). O primeiro é definido da seguinte forma: são formadas linhas consecutivas, com a primeira linha com 1 número, a segunda linha com dois números, e assim por diante. Os elementos da extremidades são iguais a 1 e os demais elementos são iguais à soma dos elementos acima.

As linhas do Triângulo de Pascal são formadas pelas iterações sucessivas, tais que a iteração zero é formada pelos elementos $\{1\}$, a segunda iteração pelos elementos $\{1,1\}$, a terceira iteração pelos elementos $\{1,2,1\}$, a quarta iteração pelos elementos $\{1,3,3,1\}$, e assim por diante. A figura 32 representa o triângulo de Pascal até a iteração 8.

Agora se constrói uma figura com a seguinte regra: representa-se cada elemento do Triângulo de Pascal como um ponto preto caso esse elemento for ímpar, e como ponto branco caso esse elemento for par. Assim, obtém-se a figura 33. Essa relação mostra que regras distintas de formação podem implicar em propriedades semelhantes, à medida que a quantidade de iterações aumenta. A construção da figura 33 se assemelha com as iterações do triângulo de Sierpinski a medida que são formadas mais linhas.

\subsection{Curva de Koch}

A curva de Koch, definida pelo matemático sueco Helge von Koch é construída de forma recursiva. Esse fractal apresenta semelhanças geométricas com formas verificadas na natureza, como um floco de neve (PEITGEN; JÜRGENS; SAUPE, 2012).

Esse fractal é construído através do seguinte processo: dado um segmento de comprimento $L$, a construção ocorre através da divisão do segmento em 3 partes, se constrói um 


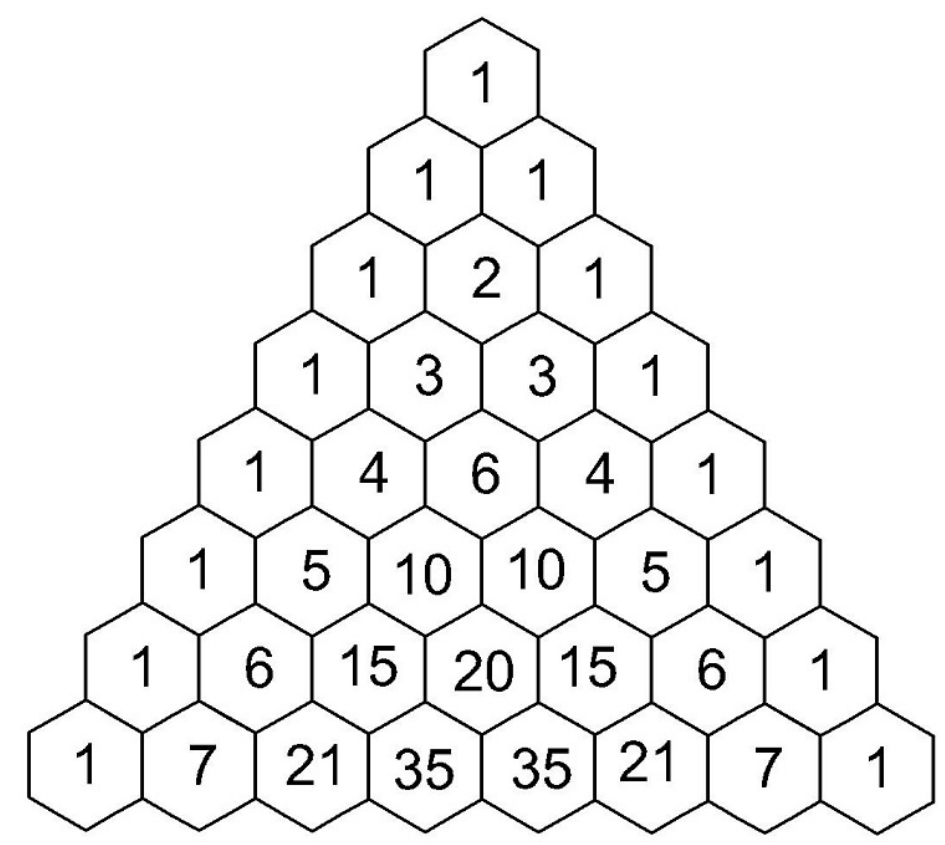

Figura 32 - Triângulo de Pascal construído até a iteração 8.

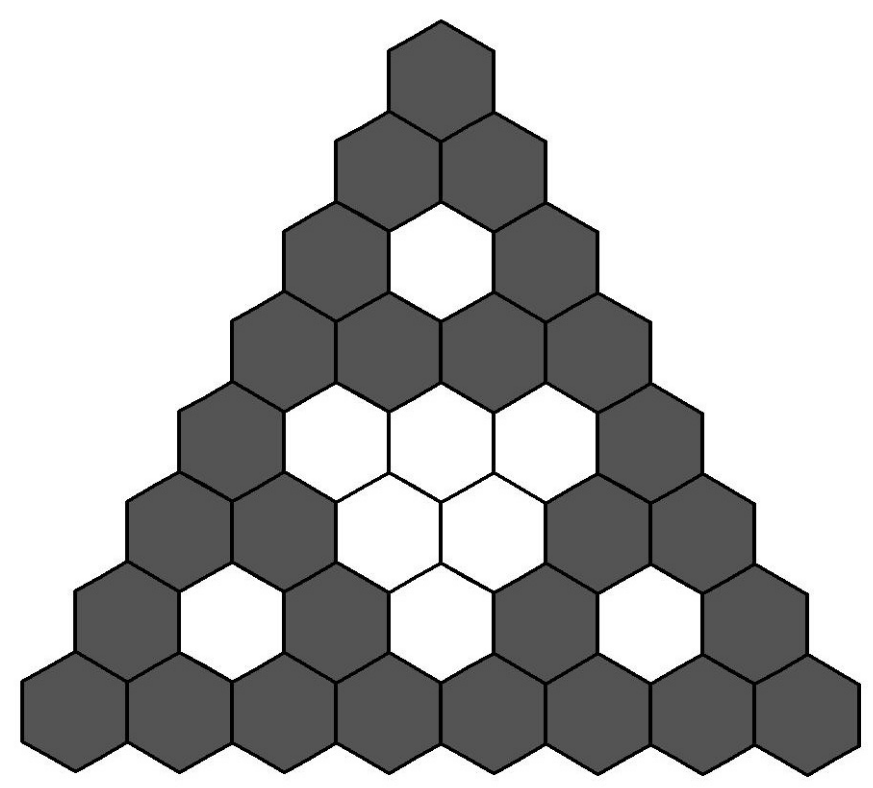

Figura 33 - Associação do triângulo de pascal com o triângulo de Sierpinski. 
triângulo equilátero de comprimento $L / 3$ com um lado coincidindo com segmento central e retira-se tal segmento.

A curva de Koch pode ser construída no plano cartesiano, através do sistema de funções de iteradas (KIRILLOV, 2013),

$$
\begin{gathered}
f_{1}(x, y)=\left(\frac{x}{3}, \frac{x}{3}\right), \\
f_{2}(x, y)=\left(\frac{x}{6}-\frac{\sqrt{3}}{6} y+\frac{1}{3}, \frac{\sqrt{3}}{6} x+\frac{y}{6}\right), \\
f_{3}(x, y)=\left(\frac{x}{6}+\frac{\sqrt{3}}{6} y+\frac{1}{2},-\frac{\sqrt{3}}{6} x+\frac{y}{6}+\frac{\sqrt{3}}{6}\right), \\
f_{4}(x, y)=\left(\frac{x}{3}+\frac{2}{3}, \frac{x}{3}\right) .
\end{gathered}
$$

Ou seja, $F=\left\{f_{1}, f_{2}, f_{3}, f_{4}\right\}$ define cada iteração para o fractal, onde são definidos o vértices. Sendo $K_{i}^{\prime \prime}$ a figura definida pelas funções de contração, que resultam em pares de pontos obtidos em cada $f$, ligados por segmentos. Para $K_{n}^{\prime \prime}=F\left(K_{n-1}\right)$, e assumindo $K_{0}=\{(0,0),(1,0)\}$, obtémse os segmentos para a próxima iteração sendo

$$
K_{1}^{\prime \prime}=\left\{\left\{(0,0),\left(\frac{1}{3}, 0\right)\right\},\left\{\left(\frac{1}{3}, 0\right),\left(\frac{1}{2}, \frac{\sqrt{3}}{6}\right)\right\},\left\{\left(\frac{1}{2}, \frac{\sqrt{3}}{6}\right),\left(\frac{2}{3}, 0\right)\right\},\left\{\left(\frac{2}{3}, 0\right),(1,0)\right\}\right\} .
$$

A curva de Koch corresponde a união aos segmentos criados a partir de par de pontos, criado na iteração $i$.

Geometricamente, o procedimento para a iteração 1 é ilustrado na figura 34. Observa-se que a figura 34 tem 4 segmentos, cada um com comprimento $L / 3$, pela construção do fractal.

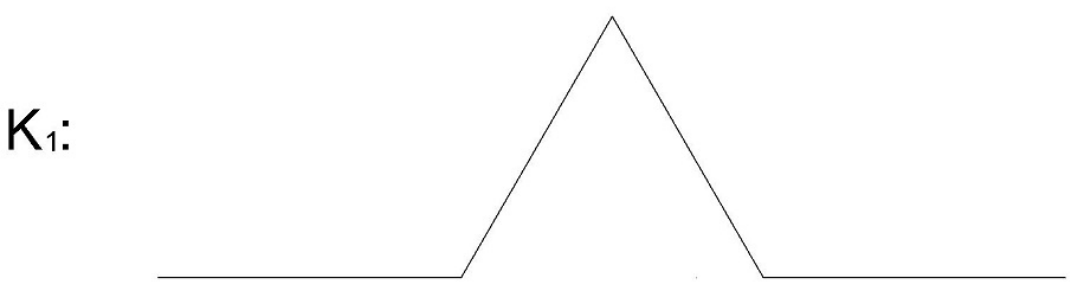

Figura 34 - A primeira iteração da curva de Koch.

Na segunda iteração, para cada segmento criado, repete-se a iteração como mostra a figura 35. Observa-se que a figura tem 16 segmentos, cada um com comprimento $L / 9$.

Para a terceira iteração observa-se que existem 64 segmentos, cada um com comprimento $L / 27$. Para as demais iterações, o procedimento é similar. 


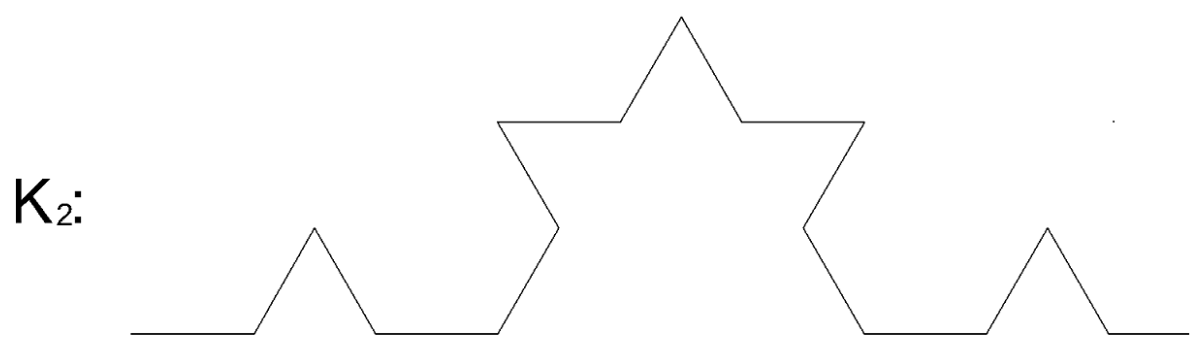

Figura 35 - A segunda iteração da curva de Koch.

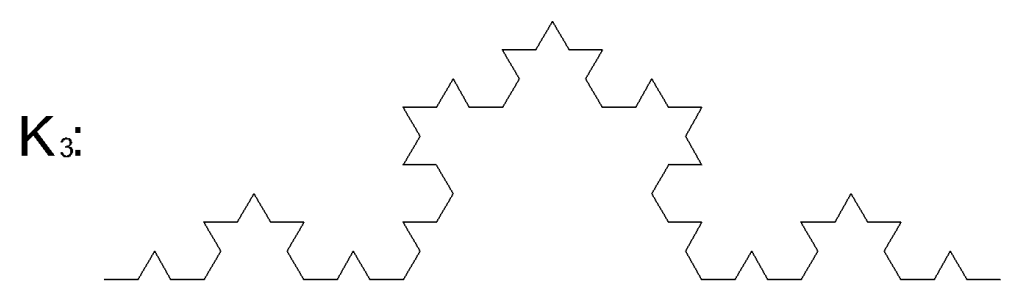

Figura 36 - A terceira iteração da curva de Koch.

Quando esse procedimento é construído sobre um triângulo equilátero, com o procedimento adotado para cada lado do triângulo, constrói-se um fractal conhecido como Floco de Neve de Koch (PEITGEN; JÜRGENS; SAUPE, 2012). A terceira iteração é ilustrada na figura 37.

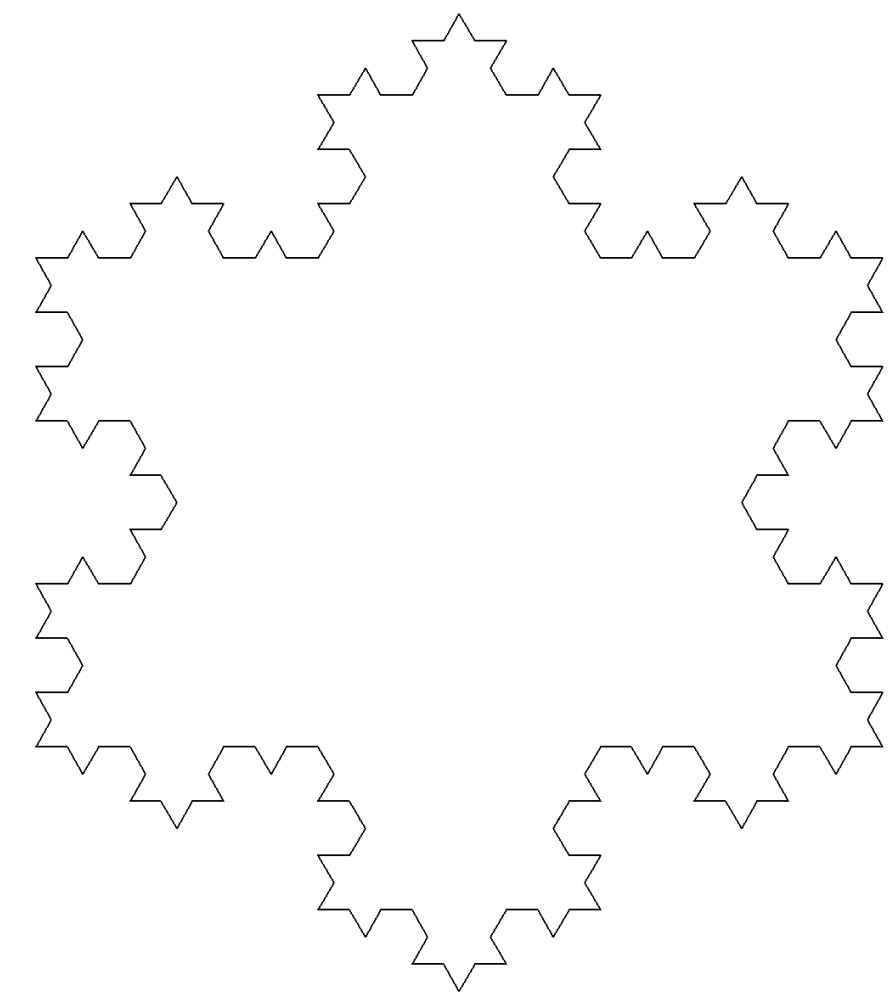

Figura 37 - A terceira iteração do floco de neve de Koch. 
O número de segmentos $n_{i}$ a cada iteração, varia de acordo com uma progressão geométrica com $n_{0}=1$ e $q=4$, como pode ser observado pela regra de construção do fractal, conforme a equação:

$$
n_{i}=4^{i}
$$

Como $q>1$, tem-se esse número de segmentos tende ao infinito quando o fractal é construído indefinidamente:

$$
\lim _{i \rightarrow \infty} n_{i} \rightarrow \infty
$$

Ao se analisar o comprimento $c_{i}$ de cada segmento a cada iteração, correspondente a uma progressão geométrica com $a_{0}=L$ e $q=1 / 3$ :

$$
c_{i}=L\left(\frac{1}{3}\right)^{i} .
$$

Verifica-se esse comprimento tende a zero, uma vez que $0<q<1$. Assim:

$$
\lim _{i \rightarrow \infty} c_{i}=0 .
$$

Uma característica interessante da curva de Koch é exposta quando se analisa o comprimento de cada curva $\left(k_{i}\right)$. Esse é dado pelo produto das equações (5.22) e (5.24). Ou seja, pela equação:

$$
k_{i}=L\left(\frac{4}{3}\right)^{i}
$$

Uma vez que $q>1$, tem-se que:

$$
\lim _{i \rightarrow \infty} k_{i} \rightarrow \infty \text {, }
$$

o que expõe uma importante características do fractal. O comprimento de cada segmento tende a zero ao passo que o total tende ao infinito.

\subsection{Conjunto de Cantor}

O conjunto de Cantor, também conhecido como "Poeira de Cantor", é um fractal definido recursivamente. Este fractal foi definido pelo seu criador Georg Cantor (1845-1918). Geometricamente, a construção do fractal ocorre através do seguinte procedimento. Dado um segmento $L$ a ser considerada como iteração 0 , para a construção da interação 1 , divide-se seu comprimento em três partes e retira-se a central. Para a construção da iteração 2 , faz-se o mesmo processo em relação aos 2 segmentos criados na iteração 1; e assim por diante (PEITGEN; JÜRGENS; SAUPE, 2012). 
As funções de iteração que definem o conjunto de Cantor são (KIRILLOV, 2013)

$$
\begin{gathered}
f_{1}(x)=\frac{1}{3} x \\
f_{2}(x)=\frac{x+2}{3} .
\end{gathered}
$$

Definindo $C_{0}=[0, L]$, tem-se que para $i>0$, o fractal fica definido por $C_{n}=F\left(C_{n-1}\right)$, com $F=\left\{f_{1}, f_{2}\right\}$. Geometricamente, os cinco primeiros passos da construção desse fractal são representados na figura 38 .
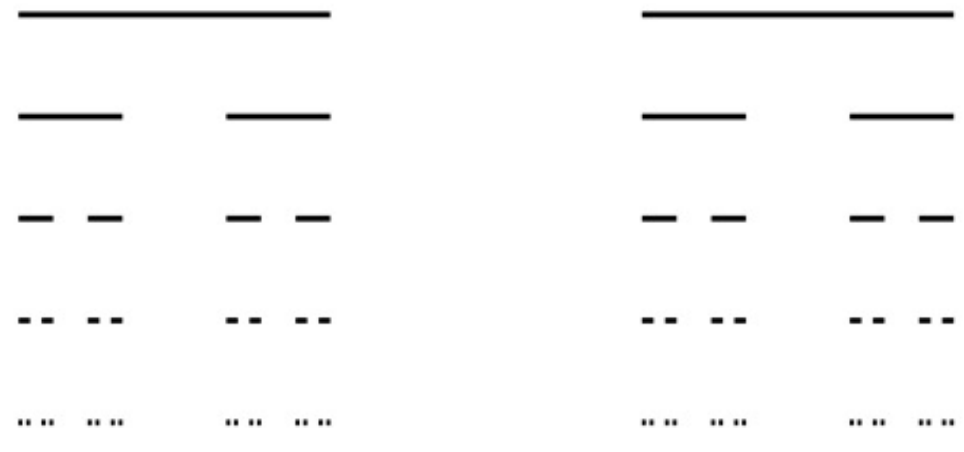

Figura 38 - As cinco primeiras iterações do conjunto de Cantor.

Usando a definição de Cantor, a iteração zero consiste no subconjunto:

$$
C_{0}=[0,1]
$$

A iteração um, são gerados três subconjuntos e retirado o central:

$$
C_{1}=\left[0, \frac{1}{3}\right] \bigcup\left[\frac{2}{3}, 1\right]
$$

Retirando-se a segunda terça parte novamente, de cada parte obtida, obtém-se a iteração 2:

$$
C_{2}=\left[0, \frac{1}{9}\right] \bigcup\left[\frac{2}{9}, \frac{1}{3}\right] \bigcup\left[\frac{2}{3}, \frac{7}{9}\right] \bigcup\left[\frac{8}{9}, 1\right] .
$$

Ao se analisar a quantidade $Q$ de segmentos gerado a cada passo, pode-se associar a uma progressão geométrica de razão 2 e primeiro termo igual a 1 . Ao se analisar o comprimento $C$ do segmento de cada iteração, pode se associar a uma progressão geométrica com primeiro termo igual a $C$ e razão igual a $1 / 3$ com primeiro termo igual a 1 . Além disso, o comprimento total dos segmentos é o produto $Q C$. Então:

$$
Q=2^{n}
$$




$$
C=\left(\frac{1}{3}\right)^{n}
$$

que resulta no comprimento total dos segmentos,

$$
Q C=\left(\frac{2}{3}\right)^{n}
$$

Observa-se que a quantidade de segmentos tende ao infinito a medida que as interações aumentam e que as medidas dos segmentos tendem a zero. O comprimento total dos segmentos para a cada iteração tende a zero. Justifica-se então o termo "Poeira de Cantor".

É interessante observar os extremos dos intervalos que compõem a Poeira de Cantor considerando as expansões em base 3 (LIMA, 1993). Um número decimal inteiro $x$ tem uma única representação tal que:

$$
x=\sum_{j=0}^{M} a_{j} 3^{j},
$$

tal que a $a_{j} \in\{0,1,2\}$. Por exemplo:

$$
19=201_{3}
$$

tal que o índice 3 representa o número na base 3. Quando considerado um número $x$ entre 0 e 1 , todos tem uma representação da forma:

$$
x=\sum_{j=-\infty}^{-1} a_{j} 3^{j} .
$$

Entretanto, esses números tem representações diferentes na base 3 para um mesmo número, assim como ocorre para a base decimal. Construído cada iteração da poeira de Cantor, seus elementos, após a iteração zero, é formado apenas pelos dígitos 0 e 2. Por exemplo, os números podem ser construídos da seguinte forma:

$$
\begin{gathered}
\frac{1}{3}=0 \times 3^{-1}+2 \times 3^{-2}+2 \times 3^{-3}+2 \times 3^{-4}+\ldots=0,0222 \ldots 3, \\
\frac{1}{3}=1 \times 3^{-1}=0,1_{3} .
\end{gathered}
$$

Os extremos da esquerda da poeira de Cantor podem ser construída como translação a partir de um ponto inicial (EDGAR, 2007). Para tal, é definido o conjunto:

$$
x+s_{i}: x \in L,
$$


onde $s_{i}$ é o incremento de cada iteração da função. Para a Poeira de Cantor, $s_{i}$ é uma progressão geométrica com razão $1 / 3$ e termo inicial igual a $2 / 3$. Os incrementos são $s_{1}=0,2, s_{2}=0,02$, $s_{3}=0,002$, e assim por diante. Para $L_{0}$ é considerado um extremo da Poeira, assim $L_{0}=0$. Para a primeira iteração:

$$
L_{1}=L_{0} \cup\left(L_{0}+s_{0}\right)=\{0\} \cup\left\{0+0,2_{3}\right\}=\left\{0 ; 0,2_{3}\right\} .
$$

Para a segunda iteração:

$$
L_{2}=L_{1} \cup\left(L_{1}+s_{1}\right)=\left\{0 ; 0,2_{3}\right\} \cup\left\{0+0,02_{3} ; 0,2_{3}+0,02_{3}\right\}=\left\{0 ; 0,02_{3} ; 0,2_{3}, 0,22_{3}\right\} .
$$

E para a terceira iteração:

$$
\begin{gathered}
L_{3}=L_{2} \cup\left(L_{2}+s_{2}\right)= \\
\left\{0 ; 0,02_{3} ; 0,2_{3}, 0,22_{3}\right\} \cup\left\{0+0,002_{3} ; 0,02_{3}+0,002_{3} ; 0,2_{3}+0,002_{3}, 0,22_{3}+0,002_{3}\right\} \\
=\left\{0 ; 0,002_{3} ; 0,02_{3}, 0,022_{3}, 0,2_{3}, 0,202_{3}, 0,22_{3}, 0,222_{3}\right\} .
\end{gathered}
$$

Assim, a quantidade incrementada corresponde a:

$$
s_{i}=2 / 3 \times(1 / 3)^{i}
$$

quando escrita em base 3, corresponde a

$$
s_{i}=0, \underbrace{0 \ldots 0}_{i} 2 \ldots
$$

É construída a sequência

$$
\begin{aligned}
& L_{0}=\{0\} \\
& L_{1}=\{0 ; 0,23\} . \\
& L_{2}=\left\{0 ; 0,02_{3} ; 0,2_{3}, 0,22_{3}\right\} \\
& L_{3}=\left\{0 ; 0,002_{3} ; 0,02_{3}, 0,022_{3}, 0,2_{3}, 0,202_{3}, 0,22_{3}, 0,222_{3}\right\} .
\end{aligned}
$$

Dessa forma, qualquer número pertencente ao conjunto $L$ tem apenas o dígito 2 em sua expansão. E quando essa sequência tende ao infinito, são obtidos os pontos do conjunto de Cantor.

Na próxima seção é apresentada uma atividade que mostra como os fractais podem ser estudados no ensino médio. E no próximo capítulo são apresentados circuitos autossimilares, ou seja, circuitos que possuem características de fractais autossimilares. 


\subsection{Atividade didática}

\subsubsection{Justificativa}

Considerando a proposta curricular do estado de São Paulo para o ensino da matemática, tem-se para o $1^{\mathrm{o}}$ bimestre da $1^{\mathrm{a}}$ série do ensino médio o conteúdo números e sequências, no qual são abordadas as progressões aritmética e geométrica. Para tal, é necessário que o aluno seja capaz de fazer operações no conjunto dos números reais, onde estas serão aprofundadas a partir das sistematizações e relações, em situações como por exemplo, de identificação de padrões geométricos (SEE-SP, 2011b).

Por vezes, esse conteúdo é apresentado de forma restrita apenas a sequência de números, nos qual os alunos buscam identificar padrões de construção para uma posterior formulação de uma modelo que descreva a formação; ou da mesma forma a partir de figuras geométricas. prevista para o $1^{\circ}$ bimestre da $2^{\circ}$ série do ensino médio.

No sentido de ampliar as possibilidades de abordagem temática para o ensino médio, com processos que podem ser feitos geometricamente, fractais introduz em processos iterativos. Podem ser trabalhadas a dedução de fórmulas gerais, o cálculo de áreas e perímetros de figuras que apresentam uma complexidade crescente e pode ser introduzido o conceito de limite. Tais conteúdos estão presentes no trabalho (SALLUM, 2005).

Como um estudo complementar às medidas euclidianas de área e perímetro, o estudo dos fractais permite um aprofundamento e contextualização com os fenômenos naturais existentes. As medidas de área e perímetro encontrados no triângulo de Sierpinski, apresentam um resultado contraditório, o que mostra ao aluno que são necessários estudos mais aprofundados para a caracterização de objetos, a princípio, simples (ASSIS et al., 2008).

\subsubsection{Proposta de atividade}

Para a realização da atividade devem ser observados os seguintes pontos,

- série: $1^{\mathrm{a}}$ série do ensino médio;

- espaço: sala de aula;

- tempo: realização em 2 horas;

- material: folha de respostas contendo a tabela 1 e o carpete de Sierpinski da figura 39.

A construção do fractal denominado Tapete de Sierpinski, também idealizado por Waclav Sierpinski é similar ao triângulo homônimo apresentado nesse capítulo. Esse fractal é feito tomando um quadrado, dividindo-o em nove quadrados menores, e removendo o quadrado central. O processo é repetido novamente para os oito quadrados restantes, e assim por diante, 
Tabela 1 - Tabela a ser distribuída aos alunos para registro das medidas consideradas para o carpete de Sierpinski.

\begin{tabular}{|c||c|c|c|}
\hline$i$ & $Q$ & $P$ & $P_{T}$ \\
\hline \hline 0 & & & \\
\hline 1 & & & \\
\hline 2 & & & \\
\hline 3 & & & \\
\hline 4 & & & \\
\hline 5 & & & \\
\hline
\end{tabular}

sempre haverão quadrados menores. Pela construção, observa-se que o carpete de Sierpinski corresponde a uma versão do conjunto de Cantor para duas dimensões (PEITGEN; JÜRGENS; SAUPE, 2012).

Sua construção é feita a partir da seguinte forma: um quadrado tem seus lados dividido em três partes, com cada segmento com medida $L / 3$. Cada extremidade gerada é conectada por um segmento de reta ao respectivo segmento oposto. Formam-se 9 quadrados menores sendo retirado o central. Verifica-se pela figura 39 a construção até a iteração 3. Observa-se que a cada iteração são adicionados quadrados pretos, com áreas cada vez mais reduzidas. Observando-se novamente a figura gerada, é possível afirmar qual ela seria para uma iteração muito grande? Suponha que a medida do lado do quadrado seja 1.

Propomos uma investigação da área em preto a ser formada, de forma a completar a tabela 1, para cada iteração da figura, onde $i$ representa o número da iteração; $Q$ é a quantidade de quadrados pretos; $P$ a área de cada quadrado em preto da iteração; e $P_{T}$ representa o total da área preta da iteração.

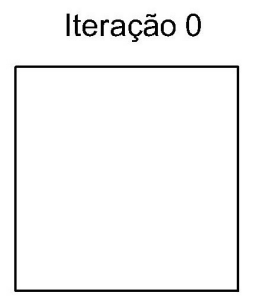

Iteração 2

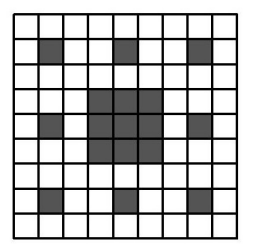

Figura 39 - As quatro iterações do Tapete de Sierpinski.
Iteração 1

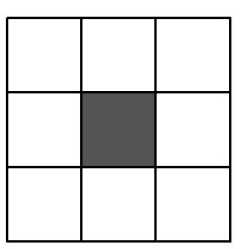

Iteração 3

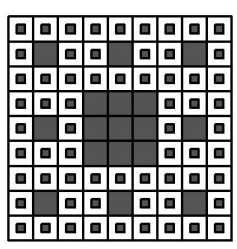

1. Observar a figura 39 e preencher a tabela 1 até a iteração número 3. Existe um padrão? Caso sim, preencha até a iteração 5.

2. Encontrar uma fórmula que dê a área total em preto em função da iteração. 
3. Encontrar uma fórmula que dê o número de quadrados pretos em função da iteração.

4. Encontrar uma fórmula que dê a área de cada quadrado preto que é aparecem a cada iteração.

5. Para qual valor de área se aproxima a área total dos quadrados pretos? Teste para diferentes iterações.

6. O que acontece a iteração do fractal tende ao infinito?

\subsubsection{Resultados esperados}

A partir da atividade se espera que o aluno consiga observar os padrões geométricos e numéricos da construção do fractal. $\mathrm{O}$ aluno pode fazer questionamentos sobre a própria construção do fractal, já que não existe um limite de construção. Entretanto, existe um valor limite de área no qual o tapete se aproxima.

O aluno deve observar a regularidade da construção do fractal. Encontrar a área dos quadradinhos pretos que surgem a cada iteração. Feito isso, deve associar o número de quadradinhos pretos a uma progressão geométrica e verificar qual o limite da soma do fractal.

Deve ser observado que a quantidade de quadrados pretos crescem associados a uma progressão geométrica de elemento inicial 1 e razão 8 . E que a área de cada quadrado preto acrescentado a cada iteração é menor em uma razão 1/9. Assim, o aluno deve perceber que a área total dos quadrados pretos corresponde a soma de uma progressão geométrica com termo inicial $1 / 9$ e razão $8 / 9$. Por fim, deve ser observado que a área dos quadrados pretos quando a progressão geométrica tende ao infinito é 1 . 



\section{CIRCUITOS AUTOSSIMILARES}

Nesse capítulo é proposta uma definição para circuitos resistivos autossimilares. A partir das descrições de grafos no capítulo 4, e de fractais autossimilares no capítulo 5, nesse capítulo é dada uma caracterização geral de circuito resistivo autossimilar, nas quais são estudadas suas propriedades e generalizações. Para tal, inicialmente é definido um circuito resistivo autossimilar, com as características que o aproxima de um grafo e de um fractal autossimilar. Definido o que é circuito autossimilar, são apresentados exemplos de circuitos com essas características.

\subsection{Circuitos resistivos autossimilares}

$\mathrm{Na}$ definição de circuito resistivo autossimilar são considerados aspectos de um fractal autossimilar, conforme a seção 5.2. Entretanto, um circuito resistivo é um grafo, que por característica não considera aspectos geométricos. Entretanto, os valores de resistência de cada resistor possibilita a indicação como um grafo com peso. Assim, veremos que a partir das propriedades de associação de resistores, estudadas no capítulo 3, é possível associar a cada circuito autossimilar um único número real, denominado resistência equivalente.

No presente trabalho, consideramos circuitos gerados através de uma função de recorrência $F$. Como definição, denomina-se circuito resistivo autossimilar $C$, quando existe uma sequência de elementos de $C$,

$$
\left\{C_{0}, C_{1}, C_{2}, \cdots\right\} \subset C
$$

gerada de forma recursiva através de uma função $F$, tal que

$$
C_{i+1}=F\left(C_{i}\right)
$$

onde $F: C \rightarrow C$. Assim, a função $F$ é a função iterada que constrói o circuito autossimilar.

Para associar esse conjunto ao conjunto dos números reais positivos, define-se a função 
$R$ tal que, $R_{i}=R\left(C_{i}\right)$, que associa a sequência $C_{i}$ em $C$, a sequência

$$
\left\{R_{0}, R_{1}, R_{2}, \cdots\right\} \subset \mathbb{R}_{+}
$$

A função $R$ é denominada resistência equivalente do circuito $i$, como caracterizado na seção 3.3.

Define-se que a sequência $\left\{C_{i}\right\}$, gerada recursivamente, é uma sequência de circuitos resistivos autossimilares se a sequência de resistências equivalentes $\left\{R_{i}\right\}$ converge para um valor $R_{e q}$ com a métrica usual,

$$
\begin{aligned}
& d: \mathbb{R}_{+} \times \mathbb{R}_{+} \rightarrow \mathbb{R} \\
& d(x, y)=|x-y|,
\end{aligned}
$$

onde |.| é a norma usual.

A função $F: C \rightarrow C$ determina o circuito $C_{i+1}$ a partir do circuito $C_{i}$. Cada um desses circuitos está associado ao um número real pela equivalência $R_{i}$. Assim como para os circuitos, existe a função $T: \mathbb{R}_{+} \rightarrow \mathbb{R}_{+}$, denominada função de recorrência do circuito resistivo autossimilar, onde

$$
R_{i+1}=T\left(R_{i}\right) \quad \text { com } \quad R_{i}=F\left(C_{i}\right)
$$

Dessa definição de circuito autossimilar é obtido um problema de ponto fixo. Podemos então invocar as condições do teorema do ponto fixo de Banach, estudado na seção 5.2. A solução desse problema existe caso $R_{e q}$ for solução da equação (6.5), ou seja:

$$
R_{e q}=T\left(R_{e q}\right)
$$

A condição para que o circuito autossimilar esteja bem definido é que a função $T$ deve ser uma contração, considerando a métrica $d$, definida pela equação (6.4). Assim sendo, através do teorema do ponto fixo de Banach, $T$ tem um único ponto fixo $\bar{x}$. Mais ainda, se $x_{0}$ é um ponto qualquer em $X$ e a sequência $\left\{x_{n}\right\}$ é definida recursivamente pela fórmula

$$
x_{n}=T\left(x_{n-1}\right), \quad n=1,2, \cdots
$$

então

$$
\lim _{n \rightarrow \infty} x_{n}=\bar{x}
$$

Conclui-se que, impondo a métrica usual em $\mathbb{R}$, temos que $(\mathbb{R}, d)$ é um espaço métrico (KIRILLOV, 2013) e o problema da definição da resistência equivalente de um circuito resistivo é um problema de ponto fixo.

Tendo em vista essas caracterizações, nas próximas seções são analisados casos particulares de circuitos resistivos autossimilares. 


\subsection{Série autossimilar}

O primeiro caso analisado é uma sequência autossimilar de resistores em série, com construção definida da seguinte forma: é atribuído um peso $\alpha$ ao circuito da iteração anterior e colocado em série um resistor de resistência $R$. A questão para a análise do circuito é relativa à convergência em função dos valores de $\alpha$.

Inicialmente, a partir de um grafo com pesos, mostrado na seção 4.2, define-se como multiplicação desse grafo por uma constante $\alpha$ como um grafo que tem todos seus pesos multiplicados por essa constante. A representação desse procedimento é mostrada na figura 40.
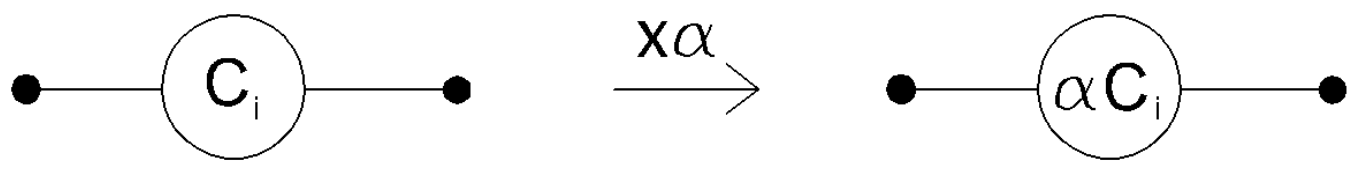

Figura 40 - Multiplicação de circuito $C_{i}$ por uma constante $\alpha$.

A série de resistores $C$ é construída recursivamente através da função $C_{1+1}=F\left(C_{i}\right)$, na qual a construção é representada na figura 42, com passo inicial descrito na figura 41. Dado o circuito da iteração $C_{i}$, é associado um resistor de resistência $R$ em série com esse circuito sendo que todos os pesos são multiplicados por uma constante $\alpha$, resultando no circuito $C_{i+1}$.

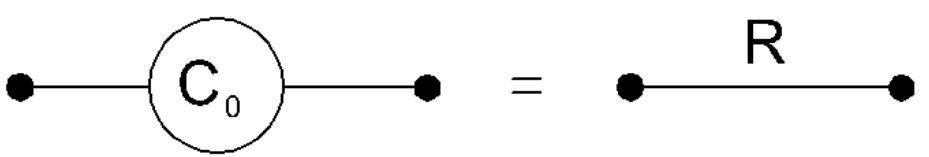

Figura 41 - Passo inicial da série autossimilar e das árvores autossimilares.

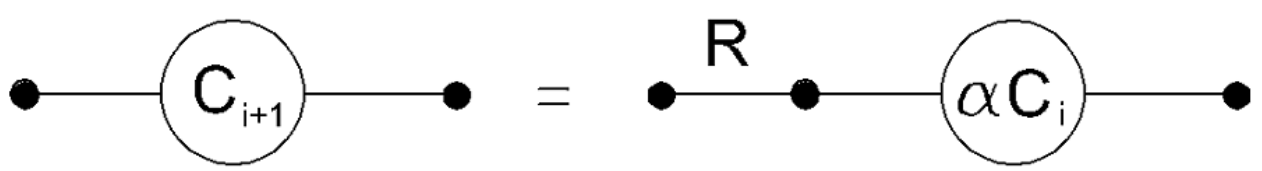

Figura 42 - Construção do circuito série de resistores.

A partir da função $F$, a construção do circuito é mostrada na figura 43, com a construção do circuito série autossimilar de resistores até a terceira iteração $C_{3}$. Como visto na seção 3.3, entre os dois terminais livres, ou entre os dois vértices livres desse grafo, as arestas podem ser substituídas por uma única aresta, a partir das propriedades de associação de resistores, como estudado na seção 3.3 . 


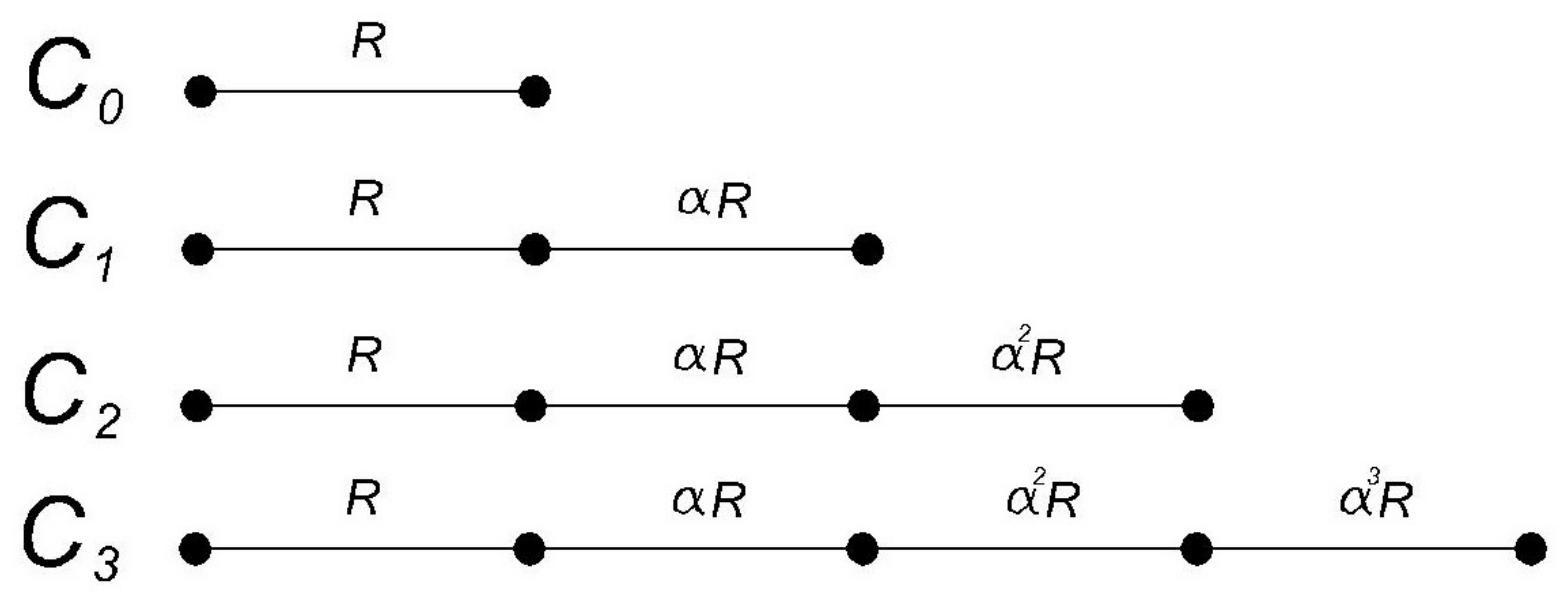

Figura 43 - As três primeiras iterações da série autossimilar de resistores.

Para dois circuitos em série, a resistência equivalente da iteração é dada pela soma das resistências, conforme seção 3.3. Assim, a partir da resistência $R_{i}$ de um circuito $C_{i}$, a resistência $R_{i+1}$ do circuito $C_{i+1}$ é dada pela soma de $R \operatorname{com} \alpha R_{i}$, ou seja,

$$
R_{i+1}=R+\alpha R_{i}
$$

A função $T$, definida na equação (6.5), é dada por

$$
T(x)=R+\alpha x
$$

Para $x$ e $y$ reais, pode-se escrever

$$
d(T(x), T(y))=|T(x)-T(y)|=|R+\alpha x-(R+\alpha y)|=\alpha|x-y|=\alpha d(x, y) .
$$

A partir da equação (5.5), que define contração para uma função de recorrência, a convergência do circuito autossimilar nas condições do Teorema de Banach é válida para $0 \leq \alpha<1$.

O valor de convergência do circuito é encontrado fazendo $R_{e q}=R_{i+1}=R_{i}$ na equação $(6.9)$

$$
R_{e q}=R+\alpha R_{e q} \rightarrow R_{e q}(1-\alpha)=R,
$$

o que indica que a resistência equivalente desse circuito é dada por

$$
R_{e q}=\frac{R}{1-\alpha}
$$

Observa-se que na equação (6.13) que $R_{e q}$ é bem definida para $0 \leq \alpha<1$. O valor da resistência equivalente torna-se grande para valores de $\alpha$ próximos de 1 . E se aproximam de $R$ para valores de $\alpha$ próximos de zero.

Na próxima seções são estudados circuitos autossimilares mais complexos, construídos a partir de árvores. 


\section{3 Árvores autossimilares}

A segunda análise desse estudo corresponde aos circuitos dispostos em árvore. Tais circuitos possuem a definição, em termos de grafo de árvore, descritas na seção 4.2. Os casos estudados nessa seção são denominados, árvore binária, generalizada para árvore com n ramos. Por fim, é estudada o caso da árvore binária com pesos.

\subsection{1 Árvore binária autossimilar}

A construção da árvore binária de resistores é feita a partir da seguinte regra: a partir de cada nó do resistor são conectados dois resistores. Nesse sentido, a iteração zero consiste em apenas um resistor. Na iteração um, a árvore consiste em um resistor associado a dois resistores, estes em paralelo. E assim por diante.

A árvore binária de resistores $C$ é construída recursivamente através da função $F$, com $C_{i+1}=F\left(C_{i}\right)$, descrita na figura 44 , sendo que o passo inicial $C_{0}$ corresponde a figura 41 . A construção desse circuito autossimilar até a iteração 3 é mostrada na figura 45 .

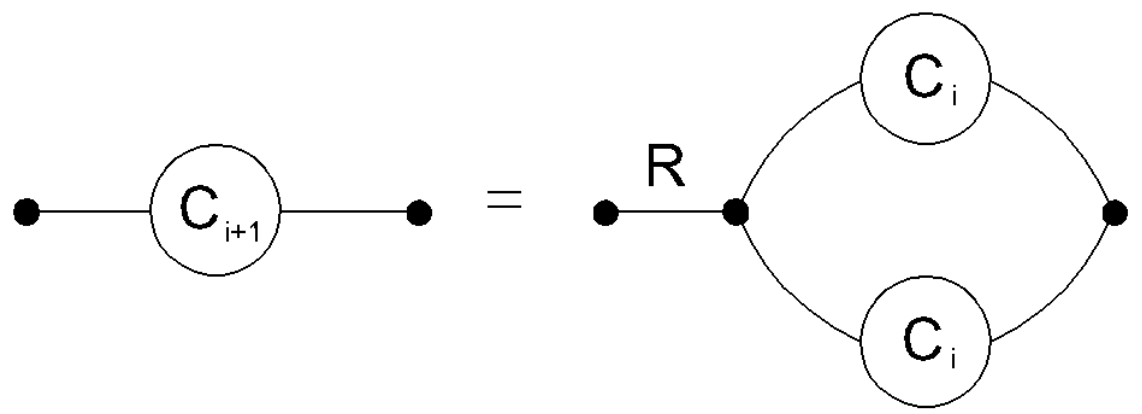

Figura 44 - Representação da recorrência da árvore binária autossimilar.

Cada circuito $C_{i}$ está associado a um número real $R_{i}$, sendo que a função de recorrência $T$ é dada por $R_{i+1}=T\left(R_{i}\right)$. Essa função $T$ corresponde a resistência equivalente para dois resistores, $R_{1}$ e $R_{2}$ em paralelo, definida na equação (3.20), é reescrita na forma de função através de uma relação auxiliar $P_{2}$ :

$$
P_{2}\left(R_{1}, R 2\right)=\frac{R_{1} \times R_{2}}{R_{1}+R_{2}}
$$

Em particular:

$$
P_{2}=P_{2}(R, R)=\frac{R}{2} .
$$

Assim, a equação de recorrência que determina a resistência do circuito do nível $i+1$, obtida a partir do circuito do nível $i$, é dada pela equação:

$$
R_{i+1}=R+P_{2}=R+\frac{R_{i}}{2} .
$$




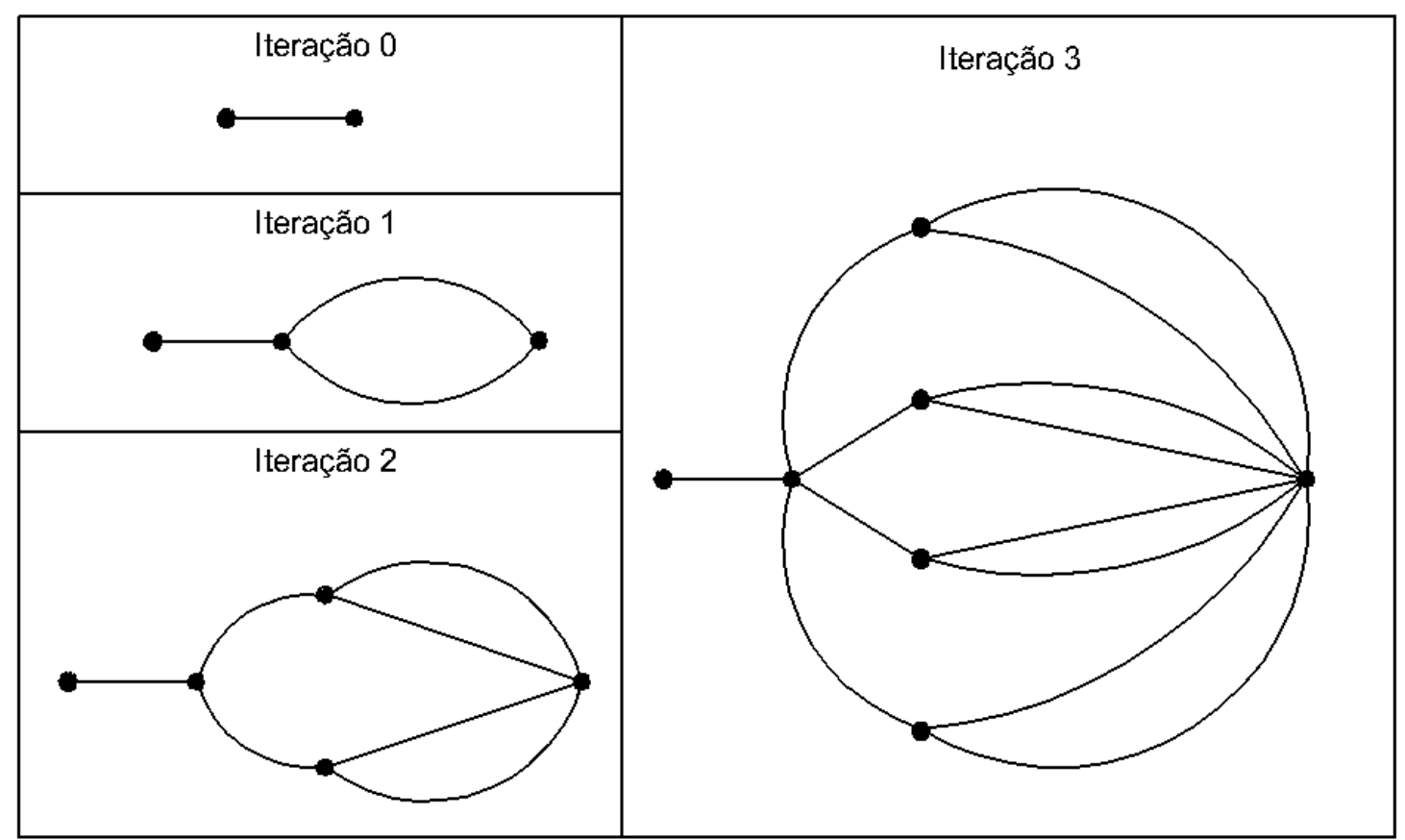

Figura 45 - Construção do circuito da árvore binária.

A fim de se verificar que $R$ é uma contração, utilizando a definição dada na seção 5.2, tem-se que

$$
T(x)=R+\frac{x}{2}
$$

A partir de dois pontos genéricos $x$ e $y$, tem-se que a função $T$ aplicada a esses pontos implicam nas distâncias entre $T(x)$ e $T(y)$ igual a

$$
d(T(x), T(y))=\left|R+\frac{x}{2}-\left(R+\frac{y}{2}\right)\right|=\frac{1}{2}|x-y|=\frac{1}{2} d(x, y) .
$$

Dessa forma, $T$ é uma contração pois $\lambda=1 / 2$. Isso indica que existe uma única $R_{e q}$ tal que $T\left(R_{e q}\right)=R_{e q}$, como afirma o resultado dado pelo teorema do ponto fixo de Banach, mostrado na seção 5.2.

Para se obter a resistência equivalente do circuito autossimilar, a partir da equação (6.16), procura-se $R_{e q}$ tal que $R_{e q}=R_{i+1}=R_{i}$. Assim, tem-se que

$$
R_{e q}=R+\frac{R_{e q}}{2} \Rightarrow \frac{R_{e q}}{2}=R
$$

Assim, o circuito autossimilar converge para uma resistência dada por

$$
R_{e q}=2 R
$$

A convergência para o circuito binário é ilustrada na figura 46, onde é construída 
iterativamente a função $t$. A partir do nível $R_{0}, \operatorname{com} R_{1}=t\left(R_{0}\right)$ é obtida a sequência

$$
\begin{aligned}
& t\left(R_{0}\right)=R_{1}=\frac{3 R_{0}}{2}, \\
& t\left(R_{1}\right)=R_{2}=\frac{9 R_{0}}{4}, \\
& t\left(R_{2}\right)=R_{3}=\frac{27 R_{0}}{8},
\end{aligned}
$$

cuja convergência é observada quando $t(x)=x$, que representa a resistência equivalente do circuito autossimilar.

A partir da árvore binária, no próximo caso é estudada a árvore com $m$ ramos, que pode ser entendida como uma generalização do caso binário.

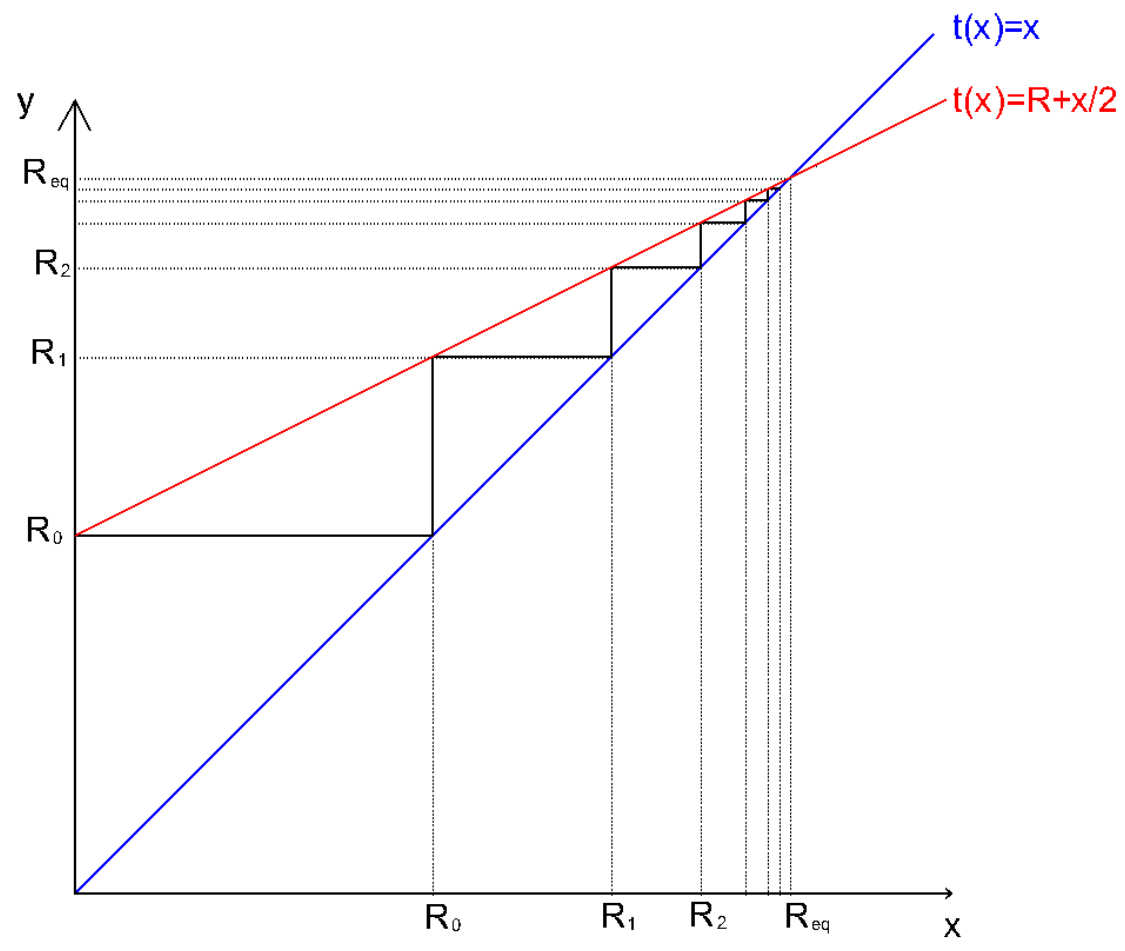

Figura 46 - Convergência para o circuito da árvore binária.

\subsection{2 Árvore autossimilar com $m$ ramos}

Agora considera-se um grafo com $n$ arestas a partir de cada aresta, como representado na Figura 48. Na iteração 0 tem-se 1 resistor, na iteração 1 , são associados $n$ resistores em paralelo a esse resistor, portanto o circuito tem $n+1$ resistores. Na iteração 2, por sua vez, $n$ resistores são associados em paralelo aos terminais de cada um dos $n$ resistores, resultando, portanto, em um total de $n^{2}+1$ resistores. E assim por diante é construído o circuito autossimilar com $m$ ramos.

A árvore de $m$ ramos $C$ é construído recursivamente através da função $F$, como mostra a figura 47, sendo que como passo inicial desse caso é considerada a figura 44. 


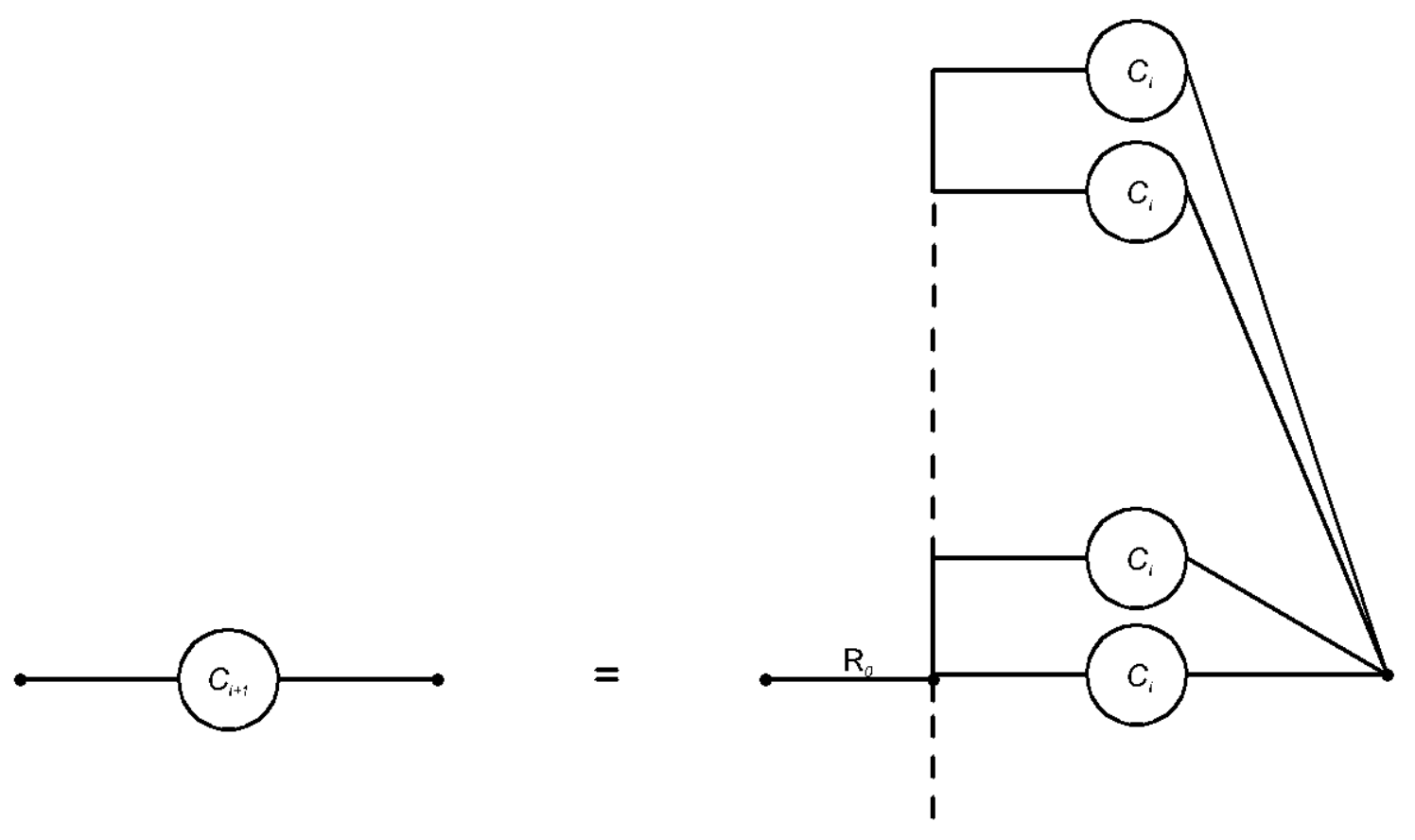

Figura 47 - Recorrência da árvore autossimilar com $m$ ramos.

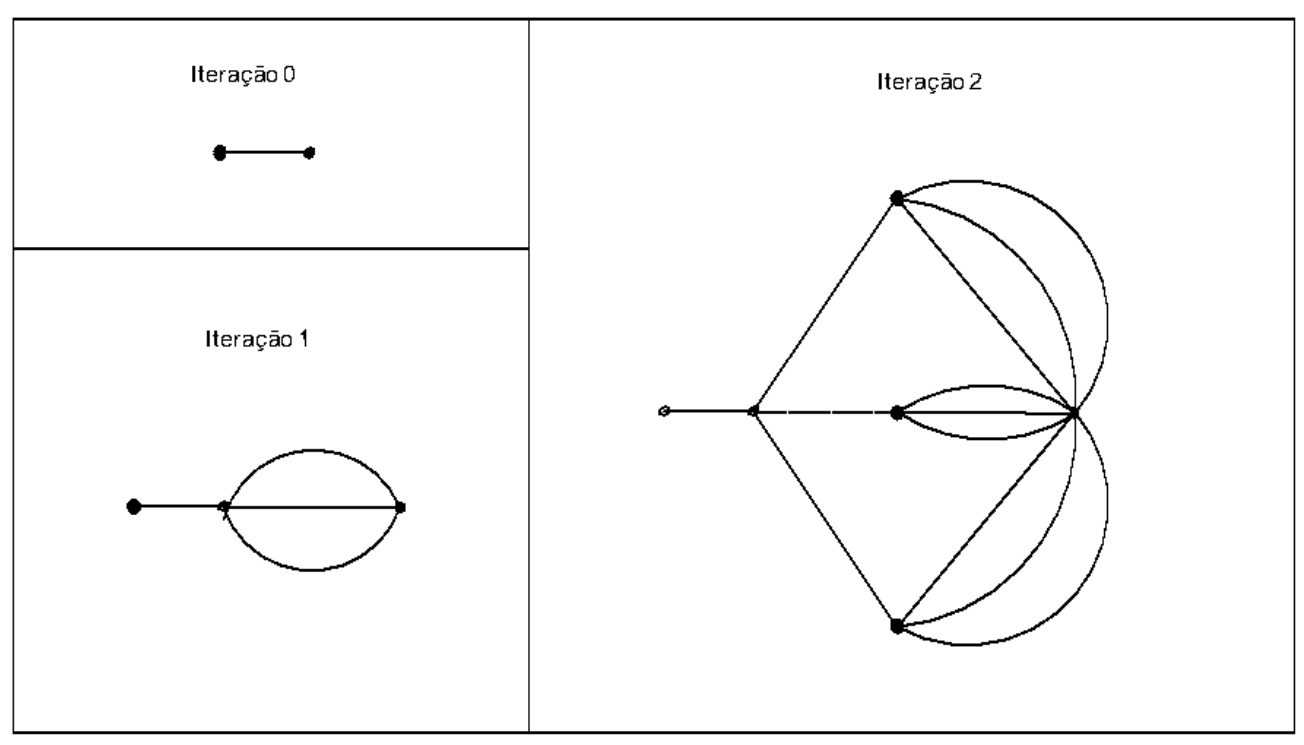

Figura 48 - Circuito autossimilar da árvore com $m$ ramos. 
A resistência equivalente $P_{m}$ para $m$ resistores $R_{1}, R_{2}, \ldots, R_{m}$ em paralelo é dada pela equação (3.20). Portanto, a função que associa $m$ resistores em paralelo é dada por:

$$
\frac{1}{P_{m}\left(R_{1}, R_{2}, R_{3}, \ldots, R_{m}\right)}=\frac{1}{R_{1}}+\frac{1}{R_{2}}+\frac{1}{R_{3}}+\ldots+\frac{1}{R_{m-1}}+\frac{1}{R_{m}} .
$$

Em particular, para $R=R_{1}=R_{2}=\cdots=R_{m}$,

$$
P_{m}(R, R, \ldots, R)=\frac{R}{m}
$$

A resistência equivalente $R_{i}$ a cada iteração $i$, é dada pela equação de recorrência:

$$
R_{i}=R+\frac{R_{i}}{m}
$$

A função $T$ correspondente a essa equação é

$$
T(x)=R+\frac{x}{m} .
$$

Para $x$ e $y$ reais, tem-se que:

$$
d(T(x), T(y))=|T(x)-T(y)|=\left|R+\frac{x}{m}-\left(R+\frac{y}{m}\right)\right|=\frac{1}{m}|x-y|=\frac{1}{m} d(x, y) .
$$

Usando essa desigualdade, a partir da equação (5.5) do teorema do ponto fixo de Banach, $T$ é uma contração pois $0 \leq \frac{1}{m}<1$ para $m>1$.

Por fim, como solução do circuito autossimilar, deve-se procurar $R_{e q}$ tal que $T\left(R_{e q}\right)=R_{e q}$. Assim, fazendo $R_{e q}=R_{i+1}=R_{i}$ e substituindo na equação (6.24), obtém-se:

$$
R_{e q}=R+\frac{R_{e q}}{m} \Rightarrow R_{e q}\left(1-\frac{1}{m}\right)=R \Rightarrow R_{e q}\left(\frac{m-1}{m}\right)=R
$$

A árvore de $m$ ramos é converge para

$$
R_{e q}=\frac{m R}{m-1}
$$

Na próximo caso é estudado um circuito autossimilar, semelhante a árvore binária, mas que no qual é atribuído peso a cada iteração do circuito.

\subsection{3 Árvore binária com pesos}

Esse grafo é semelhante à árvore binária, entretanto é um grafo com peso no qual é atribuído um valor de aresta $\alpha^{i}$ a cada iteração $i$. A função $F$ associada a construção dessa árvore é mostrada na figura 49. 


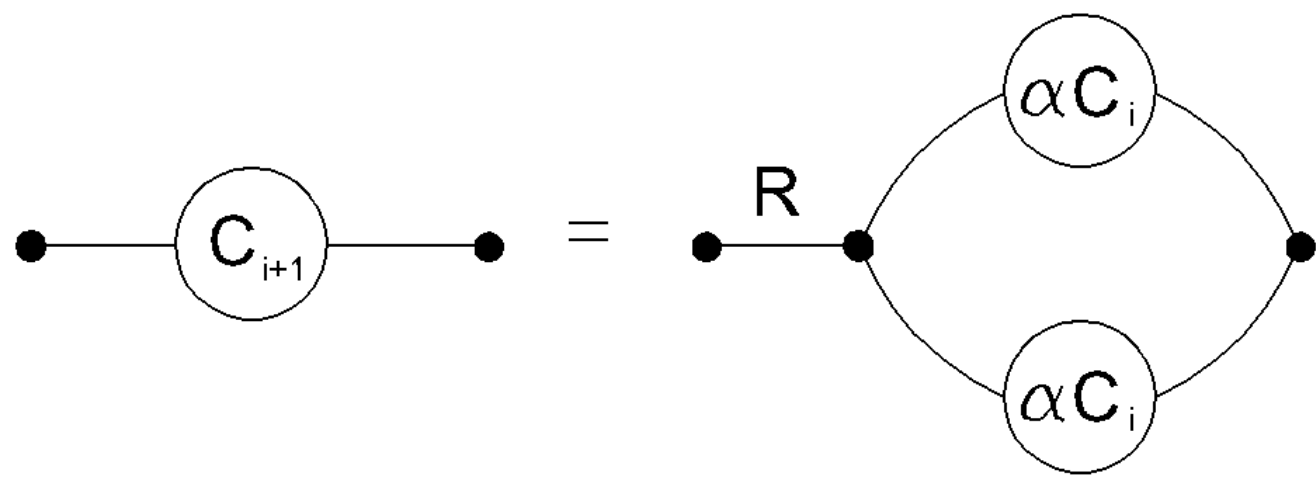

Figura 49 - Construção da árvore binária com pesos.

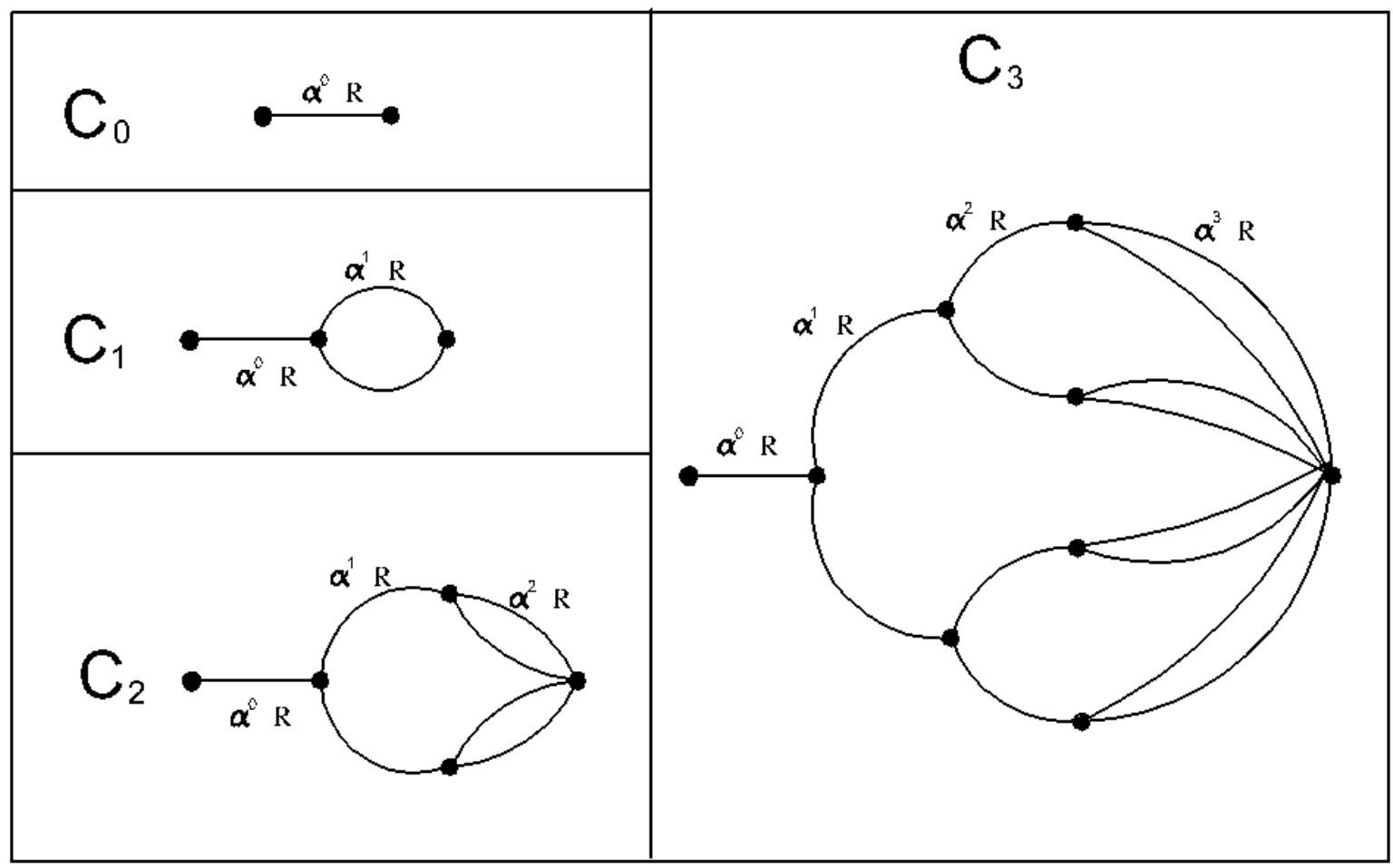

Figura 50 - Árvore binária com pesos representada até a iteração 3.

A figura 50 representa uma construção desse grafo até a iteração 3. A resistência equivalente na iteração $i$ é dada por um resistor em série conectado a dois resistores em paralelo, com um fator $i$. A cada iteração tem-se a resistência equivalente dada por

$$
R_{i+1}=R+\alpha P_{2}\left(R_{i}, R_{i}\right)
$$

e substituindo a equação (6.15), obtém-se

$$
R_{i+1}=R+\alpha \frac{R_{i}}{2}
$$

A função $T$ associada a essa equação é dada por

$$
T(x)=R+\alpha \frac{x}{2} .
$$


A fim de se analisar a contração de $T$, para $x$ e $y$ reais, tem-se que

$$
d(T(x), T(y))=|T(x)-T(y)|=\left|R+\alpha \frac{x}{2}-\left(R+\alpha \frac{y}{2}\right)\right|=\frac{\alpha}{2}|x-y|=\frac{\alpha}{2} d(x, y) .
$$

Assim, $T$ é uma contração para

$$
0 \leq \frac{\alpha}{2}<1 \Rightarrow 0 \leq \alpha<2
$$

O valor de resistência que esse circuito converge é encontrado substituindo a igualdade $T\left(R_{e q}\right)=R_{e q}$ na equação (6.31), obtendo assim

$$
R_{e q}=R+\alpha \frac{R_{e q}}{2} \Rightarrow R_{e q}\left(1-\frac{\alpha}{2}\right)=R \Rightarrow R_{e q}\left(\frac{2-\alpha}{2}\right)=R
$$

Assim, observa-se que a árvore binária com pesos converge para

$$
R_{e q}=\frac{2}{2-\alpha} R
$$

$\operatorname{com} 0 \leq \alpha<2$

Na próxima seção é proposto um circuito que apresenta semelhanças com o fractal triângulo de Sierpinski.

\subsection{Circuito de Sierpinski}

O último circuito analisado é inspirado no fractal autossimilar triângulo de Sierpinski, descrito na seção 5.3. Esse circuito autossimilar é construído a partir de uma configuração $\Delta$ de resistores, mostrada na seção 3.3. A cada iteração é aplicada uma configuração $\Delta$ no vértice da configuração $\Delta$ anterior.

A função de recorrência $F$ para o circuito é mostrada na figura 52. Para um circuito $C_{i+1}$ são associados três circuitos entre seus terminais $a$ e $b, b$ e $c$, e $a$ e $c$, multiplicados por uma constante $\alpha$ e interligados entre eles com uma resistência $R$. O passo inicial do circuito de Sierpinski é mostrado na figura 51. Tem-se como $C_{0}$ a configuração $\Delta$ de resistores com resistências $R$, com terminais externos $b$ e $c$.

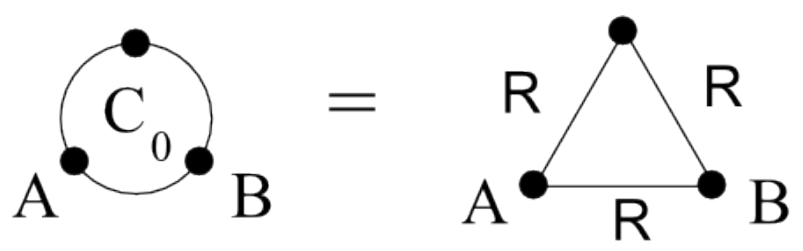

Figura 51 - Passo inicial do circuito de Sierpinski.

A partir dessa construção, nas figuras 53 e 54 mostram-se respectivamente a primeira e a segunda iterações do circuito autossimilar. Para a figura 54 arestas com mesma cor tem o mesmo peso. Apesar da figura ser um grafo, o circuito é construído inspirado no triângulo de Sierpinski. 


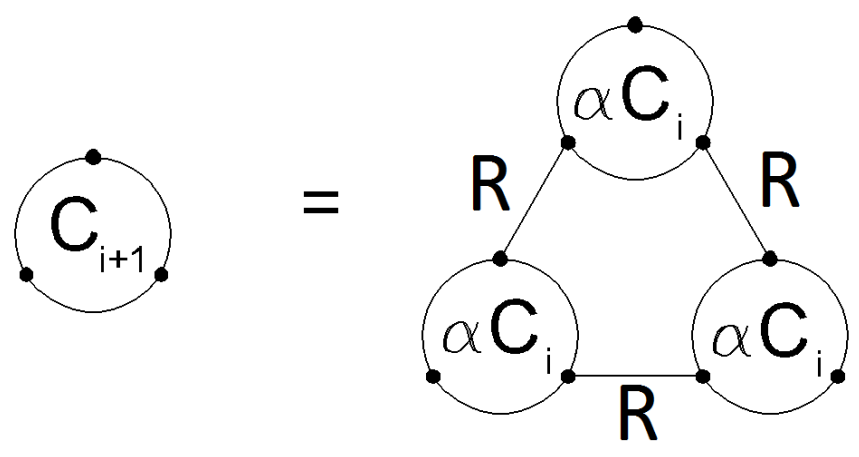

Figura 52 - A recorrência do circuito de Sierpinski.

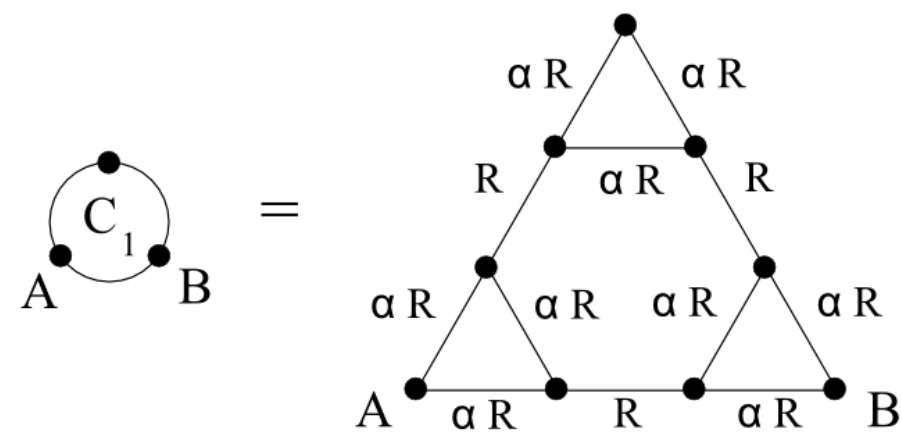

Figura 53 - A primeira iteração do circuito de Sierpinski.

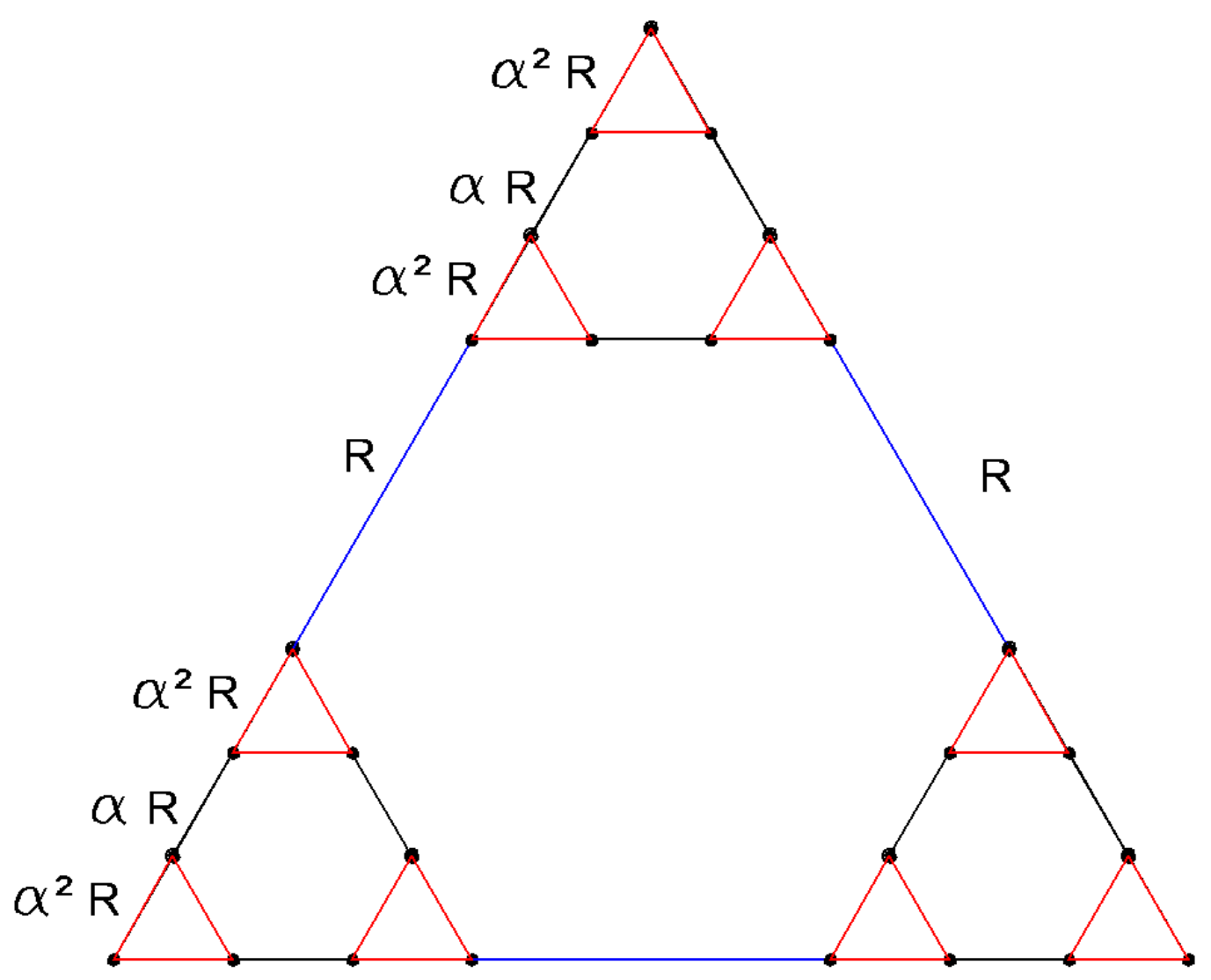

Figura 54 - A segunda iteração do circuito de Sierpinski. 
Um resultado importante é obtido ao se calcular a resistência equivalente entre dois nós de um circuito na configuração $\Delta$, mostrado na figura 55. Para tal, a resistência é dada por

$$
\frac{1}{R_{i}}=\frac{1}{2 r_{i}}+\frac{1}{r_{i}} \Rightarrow R_{i}=\frac{2}{3} r_{i}
$$

Essa resistência equivalente é obtida através da transformação $\mathrm{Y}$, onde cada aresta tem peso $R / 3$, o que implica que o trecho $B$ a $C$ tem resistência dada por $2 R / 3$, como é mostrado na figura 56 .

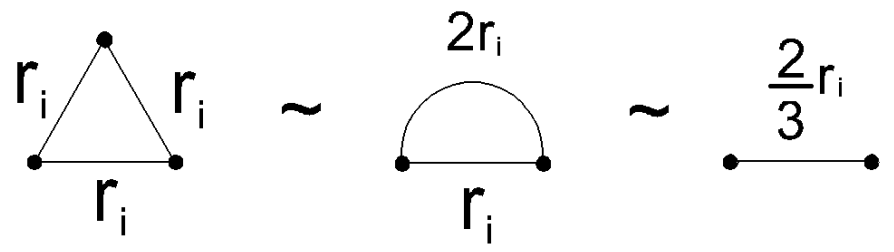

Figura 55 - A resistência entre dois nós para uma configuração $\Delta$.

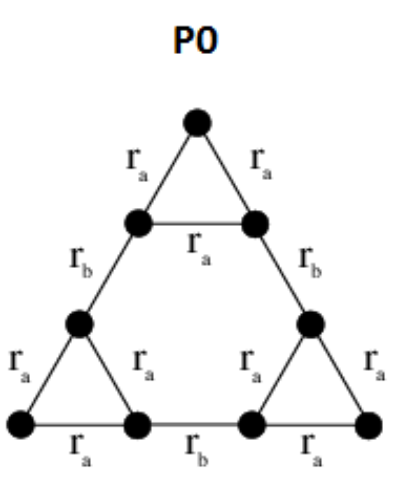

P3

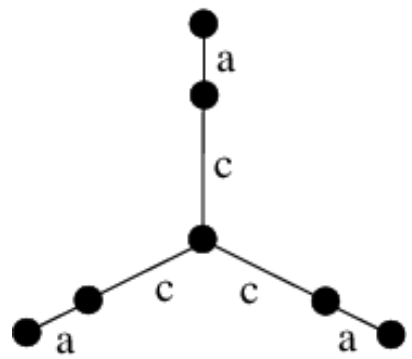

P1

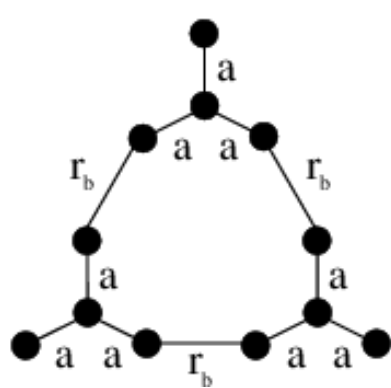

P4

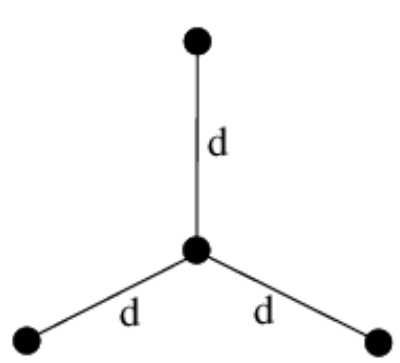

P2

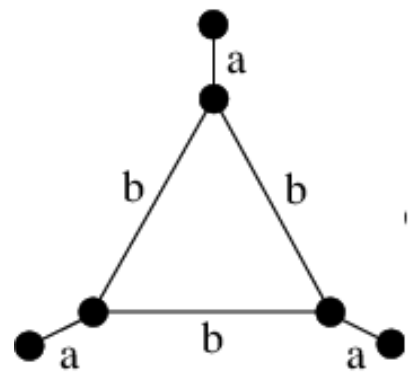

P5

Figura 56 - Resistência equivalente entre dois nós para $C_{i}$.

A partir de sucessivas transformações $\Delta-Y$ e $Y-\Delta$, mostradas na figura 56, obtém-se uma configuração $\Delta$ para um circuito na iteração $i+1$, a partir da iteração $i$. Em termos dos pesos mostrados na figura, de $P 0$ para $P 1$ até $P 2$, aplica-se uma transformação $\Delta-Y$, na qual obtém-se

$$
b=2 a+r_{b}=\frac{2}{3} r_{a}+r_{b}
$$


Na disposição $\Delta$ é aplicada novamente uma transformação até $Y$, na qual a partir dos passo $P 2$ obtém-se os passos $P 3$ e $P 4$. As equações são dadas por

$$
c=\frac{b}{3}=\frac{2}{3} r_{a}+\frac{r_{b}}{3}, \quad d=a+c=\frac{5}{9} r_{a}+\frac{r_{b}}{3} .
$$

Por fim, é aplicada na configuração $Y$ em $P 4$ a transformação até obter-se a configuração $\Delta$ em $P 5$

$$
r_{f}=3 d=\frac{5}{3} r_{a}+r_{b}
$$

A figura 57 mostra como um circuito na iteração $i+1$ pode ser representado em uma configuração $\Delta$ em função do pesos do circuito $i$.
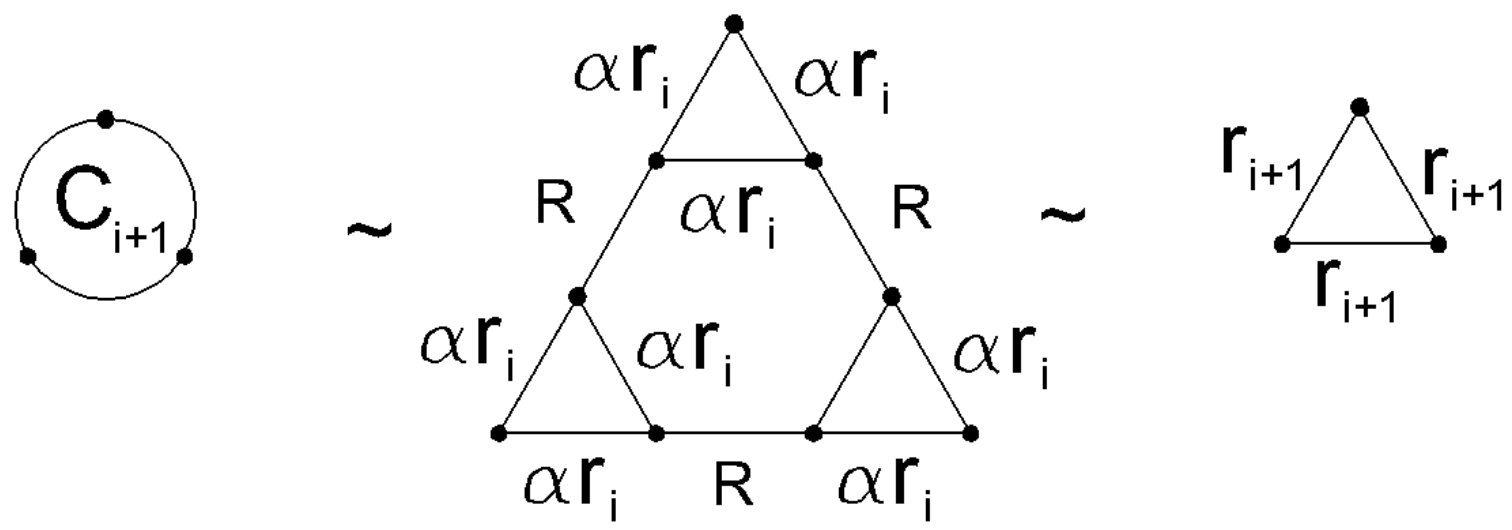

Figura 57 - Representação como circuito em $\Delta$ de um circuito $i+1$ em função dos pesos do circuito $i$.

Com a definição da recorrência do circuito de Sierpinski e da equação 6.39, é obtida a equação de recorrência

$$
r_{i+1}=\frac{5}{3} \alpha r_{i}+R
$$

Usando a equação 6.36, tem-se a resistência equivalente entre dois nós $A$ e $B$

$$
R_{i+1}=\frac{5}{3} \alpha R_{i}+\frac{2}{3} R
$$

Essa equação pode ser reescrita como

$$
T(x)=\frac{5}{3} \alpha x+\frac{2}{3} R .
$$

A convergência dessa equação é obtida a partir da equação

$$
d(T(x), T(y))=|T(x)-T(y)|=\left|\frac{5}{3} \alpha x-\frac{5}{3} \alpha y\right|=\frac{5}{3} \alpha|x-y|=\frac{5}{3} \alpha d(x, y)
$$

Com a convergência quando

$$
0 \leq \frac{5}{3} \alpha<1 \Rightarrow 0 \leq \alpha<\frac{3}{5}
$$


A solução dessa equação é obtida fazendo $R_{e q}=R_{i+1}=R_{i}$

$$
R_{e q}=\frac{5}{3} \alpha R_{e q}+\frac{2}{3} R \Rightarrow R_{e q}=\frac{2}{3-5 \alpha} R \text {. }
$$

Na próxima seção é proposta uma atividade didática para alunos do ensino médio, abordando alguns tópicos estudados.

\subsection{Atividade didática}

\subsubsection{Justificativa}

A atividade a seguir consiste na exploração, no contexto do aluno do ensino médio, de um circuito autossimilar. Os conteúdos explorados nesse trabalho são abordados nessa atividade final.

Considerando a proposta curricular do estado de São Paulo para matemática (SEE-SP, 2011b) e de física (SEE-SP, 2011a), o aluno da $3^{\text {a }}$ série de ensino médio explora em física o tema circuitos elétricos e em matemática faz uma exploração sobre as funções que foram estudadas ao longo do ensino médio.

Nessa atividade didática propõe-se a construção de um circuito resistivo autossimilar binário, onde o aluno de ensino médio deve identificar o padrão de construção e fazer a representação em grafo para as duas próximas iterações.

A percepção da identificação de um padrão de uma sequência é importante em amplos contextos, sendo que para a atividade didática pergunta-se sobre a equação que descreve a resistência equivalente para o circuito (FERNANDES, 2003).

\subsubsection{Proposta de atividade}

Para a atividade proposta, sugere-se a seguinte organização de tempos e espaço:

- atividade a ser realizada na terceira série do ensino médio;

- espaço: sala de aula;

- atividade individual;

- tempo previsto: 2 horas.

Além do problema das pontes de Königsberg, um circuito de resistores também pode ser representado como um grafo. Tal representação apresenta-se útil por simplificar a visão de um problema, deixando-o de uma forma mais simples. 
Essa lógica pode ser aplicada para o grafo de um circuito de resistores, feito na figura 58, onde os nós correspondem aos vértices do grafo; e os resistores correspondem às arestas. Para cada iteração, existe um grafo correspondente a um circuito. Nessa figura é feita a construção até a iteração 2.

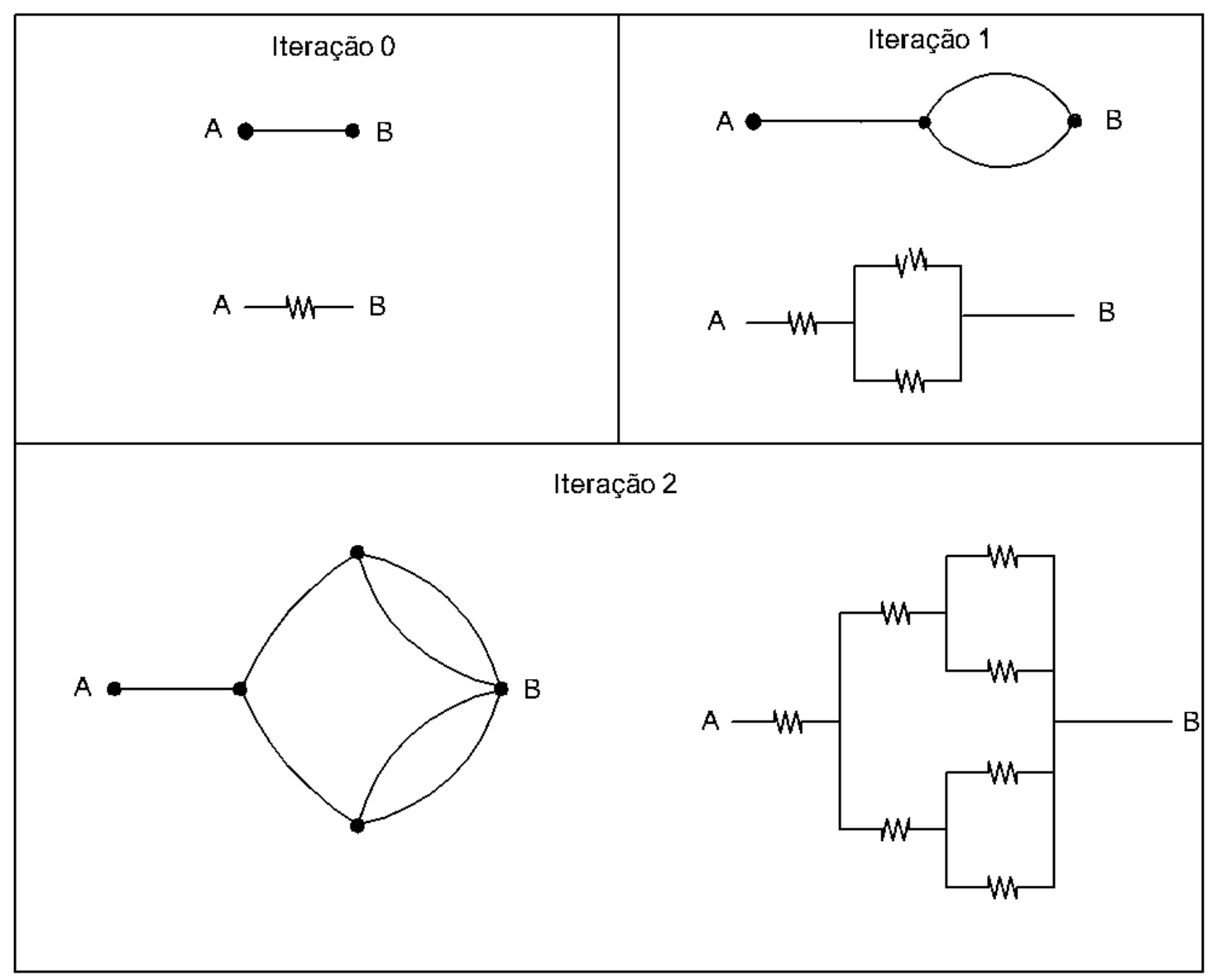

Figura 58 - Representações dos circuitos das iterações da atividade proposta.

Em tal grafo, pode ser visualizada a construção de um grafo autossimilar da árvore binária, com resistência igual a $1 \Omega$, onde cada figura corresponde à construção do grafo a partir do anterior, em um processo chamado iteração, como mostrado na figura 58.

Usando as propriedades de associação de resistores, pode ser encontrada uma medida de resistência equivalente para cada iteração do circuito. Assim sendo, propõe-se nessa atividade os pontos listados a seguir:

1. Considerando a regularidade da construção da árvore binária, construir o circuito da iteração 3.

2. Usando as propriedades de associação de resistores, descritas na seção 3.3, encontrar a resistência equivalente das iterações 1,2 e 3 .

3. Encontrar uma fórmula que determina a resistência equivalente a cada iteração. 
4. Para qual valor de resistência o circuito se aproxima, a medida que as iterações aumentam?

\subsubsection{Resultados esperados}

Espera-se que o aluno consiga relacionar os conteúdos vistos nas atividades didáticas anteriores, onde foram estudadas as propriedades das associações dos resistores, representação de problemas como grafos e o estudo de um fractal autossimilar. Tais conhecimentos são respectivamente necessários para o cálculo da resistência equivalente dos circuitos propostos, representar um circuito como um grafo e a observação dos padrões de construção de cada circuito.

O aluno deve perceber como os circuitos são construídos recursivamente a partir do anterior. E que para cada circuito está relacionado um valor de resistência equivalente. É esperado que o aluno modele o problema e perceba que essa sequência de resistências equivalentes correspondem a uma progressão geométrica. Para tal identificação é necessário a identificação da razão e da convergência quando o número de iterações tendem ao infinito.

De forma geral, espera-se que o aluno perceba que os conteúdos estudados no ensino médio representam um pequeno recorte dos temas que se apresentam em física e em matemática, sendo que as possibilidades de estudos vão além das progressões, funções, lei de Ohm, associação de resistores, área e perímetro. Assim, espera-se que o aluno identifique as potencialidades criando relações dentro e fora dos conteúdos escolares.

Espera-se que o aluno consiga identificar o padrão de construção dos circuito autossimilar, e faça a identificação com o grafo, ressaltando a importância dessa representação para complexidades maiores. $\mathrm{O}$ aluno deve perceber que as construções podem ser feitas independentes da forma que o grafo seja construído, ressaltando a importância de como os vértices são ligados pelas arestas.

Enfim, usando as propriedades de resistência equivalente, descritas no capítulo 3, o aluno deve identificar as resistências equivalentes de $1 \Omega, 3 / 2 \Omega$ e $7 / 8 \Omega$. O aluno deve perceber que a resistência equivalente para o nível $i$ corresponde à soma de uma progressão geométrica com termo inicial $1 \Omega$ e razão $1 / 2$. Assim, deve ser obtida a equação da forma

$$
R_{i}=2 \Omega-\left(\frac{1}{2}\right)^{i} \Omega .
$$

Por fim, o aluno deve observar que a resistência equivalente do circuito tende a $2 \Omega$ quando as iterações tendem ao infinito. 



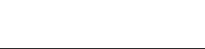

\section{CONSIDERAÇÕES FINAIS}

Os circuitos resistivos autossimilares são circuitos resistivos construídos recursivamente. Mostrou-se que esses podem ser representados como grafos, pois é apenas relevante como os resistores são ligados e não a disposição entre eles. Estes circuitos apresentam a autossimilaridade presente em uma classe de fractais, ou seja, são obtidos recursivamente a partir de um conjunto de funções iteradas.

Para caracterizar um circuito resistivo autossimilar, descreveu-se os elementos presentes em um circuito resistivo. Em relação aos conceitos básicos, foram definidos e mostradas propriedades relacionadas a corrente, diferença de potencial e resistência. Ainda nesse capítulo foram mostrados que os circuitos resistivos podem ser formados por associações em série, paralelo, $\Delta$-Y, ou uma combinação delas.

Foi mostrado como um circuito resistivo corresponde a um grafo, considerando a equivalência de seus resistores como aresta, assim como os nós correspondem aos vértices e as resistência aos pesos do grafo (SCOTT, 1960). Essa representação como grafo mostrou-se especialmente útil para circuitos resistivo com complexidades maiores, e em particular para a nossa proposta de circuitos autossimilares.

Para a definição dos circuitos autossimilares, é feito um estudo sobre os fractais que apresentam a autossimilaridade. Para os fractais de uma forma geral, foi dada uma definição informal, suas aplicações e como aparecem na natureza (MANDELBROT, 1983). Sobretudo, o fato de serem caracterizados pela autossemelhança e por serem construídos indefinidamente são as características importantes dos circuitos resistivos propostos.

Para caracterizar os fractais autossimilares, alguns conceitos fundamentais de espaços métricos foram estudados para se definir a convergência de sistemas de funções iteradas, que definem essa classe de fractais (KIRILLOV, 2013). Nesse sentido, foi proposta uma definição geral para circuitos autossimilares, acompanhado de exemplos desses circuitos e dessa medida de convergência, representada pela resistência equivalente. Os circuitos foram construídos 
recursivamente, com um novo diagrama obtido a partir do anterior. Para cada circuito autossimilar foi definida uma função de recorrência para a caracterização da resistência equivalente.

Como visto, as sequências apresentavam restrições para que essas fossem convergentes. Tais restrições foram justificadas com a existência e unicidade através do Teorema do ponto fixo de Banach. Foi analisada a convergência dos circuitos resistivos autossimilares denominados: série autossimilar; árvores autossimilares, entre elas, árvore binária árvore autossimilar com $n$ ramos e árvore binária com pesos; e o circuito de Sierpinski. Os valores de resistência equivalente desses circuitos foram obtidos usando equações de associações em série e em paralelo, para todos os circuitos, e usando a associação $\Delta$ - Y para o circuito de Sierpinski.

Como tópicos complementares nesse estudo, destacam-se conjuntos numéricos quando são identificadas as medidas de comprimento, área e resistência; sequências numéricas na construção dos fractais e dos circuitos autossimilares acompanhada de uma definição básica de limite, durante a análise da convergência.

A partir de conteúdos de nível médio e de tópicos que tipicamente são vistos no ensino superior, como espaços métricos, fractais e grafos, podem ser aplicados com o devido cuidado no ensino médio, com o intuito de ampliar as possibilidades do aluno relacionar a matemática com o dia a dia e com outros temas dentro e fora da matemática.

Para o processo de ensino e aprendizagem no ensino médio, o uso da interdisciplinaridade é uma estratégia para a construção do conhecimento, através da conexão entre os conteúdos das disciplinas (MACHADO, 1995). Essa prática determina que os conteúdos devem ser organizados de uma forma flexível, de tal forma que sempre se ofereça de se estabelecer conexões entre os conteúdos (CARVALHO, 2014).

Entre as competências destacou-se pensamento matemático, modelagem matemática, formular e resolver problemas, e argumentação matemática. Estes são pontos importantes a se desenvolver para a efetiva aprendizagem do aluno. Atingidas essas competências, o aluno tem conhecimento para utilizá-la em amplos contextos onde a matemática tem papel relevante. Nas situações existentes no cotidiano, a partir de um conjunto de habilidades é capaz de mobilizar uma ação (PERRENOUD; RAMOS, 2000).

Como estratégia para aplicação desses conteúdos tendo em vista a interdisciplinaridade e o ensino por competências, foi elaborada uma sequência de conteúdos seguidos por atividades didáticas, com os temas que eram importantes para a caracterização do tema central, que basicamente foi a definição e exploração de grafos de circuitos resistivos autossimilares.

Para abordar esses conteúdos em nível médio, é proposta a reprodução de três circuito resistivo em uma matriz de contatos, sendo que foi pedida a verificação dos valores de corrente e diferença de potencial a partir dos valores obtidos teoricamente. No capítulo 4 é proposta a reprodução do problema das pontes de Königsberg (MALTA, 2008). No capítulo 5 são avaliadas as progressões contidas no carpete de Sierpinski, com uma especial análise da convergência 
quando as iterações crescem indefinidamente (PEITGEN; JÜRGENS; SAUPE, 2012). No capítulo 6 é analisado o circuito similar árvore binária, sendo proposto aos alunos a representação do circuito com um grafo e a o cálculo da resistência equivalente do circuito.

Como possibilidade de continuação para esse trabalho pode-se citar atribuir uma distribuição de probabilidade aos valores de resistência conforme o tratamento proposto em (ESSOH; BELLISSARD, 1989), considerar outras representações de circuitos autossimilares e ampliar as atividades didáticas voltadas para o ensino médio. 

ALSTROM, P.; STASSINOPOULOS, D.; STANLEY, H. E. A thermodynamical formalism for an infinite hierarchy of fractal resistor networks. Physica A: Statistical Mechanics and its Applications, Elsevier, 1988. Citado na página 21.

ASSIS, T.; MIRANDA, J.; MOTA, F.; ANDRADE, R.; CASTILHO, C. Geometria fractal: propriedades e caracteristicas de fractais ideais. Scielo Brasil, 2008. Acessado em 19 de outubro de 2015. Disponível em: <http://www.scielo.br/pdf/rbef/v30n2/a05v30n2.pdf>. Citado 2 vezes nas páginas 20 e 73.

BARBOSA, R. M. Descobrindo a geometria fractal: para a sala de aula. Belo Horizonte: Autêntica, 2002. 160 p. Citado na página 18.

BEDROSIAN, S. D.; SUN, X. Pascal-Sierpinski gasket fractal networks: some resistance properties. Elsevier, 1989. 503-509 p. Acessado em 24 de setembro de 2015. Disponível em: <http://www.sciencedirect.com/science/article/pii/0016003289900471>. Citado na página 22.

BEINEKE, R. J. W. L. Topics in algebraic graph theory. Cambridge University Press, Nova York, 2005. Disponível em: <http://web.xidian.edu.cn/zhangxin/files/20150825_221911.pdf>. Citado 2 vezes nas páginas 49 e 52 .

BOYLE, B.; CEKALA, K.; FERRONE, D.; RIFKIN, N.; TEPLYAEV, A. Electrical resistance of N-gasket fractal networks. 2007. 15-40 p. Acessado em 8 de julho de 2015. Disponível em: $<$ http://davidferrone.org/pdf/NGasket.pdf $>$. Citado na página 21.

BRASIL. Lei no 9.394, de 20 de dezembro de 1996. Ministério da Educação, 1996. Acessado em 19 de outubro de 2015. Disponível em: <http://www.planalto.gov.br/ccivil_03/Leis/L9394. htm>. Citado na página 30.

. Parâmetros curriculares nacionais. 2010. Acessado em 25 de julho de 2015. Disponível em: <http://portal.mec.gov.br/par/195-secretarias-112877938/seb-educacao-basica-2007048997/ 12598-publicacoes-sp-265002211>. Citado 3 vezes nas páginas 29, 30 e 31.

BUSQUINI, J. A. Proposta curricular do estado de são paulo de 2008: discurso, participação e práticas dos professores de matemática. Tese (Doutorado) - Universidade de São Paulo, 2013. Citado 3 vezes nas páginas 26, 27 e 30.

CARVALHO, D. L. de. Metodologia do ensino da matematica. São Paulo: Cortez Editora, 2014. 120 p. Citado 4 vezes nas páginas 17, 29, 30 e 96.

CLOSE, C. M. Circuitos Lineares. São Paulo: Editora da Universidade de São Paulo, 1975. 550 p. Citado 4 vezes nas páginas 35, 38, 40 e 54.

COHEN, R.; EYLON, B.; GANIEL, U. Potential difference and current in simple electric circuits: A study of students concepts. American Journal of Physics, American Association of Physics Teachers, v. 51, n. 5, p. 407-412, 1983. Citado 2 vezes nas páginas 19 e 33. 
CORTS, A.; CALLEJO, M. L. Matemática para aprender a pensar. Porto Alegre: Artmed Editora, 2006. 212 p. Citado na página 55.

COSTA, P. P. Teoria dos Grafos e suas Aplicações. Dissertação (Mestrado) - Universidade Estadual Paulista, Rio Claro, 2011. Citado 2 vezes nas páginas 13 e 56.

EDGAR, G. Measure, topology, and fractal geometry. Nova Iorque: Springer Science \& Business Media, 2007. 230 p. Citado 4 vezes nas páginas 61, 62, 65 e 71.

ESSOH, C. D.; BELLISSARD, J. Resistance and fluctuation of a fractal network of random resistors: a non-linear law of large numbers. Journal of Physics A: Mathematical and General, IOP Publishing, v. 22, n. 21, p. 4537, 1989. Citado 2 vezes nas páginas 21 e 97.

FERNANDES, J. G. M. S. A. Formas de abordagem do conteúdo em questões de física. 2003. 15 de julho de 2015. Disponível em: <http://www.nutes.ufrj.br/abrapec/vienpec/CR2/p267.pdf>. Citado 2 vezes nas páginas 45 e 91.

HALLIDAY R. RESNICK, J. W. D. Fundamentos de Física. Rio de Janeiro: Livros Técnicos e Científicos, 2009. Citado 3 vezes nas páginas 35, 37 e 39.

KIRILLOV, A. A. A tale of two fractals. Vitória, Canadá: Birkhauser, 2013. 138 p. Citado 8 vezes nas páginas 13, 22, 62, 63, 67, 70, 78 e 95.

LAVAQUI, V.; BATISTA, I. d. L. Interdisciplinaridade em ensino de ciências e de matemática no ensino médio. Ciência \& educação, SciELO Brasil, 2007. Citado na página 20.

LIMA, E. L. Espaços Métricos. Rio de Janeiro: Instituto de Matemática Pura e Aplicada, 1993. 337 p. Citado 3 vezes nas páginas 61, 62 e 71.

MACHADO, N. J. Epistemologia e didatica. São Paulo: Cortez Editora, 1995. 320 p. Citado 4 vezes nas páginas 17, 28, 29 e 96.

MALTA, G. Grafos no ensino médio: uma inserção possível. Dissertação (Mestrado) - Universidade Federal do Rio Grande do Sul, 2008. Disponível em: <http://www.lume.ufrgs.br/ handle/10183/14829>. Citado 4 vezes nas páginas 18, 21, 55 e 96.

MANDELBROT, B. B. The fractal geometry of nature. Nova Iorque: WH Freeman and Co, 1983. 495 p. Citado 3 vezes nas páginas 59, 61 e 95.

NILSSON, S. A. R. J. W. Circuitos Elétricos. Rio de Janeiro: Livros Técnicos e Científicos, 2003. Citado 5 vezes nas páginas 31, 36, 37, 38 e 41.

NISS, M. Mathematical competencies and the learning of mathematics: The Danish KOM project. 2003. 115-124 p. Citado 2 vezes nas páginas 26 e 27.

NUSSENZVEIG, M. Curso de Física Básica. São Paulo: Editora Edgard Blücher, 1999. 296 p. Citado 2 vezes nas páginas 35 e 36.

OCDE. The definition and selection of key competencies. 2005. Acessado em 18 de outubro de 2015. Disponível em: <http://www.deseco.admin.ch/bfs/deseco/en/index/02.parsys.43469. downloadList.2296.DownloadFile.tmp/2005.dskcexecutivesummary.en.pdf>. Citado na página 26.

OLIVEIRA, G. P. de. Generalização de padrões, pensamento algébrico e notações: o papel das estratégias didáticas com interfaces computacionais. 2008. Citado na página 18. 
PEITGEN, H.-O.; JÜRGENS, H.; SAUPE, D. Fractals for the Classroom. Nova Iorque: Springer Science \& Business Media, 2012. 450 p. Citado 10 vezes nas páginas 18, 20, 59, 61, 63, 65, $68,69,74$ e 97.

PERRENOUD, P.; RAMOS, P. C. Dez novas competências para ensinar. São Paulo: Artmed editora, 2000. 162 p. Citado 2 vezes nas páginas 25 e 96.

RABAY, Y. S. F. Aplicações da Geometria Fractal. Dissertação (Mestrado) - Universidade Federal da Paraíba, 2013. Disponível em: <http://bit.profmat-sbm.org.br/xmlui/bitstream/handle/ 123456789/436/2011_00319_YARA_SILVIA_FREIRE_RABAY.pdf? sequence=1>. Citado na página 20.

SALLUM, É. M. Fractais no ensino médio. 2005. 1-8 p. Acessado em 8 de julho de 2015. Disponível em: <http://www.ufrgs.br/espmat/disciplinas/novos_conteudos/2009/modulo_II/pdf/ rpm_fractais.pdf $>$. Citado 2 vezes nas páginas 20 e 73.

SCOTT, R. Linear Circuits. Massachusetts: Addison-Wesley Publishing Company, 1960. Citado 6 vezes nas páginas 37, 40, 42, 43, 54 e 95.

SEE-SP. Proposta curricular do estado de São Paulo: Ciências da natureza e suas tecnologias. 2011. (Coordenação: Maria Inês Fini). Citado 4 vezes nas páginas 33, 34, 44 e 91.

Proposta curricular do estado de São Paulo: Matemática e suas tecnologias. 2011. (Coordenação: Nilson José Machado). Citado 7 vezes nas páginas 17, 31, 32, 33, 55, 73 e 91.

SÉRÉ, M.-G.; COELHO, S. M.; NUNES, A. D. O papel da experimentação no ensino da física. 2003. 30-42 p. Acessado em 20 de outubro de 2015. Disponível em: <https://periodicos. ufsc.br/index.php/fisica/article/view/6560>. Citado 2 vezes nas páginas 13 e 45 .

SOUZA, A. L. de. Teoria dos grafos e suas aplicações. Dissertação (Mestrado) - Universidade Federal do Amazonas, 2013. Disponível em: < http://bit.profmat-sbm.org.br/xmlui/bitstream/ handle/123456789/1396/2011_01201_AUDEMIR_LIMA_DE_SOUZA.pdf?sequence=1>. Citado na página 21.

TAYLOR, R.; NEWELL, B.; SPEHAR, B.; CLIFFORD, C. Fractals: a resonance between art and nature. 2005. Citado 2 vezes nas páginas 13 e 60.

WEST, D. B. et al. Introduction to graph theory. Nova Jersey: Prentice hall, 2001. Citado 3 vezes nas páginas 19,52 e 53.

ZIMMERMANN, E.; CARLOS, J. G. Interdisciplinaridade e ensino de física: Quais as possibilidades. $2005.425-3$ p. 20 de outubro de 2015. Disponível em: <http://www.cienciamao. usp.br/tudo/exibir.php?midia=snef\&cod=_interdisciplinaridadeeen $>$. Citado na página 29. 